PNL-10503

UC-510

\title{
Computer Simulation of Mobilization and Mixing of Kaolin with Submerged Liquid Jets in 25,000-Gallon Horizontal Cylindrical Tanks
}

\author{
L.L.Eyler \\ L.A.Mahoney
}

March 1995

Prepared for

the U.S. Department of Energy

under Contract DE-AC06-76RLO 1830

Pacific Northwest Laboratory

Richland, Washington 99352 


\section{DISCLAIMER}

This report was prepared as an account of work sponsored by an agency of the United States Government. Neither the United States Government nor any agency thereof, nor any of their employees, make any warranty, express or implied, or assumes any legal liability or responsibility for the accuracy, completeness, or usefulness of any information, apparatus, product, or process disclosed, or represents that its use would not infringe privately owned rights. Reference herein to any specific commercial product, process, or service by trade name, trademark, manufacturer, or otherwise does not necessarily constitute or imply its endorsement, recommendation, or favoring by the United States Government or any agency thereof. The views and opinions of authors expressed herein do not necessarily state or reflect those of the United States Government or any agency thereof. 


\section{DISCLAIMER}

Portions of this document may be illegible in electronic image products. Images are produced from the best available original document. 


\section{Summary}

This report presents and analyzes the results of computer model simulation of mobilization and mixing of kaolin using the TEMPEST computer program developed by the Pacific Northwest Laboratory. The simulations are conducted in a horizontal cylindrical geometry, which replicates a $95 \mathrm{~m}^{3}$ $(25,000$ gal) test tank at Oak Ridge National Laboratory. The test tank configuration is scaled to approximate Melton Valley Storage tanks, which are $190 \mathrm{~m}^{3}$ (50,000 gal). Mobilization and mixing is accomplished by two submerged liquid jets. The jets are $3.5 \mathrm{~cm}(1.38 \mathrm{in}$.) corresponding to 1.25 in. schedule 40 nozzles. The jet axis is parallel to the tank axis. The centerline of the jets is $16.4 \mathrm{~cm}$ ( 6.5 in.) above the tank floor. Two configurations are simulated-one with the jets located at the center of the tank lengthwise and one with the jets located at $1 / 4$ of the tank length from one end. For the center jet location, the recirculation suction inlet is adjacent to the jets at the tank center. For the quarter jet location, the recirculation suction is located at the opposite end of the tank and $1 / 8$ of the tank length from the end. The suction for the latter configuration is $52 \mathrm{~cm} \mathrm{(20} \mathrm{in.)} \mathrm{above} \mathrm{the} \mathrm{tank}$ floor.

Computer simulations of both jet and suction configurations are performed. Total flow rates of 50,100 , and $200 \mathrm{gpm}$ are modeled. These flow rates correspond to jet velocities of $1.52,3.05$, and $6.10 \mathrm{~m} / \mathrm{s}(5,10$, and $20 \mathrm{ft} / \mathrm{s})$. Calculations were performed to a time of $2 \mathrm{~h}$ for the center jet location and to a little over $1 \mathrm{~h}$ for the quarter jet location. Results presented in this report include the computer and fluid properties model basis, preliminary numerical testing, and the application results. The application results are presented in the form of flow field and sludge layer contours. The degree of mobilization is presented in the form of the fraction of initial sludge layer remaining as a function of time.

The results obtained for the center location of the jets indicate that at $200 \mathrm{gpm}$, the sludge layer is completely mobilized in just over $1 \mathrm{~h}$. For $100 \mathrm{gpm}$ flow, about $5 \%$ of the sludge layer remains after $2 \mathrm{~h}$. For $50 \mathrm{gpm}$ flow, nearly $40 \%$ of the initial sludge layer remains after $2 \mathrm{~h}$. For the jets at quarter-length location, at $200 \mathrm{gpm}$, about $10 \%$ of the initial sludge layer remains after $1 \mathrm{~h}$. For $100 \mathrm{gpm}$, about $40 \%$ of the sludge layer remains after $1 \mathrm{~h}$. These estimates for remaining sludge are based on the assumption that the boundary of the sludge layer is defined as $98 \%$ of the maximum packing for the particles. Mixing time estimates for these cases range from between $9.4 \mathrm{~h}$ and $16.2 \mathrm{~h}$, depending upon the assumptions used in making the estimate. Upon completion of the experimental tests, a more critical evaluation and comparison of the predicted results and the test results is needed.

Additional model development work is needed to improve the mobilization predictions capability. To accomplish an improved model approach, it is recommended that the following steps be taken:

- Review recent 1/25-scale kaolin mobilization experiments conducted at PNL to determine the important parameters that have been identified.

- Implement logic in TEMPEST to track an approximate interface between a strength-containing sludge region and adjacent fluid region. 
- Implement an interface mass transport model.

- Numerically test the model improvements to demonstrate that they can be used to predict partial mobilization of a sludge layer.

Subsequent to numerically testing and demonstrating this approach, simulations of the $95 \mathrm{~m}^{3}$ $(25,000$-gal) tank kaolin sludge mobilization tests need to be re-computed to determine the applicability of the improved model to real data. Proposed application of this approach to MVST and other tank sludge at ORNL is dependent upon successful application to the scaled experiments. 


\section{Acknowledgment}

This work was conducted under P.O. 10X-SL490V (Tom Hylton, Technical Contact) for Oak Ridge National Laboratory, operated by Martin Marietta Energy Systems for the U.S. Department of Energy under Contract DE-AC05-840R2 1400. The work was conducted by the Pacific Northwest Laboratory, operated by Battelle Memorial Institute for the U.S. Department of Energy under Contract DE-AC06-76RLO 1830. 



\section{Contents}

Summary $\ldots \ldots \ldots \ldots \ldots \ldots \ldots \ldots \ldots \ldots \ldots \ldots \ldots \ldots$ ii

Acknowledgments $\ldots \ldots \ldots \ldots \ldots \ldots \ldots \ldots \ldots \ldots \ldots \ldots \ldots$

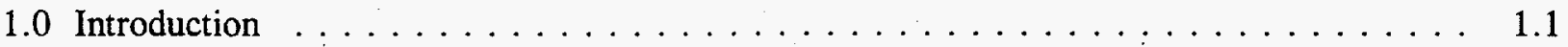

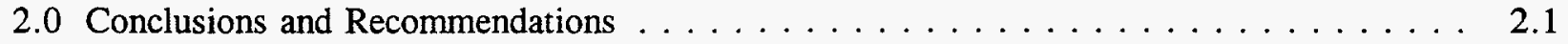

3.0 Computer Model Setup and Preliminary Numerical Testing $\ldots \ldots \ldots \ldots \ldots \ldots$

3.1 Tank Geometry . . . . . . . . . . . . . . . . . 3.1

3.2 Fluid Properties $\ldots \ldots \ldots \ldots \ldots \ldots \ldots \ldots \ldots \ldots \ldots \ldots$

3.2 .1 Base Fluid Properties $\ldots \ldots \ldots \ldots \ldots \ldots \ldots \ldots \ldots \ldots$

3.2.2 Overburdened Sludge Properties $\ldots \ldots \ldots \ldots \ldots \ldots \ldots \ldots$

3.2.3 Fluid Properties Used in Sensitivity Tests $\ldots \ldots \ldots \ldots \ldots \ldots$

3.3 Results of Preliminary Numerical Testing $\ldots \ldots \ldots \ldots \ldots \ldots$

3.4 Discussion of Preliminary Numerical Testing Results $\ldots \ldots \ldots \ldots \ldots . \ldots \ldots$

4.0 Sludge Layer Mobilization Results $\ldots \ldots \ldots \ldots \ldots \ldots \ldots \ldots$

4.1 Flow Field and Sludge Layer Characteristics $\ldots \ldots \ldots \ldots \ldots . \ldots \ldots$

4.2 Sludge Layer Material Retention Results $\ldots \ldots \ldots \ldots \ldots \ldots \ldots$

4.3 Recirculation Line Concentration and Estimates of Mixing Time Results . . . . . . 4.14

4.4 Discussion of Computer Requirements $\ldots \ldots \ldots \ldots \ldots \ldots \ldots \ldots \ldots$

4.5 Discussion of Mobilization Resistance and Computer Model Criteria . . . . . . . 4.34

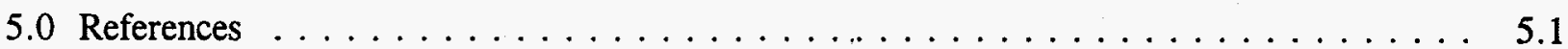




\section{Figures}

3.1 Schematic of the tank configuration used in computational models

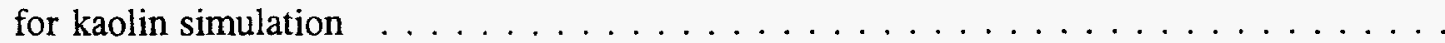

3.2 Stress/strain rate relationships for sludges settled from slurries of $15 \mathrm{wt} \%$ kaolin

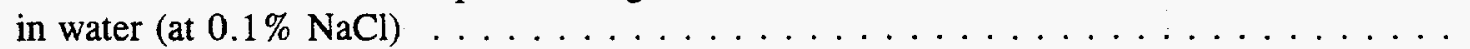

3.3 Fitting Bingham models to kaolin sludge rheological data derived from Terrones and Eyler $(1993) \quad \ldots \ldots \ldots \ldots \ldots \ldots \ldots$

3.4 Comparison of concentration contours from preliminary numerical testing with a Bingham model (curves 1,2), a power-law model (curves 3,4), and an overburdened Bingham model (curves 5,6)

3.5 Comparison of concentration contours from preliminary numerical testing at center jet location and three jet velocities: $5 \mathrm{ft} / \mathrm{s}$ (curves 1,2 ), $10 \mathrm{ft} / \mathrm{s}$ (curves 3,4 ), and $20 \mathrm{ft} / \mathrm{s}$ (curves 5,6 )

3.6 Comparison of concentration contours from preliminary numerical testing at base-case (curve 1,2), low diffusivity (curves 3,4 ), and high density (curves 5, 6)

3.7 Simulated stationary sludge banks

4.1 Flow field and volume fraction contours for the center jet location at 1 and $2 \mathrm{~h}$ for flow rates of 50,100 , and $200 \mathrm{gpm} \ldots \ldots \ldots \ldots \ldots$

4.2 Volume fraction contours at 10-min intervals for 50,100 , and $200 \mathrm{gpm}$ showing mobilization of sludge layer for the center jet location . . . . . . . . .

4.3 Comparison of the sludge layer interface contour at 1 and $2 \mathrm{~h}$ for flow rates of 50,100 , and $200 \mathrm{gpm}$ for the center jet location $\ldots \ldots \ldots \ldots$

4.4 Flow field and volume fraction contours for the quarter jet location at

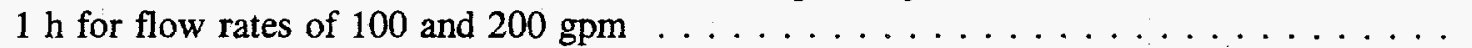

4.5 Volume fraction contours at 10-min intervals for 100 and $200 \mathrm{gpm}$ showing mobilization of sludge layer for the quarter jet location

4.6 Comparison of the sludge layer interface contour at $1 \mathrm{~h}$ for flow rates of 100 and $200 \mathrm{gpm}$ for the quarter jet location

4.7 Fraction of the tank volume containing a solids volume fraction as a function of time for the center jet location 
4.8 Fraction of the tank volume containing a solids volume fraction as a function of time for the quarter jet location

4.9 Normalized fraction of the initial sludge layer volume as a function

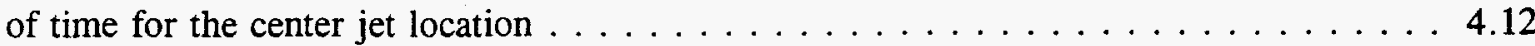

4.10 Normalized fraction of the initial sludge layer volume as a function

of time for the quarter jet location.

4.11 Concentration of solids in the recirculation line as a function of time

for the center jet location

4.12 Concentration of solids in the recirculation line as a function of time

for the quarter jet location

4.13 Solids fraction volume concentration distribution at 10 -min intervals

for the center jet location and flow rate of $200 \mathrm{gpm}$

4.14 Solids fraction volume concentration distribution at 10-min intervals

for the center jet location and flow rate of $100 \mathrm{gpm}$

4.15 Solids fraction volume concentration distribution at 10 -min intervals

for the center jet location and flow rate of $50 \mathrm{gpm}$

4.16 Position of the fully mixed concentration contour as a function of time

for the center jet location at 50,100 , and $200 \mathrm{gpm}$

4.17 Curve fit 1 of data in Figure 4.16

4.18 Curve fit 2 of data in Figure 4.16

4.19 Curve fit 3 of data in Figure 4.16

4.20 Solids fraction volume concentration distribution at 10 -min intervals

for the quarter jet location and flow rate of $200 \mathrm{gpm}$

4.21 Solids fraction volume concentration distribution at 10 -min intervals for the quarter jet location and flow rate of $\mathbf{2 0 0}$ gpm for a modified strength criterion

4.22 Solids fraction volume concentration distribution at 10-min intervals for the quarter jet location and flow rate of $100 \mathrm{gpm}$

4.23 Position of the fully mixed concentration contour as a function of time for the quarter jet location at 100 and $200 \mathrm{gpm}$

4.24 Curve fit 1 of data in Figure 4.23

ix 


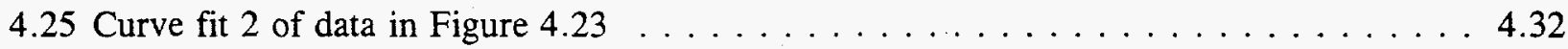

4.26 Curve fit 3 of data in Figure $4.23 \ldots \ldots \ldots \ldots \ldots \ldots \ldots \ldots$

\section{Tables}

4.1 Specified Jet Velocity and Equivalent Values $\ldots \ldots \ldots \ldots \ldots \ldots$

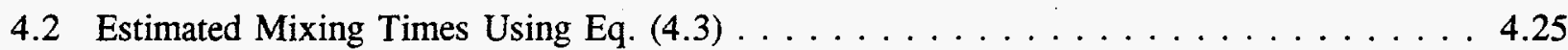

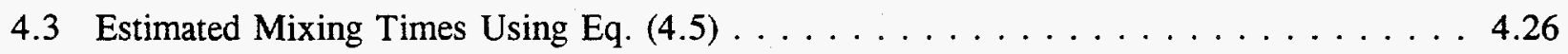




\subsection{Introduction}

The retrieval and treatment of radioactive sludges stored in tanks constitute a prevalent problem at several U.S. Department of Energy sites. The tanks typically contain a settled sludge layer with non-Newtonian rheological characteristics covered by a layer of supernatant. One of the first steps in retrieval of tank waste is the mobilization and mixing of the supernatant and sludge in the storage tanks. Submerged liquid jets have been proposed to achieve sludge mobilization and mixing in tanks, including the $189 \mathrm{~m}^{3}$ (50,000-gal) Melton Valley Storage Tanks (MVST), the Old Hydrofracture Facility, the gunnite tanks, and the planned $378 \mathrm{~m}^{3}(100,000-\mathrm{gal})$ tanks being designed as part of the MVST Capacity Increase Project (MVST-CIT) at Oak Ridge National Laboratory (ORNL).

This report focuses on the modeling of mobilization and mixing of kaolin with submerged liquid jets. The goal of the work is to simulate kaolin mobilization experiments planned and being conducted at ORNL in a $95 \mathrm{~m}^{3}(25,000-\mathrm{gal})$ tank as accurately as possible using the TEMPEST computer program developed by Pacific Northwest Laboratory (PNL). The simulations were to use properties of kaolin supplied by ORNL. Experiment plans called for the sludge to be uniformly distributed at a depth of $46 \mathrm{~cm}(1.5 \mathrm{ft})$ at the start of each simulation. The jet configuration is a double jet made of $3.2 \mathrm{~cm}$ (1.25 in.) schedule 40 pipe having an internal diameter of $3.5 \mathrm{~cm}(1.38$ in.). Two jet locations are simulated: at the center (lengthwise) of the tank and at approximately 1/4-tank length from one end. For the former location, the suction line is also located at the center and for the latter location, the suction line is at the opposite end of the tank at $1 / 8$ the tank length and $52 \mathrm{~cm}$ ( 20 in.) above the tank floor. The jets are parallel to the tank floor and several jet diameters above the floor. Three flow rates (jet velocities) were to be simulated for each jet location.

The approach used in this work included using the TEMPEST computer program (Trent and Eyler 1993) to simulate the combined mobilization and mixing processes in the horizontal cylindrical tank configuration with submerged liquid jets and an initially settled sludge layer. The basis for the approach applied to the present problem had been developed in previous related tasks (Terrones and Eyler 1993, Mahoney, Terrones and Eyler 1994). That work included, among other things, developing and demonstrating simulation of mixing processes in horizontal cylindrical tanks using nonhomogeneous non-Newtonian rheology models. Applying the approach to the present task included

- development of the appropriate rheology model using measured kaolin theology data supplied by ORNL and available from other sources.

- development of a discretized computer model of the tank, sludge layer, and mixing jets.

- simulation of the mobilization and mixing processes for planned experiment conditions.

Once the rheology model of the kaolin sludge was developed and the computer model prepared, preliminary simulations were conducted. These results are presented in Section 3 of this report. It was determined from these preliminary simulations that there was a weakness in the either the approach or in the computer model. This was identified by the results that indicated the kaolin sludge layer was predicted to mobilize in a rather short time, approximately $10-20 \mathrm{~min}$. The first experiments conducted at about $200 \mathrm{gpm}$ indicated that some fraction of the initial sludge layer 
$(\sim 35 \%)$ remained and was unmixed. Complete mixing of the mobilized fraction of the initial sludge layer $(\sim 65 \%)$ took approximately $10 \mathrm{~h}$ according to ORNL test personnel.

Extensive efforts were devoted to identifying the primary cause of the apparent discrepancy between the preliminary numerical simulations and the preliminary test data. Numerical experiments were conducted to investigate the numerical method used to approximate retention of a sludge material exhibiting strength. These numerical experiments were successful and showed that under certain conditions, a sludge bank could be retained numerically. This led to further investigations into definition of the criterion for approximating the combined effects of a sludge bank with strength, but which could be mobilized under the influence of the mixing jet, with the mixing effects in the dilute liquid. Simulations of the two jet configurations at two locations were then conducted to a time of $2 \mathrm{~h}$. Results of this phase of the work are presented in Section 4 of this report.

The final results obtained for the center location of the jets indicate that at a total flow rate of about $200 \mathrm{gpm}$, the sludge layer is completely mobilized in just over $1 \mathrm{~h}$. For the $100 \mathrm{gpm}$ flow case, about $5 \%$ of the sludge layer remains after $2 \mathrm{~h}$. For $50 \mathrm{gpm}$ flow, nearly $40 \%$ of the initial sludge layer remains after $2 \mathrm{~h}$. For the jets at quarter-length location, at $200 \mathrm{gpm}$, about $10 \%$ of the initial sludge layer remains after $1 \mathrm{~h}$. For $100 \mathrm{gpm}$, about $40 \%$ of the sludge layer remains after $1 \mathrm{~h}$. These estimates for remaining sludge are based on the assumption that the boundary of the sludge layer is defined as $98 \%$ of the maximum packing for the particles. Mixing time estimates for these cases range from between $9.4 \mathrm{~h}$ and $16.2 \mathrm{~h}$, depending upon the assumptions used in making the estimate. 


\subsection{Conclusions and Recommendations}

By comparing the results presented in this report with preliminary test results, it must be concluded that the predictions of the mobilization of kaolin sludge are not totally successful. Improvement in the prediction of mobilization of kaolin sludge can only be accomplished with additional numerical model developments. This conclusion is based principally on the comparison of results at $200 \mathrm{gpm}$ flow range. The preliminary test results indicate ${ }^{(\mathrm{a})}$ that only about $65 \%$ of the initial sludge layer is mobilized. The predictions for this case indicate that all of the layer is mobilized after about $1.2 \mathrm{~h}$ of operation using the assumptions in the computer model for the yield strength. For this case, approximately $11 \mathrm{~h}$ of test operation was required for the fraction of material that is mobilized to be totally mixed, as indicated by the approach of the visible particulate material to the top of the liquid. The computer model predictions for mixing time using an approach of an interface towards the top of the tank range from $9.4 \mathrm{~h}$ to $16.2 \mathrm{~h}$ depending upon assumptions. Upon completion of the experimental tests, a more critical evaluation and comparison of the predicted results and the test results is needed.

Additional model development work is needed to improve the mobilization predictions capability. To accomplish an improved model approach, it is recommended that the following steps be taken:

- Review recent $1 / 25$-scale kaolin mobilization experiments conducted at PNL to determine the important parameters that have been identified.

- Implement logic in TEMPEST to track an approximate interface between a strength-containing sludge region and adjacent fluid region.

- Implement an interface mass transport model.

- Numerically test the model improvements to demonstrate that in fact they can be used to predict partial mobilization of a sludge layer.

Subsequent to numerically testing and demonstrating this approach, simulations of the $95 \mathrm{~m}^{3}$ (25,000-gal) tank kaolin sludge mobilization tests need to be re-computed to determine the applicability of the improved model to real data. Proposed application of this approach to MVST and other tank sludge at ORNL is dependent upon successful application to the scaled experiments.

(a) Tom Hylton, Oak Ridge National Laboratory, personal communication, September 1994. 


\subsection{Computer Model Setup and Preliminary Numerical Testing}

This section presents the basis for the computer model setup, fluid physical properties, and kaolin sludge layer rheology model. Results of sensitivity testing are also presented.

The objective of this work was to simulate the mobilization and mixing behavior of kaolin sludge in a $95 \mathrm{~m}^{3}(25,000$-gal) horizontal cylindrical tank so that model predictions and experimental observations could be compared. Two different jet/suction configurations were modeled. In the first configuration, the two opposed jets were centrally located between the tank ends and near the tank bottom. The axis of the jets was aligned with the horizontal tank axis and the suction was located adjacent to and slightly above the jets. In the second configuration, the two opposed jets were located close to the bottom and at $1 / 4$ of the tank length along the lengthwise center plane. The suction was located $1 / 8$ of the tank length away from the opposite end of the tank. In both configurations the computer model assumed the tank was completely filled whereas the experiment tank was approximately $85-90 \%$ full. While not specifically investigated, it is not expected that the small difference in liquid level would affect mobilization predictions.

\subsection{Tank Geometry}

The modeled tank was a horizontal cylinder $3.25 \mathrm{~m}$ (128 in.) in diameter and $11.8 \mathrm{~m}$ (466 in.) long, completely filled with supernatant. The jets' centerline was $16.4 \mathrm{~cm}(6.5 \mathrm{in}$.) above the tank bottom, and the diameter of each jet was $3.5 \mathrm{~cm}$ (1.38 in.), corresponding to a 1.25 -in. schedule 40 nozzle. The pipe leading down into the jets had a diameter of $9.2 \mathrm{~cm}(3.6 \mathrm{in}$.), and the suction lines had a diameter of $19.4 \mathrm{~cm}(7.6 \mathrm{in}$.). These lines were to represent the 2 -in. and 3-in. schedule 80 pipes in the test tank; model constraints on the placement of the lines and the relative sizes of adjacent computational cells made it infeasible to more closely match the experimental dimensions of the recirculation lines. The actual modeled tank volume was $95.3 \mathrm{~m}^{3}(25,200$ gal).

In the first of the two jet/suction configurations modeled, the jets were located at the center of the tank length and the recirculation suction was located above the jets, $25.6 \mathrm{~cm}$ (10 in.) from the bottom of the tank. In this case, the model used two symmetry planes, one providing end-to-end symmetry and one side-to-side symmetry.

In the second configuration modeled, the suction and the jets were located at opposite ends of the tank. The jets were placed at a distance of $1 / 4$ the length from one end and the suction at $1 / 8$ the length from the other end. Only one symmetry plane (the side-to-side one) could be used in modeling this configuration. This configuration had the suction located about $52 \mathrm{~cm}(20 \mathrm{in}$.) above the tank bottom.

Figure 3.1 shows a schematic of the two configurations modeled. The experimental tank drawings from which the computer model was developed showed jet lines and jets at the 1/4-, 1/2-, and 3/4-tank length locations, and suction lines at the 1/8-, 1/2-, and 7/8-tank length locations. The unused lines and jets for each configuration were approximated in the computer model as solid obstacles, though they are not shown as such in Figure 3.1. 


\section{Center jet/suction.}
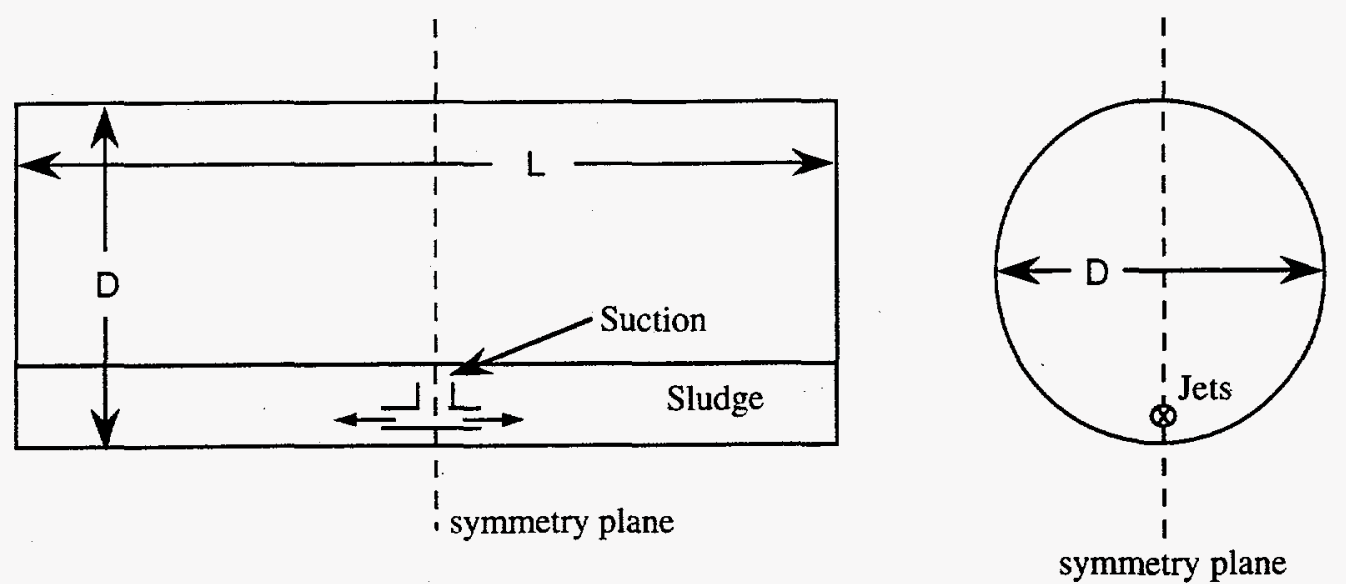

$$
\begin{array}{ll}
\mathrm{D}=3.25 \mathrm{~m} & \text { jet diameter }=3.5 \mathrm{~cm} \\
\mathrm{~L}=11.8 \mathrm{~m} & \text { jet height }= \\
\mathrm{V}=95.3 \mathrm{~m}^{3} & \text { suction height }=25.6 \mathrm{~cm} \\
\text { sludge depth }=0.57 \mathrm{~m}
\end{array}
$$

End jet/suction.

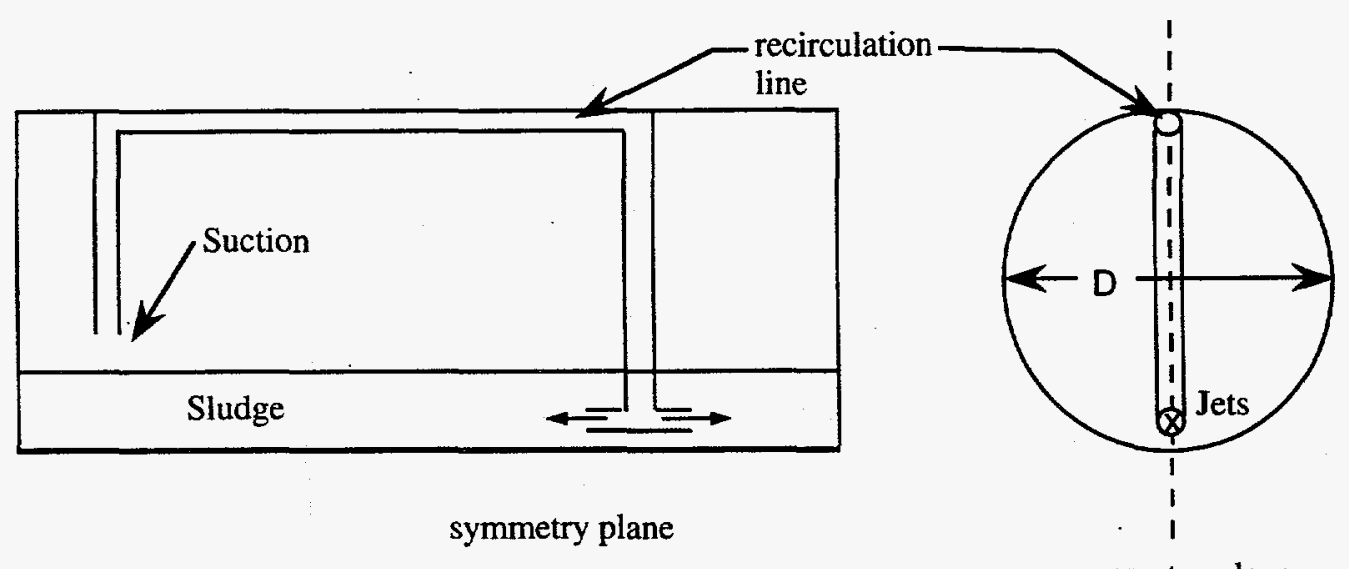

symmetry plane

$$
\begin{array}{ll}
\mathrm{D}=3.25 \mathrm{~m} & \text { jet diameter }=3.5 \mathrm{~cm} \\
\mathrm{~L}=11.8 \mathrm{~m} & \text { jet height }=16.4 \mathrm{~cm} \text { (to nozzle centerline) } \\
\mathrm{V}=95.3 \mathrm{~m}^{3} & \text { suction heights }=0.52 \mathrm{~m} \text { and } 1.05 \mathrm{~m} \\
& \text { suction diameter }=0.19 \mathrm{~m} \\
\text { sludge depth }=0.57 \mathrm{~m}
\end{array}
$$

Figure 3.1. Schematic of the tank configuration used in computational models for kaolin simulation 
In the experiment, $4100 \mathrm{~kg}(9,000 \mathrm{lb})$ of kaolin were added to the tank. At an intrinsic density of $2.15 \mathrm{~g} / \mathrm{cc}$, the kaolin would occupy $2 \mathrm{vol} \%$ of the tank. Based on a maximum packing fraction of 0.173 , which was derived from the $31 \mathrm{wt} \%$ solids value supplied by ORNL, the $4100 \mathrm{~kg}$ of kaolin was modeled as a layer of sludge $57 \mathrm{~cm}$ (22 in.) deep at its centerline. However, when water exclusion due to extended settling occurs, the layer may not be this deep in the actual test. An uncertainty in the maximum packing factor and the effect of water exclusion with extended settling times leads to some uncertainty in prescribing initial conditions in the computer model and leads to some uncertainty in the in situ rheology and strength of the sludge.

\subsection{Fluid Properties}

Preliminary computer simulations were carried out with different sets of sludge properties so that the sludge could be modeled both with and without the viscosity gradient produced by long-term settling under an overburden, and so that sensitivity tests could be made.

\subsubsection{Base Fluid Properties}

The base sludge properties-that is, those without overburden effects or parametric variation-came from three sources: data supplied by ORNL for the batch of kaolin used in the experiment, data in earlier work done for ORNL (Terrones and Eyler 1993), and data in Selby (1981). The ORNL kaolin sludge was that which had settled from a $15 \mathrm{wt} \%$ slurry of kaolin clay in water, with $0.1 \mathrm{wt} \%$ salt $(\mathrm{NaCl})$ present. Its properties were measured within a few days after settling. The data made it clear that the kaolin slurry had undergone enough shear (mixing) to give shear-stable rheological behavior.

The supernatant density was taken to be $1.0 \mathrm{~g} / \mathrm{cc}$. The kaolin particles were modeled with a density of $2.15 \mathrm{~g} / \mathrm{cc}$ (Terrones and Eyler 1993) and a maximum (unhindered) settling velocity of 6.7 $\mathrm{x} 10^{-4} \mathrm{~m} / \mathrm{s}(3.8 \mathrm{~cm} / \mathrm{min})$ based on data supplied by ORNL. The Stokes-regime hindered settling model (Perry and Chilton 1973) was used to represent the decreased settling velocity at high concentration:

$$
V_{s}=V_{s 0}\left(1-C_{r}\right)^{4.65}
$$

where $\quad V_{s} \quad=$ hindered settling velocity

$\mathrm{V}_{\mathrm{s} 0} \quad=$ low-concentration settling velocity

$\mathrm{C}_{\mathrm{r}}=$ reduced concentration $=\mathrm{C}_{\mathrm{v}} / \mathrm{C}_{\mathrm{v}, \max }$

$\mathrm{C}_{\mathrm{v}} \quad=$ volume fraction solids

$\mathrm{C}_{\mathrm{v}, \max }=$ maximum packed volume fraction $(=0.173)$.

Figure 3.2 shows the ORNL-supplied kaolin rheological measurements, the Bingham and powerlaw correlations of those data, and the measurements and correlations for the PNL study conducted by Terrones and Eyler (1993). These were all for undiluted kaolin sludge from a $15 \mathrm{wt} \%$ slurry. PNL data were measured for both increasing and decreasing strain rates; the ORNL measurement technique is not known. The PNL study was conducted at two different salt concentrations- $0 \mathrm{wt} \%$ and $1 \mathrm{wt} \%$-and the ORNL data were taken at $0.1 \mathrm{wt} \%$ salt. The power-law correlation for the PNL kaolin sludges (averaged from up and down sweeps) provides a good description of the ORNL 


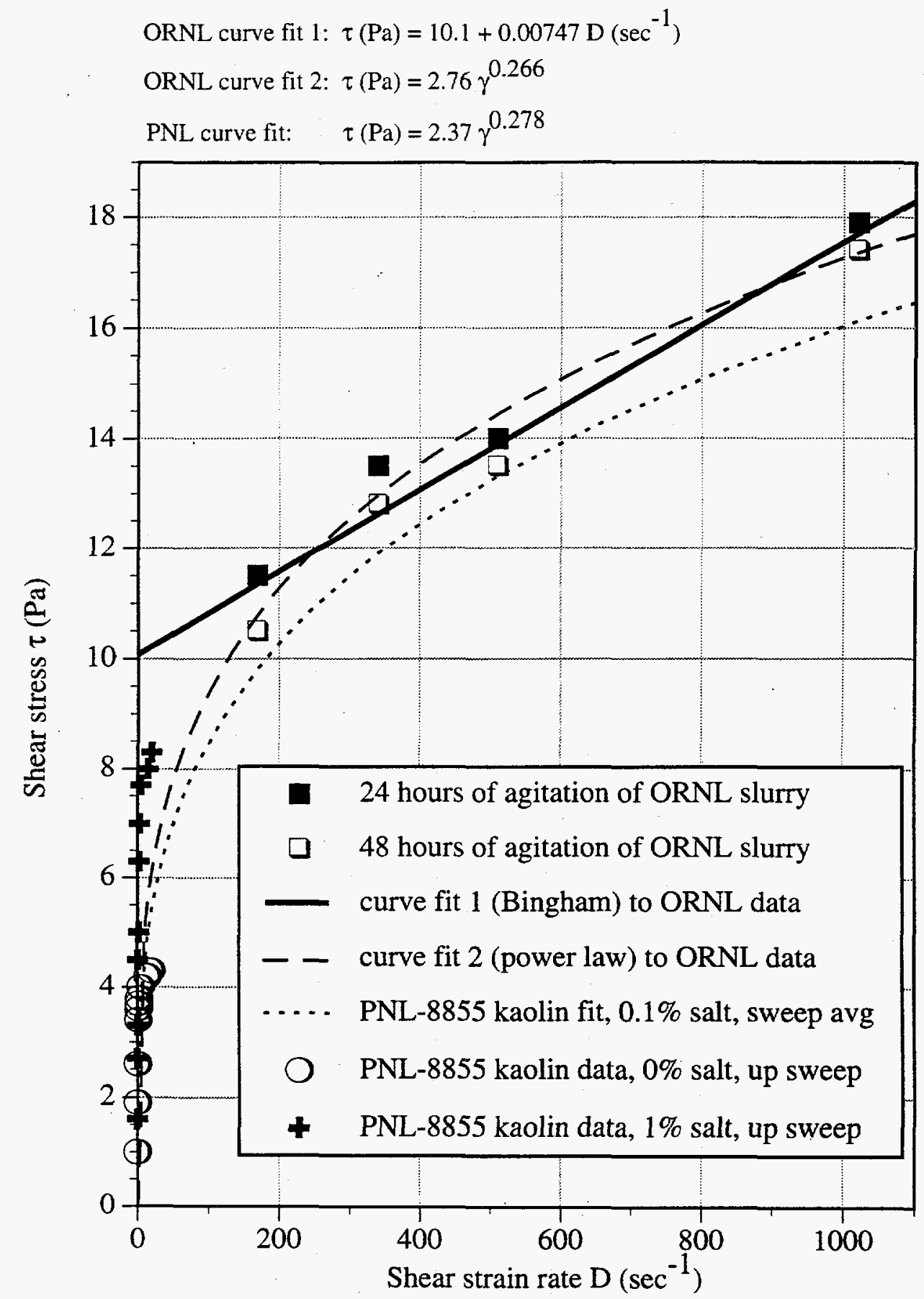

Figure 3.2. Stress/strain rate relationships for sludges settled from slurries of $15 \mathrm{wt} \%$ kaolin in water (at $0.1 \% \mathrm{NaCl}$ ) 
measurements, even though the PNL data were taken at strain rates much lower than those used by ORNL. The PNL correlation was interpolated to $0.1 \mathrm{wt} \%$ salt.

The ORNL data were all taken at zero dilution, providing no information on the variation of viscosity with sludge concentration. However, the good comparison between PNL and ORNL rheological measurements at zero dilution meant that the PNL correlations for the concentration variation of kaolin sludge viscosity could also be used for ORNL kaolin modeling. Two different models from the PNL power-law correlations were developed, one that treated kaolin as a Bingham fluid and the other as a power-law fluid. The Bingham model was derived by fitting a line to the part of the power-law correlation that lay between 200 and $1000 \mathrm{sec}^{-1}$, the range in which the ORNL data lay. These Bingham and power-law fits for undiluted sludge, and the ORNL data, are shown in Figure 3.3 .

Bingham correlation:

$$
\begin{aligned}
\mu & =0.001\left(1+6.07 \mathrm{C}_{\mathrm{r}}^{1.27}\right) \\
\tau_{\mathrm{y}} & =9.18 \mathrm{C}_{\mathrm{r}}^{3.74} \\
\tau & =\tau_{\mathrm{y}}+\mu \mathrm{D}
\end{aligned}
$$

Power-law correlation:

$$
\begin{aligned}
& \mathrm{K}=0.001\left(1+2472 \mathrm{C}_{\mathrm{r}}^{2.873}\right) \\
& \mathrm{m}=1+10.51^{-\mathrm{Cr}}-1.115^{-\mathrm{Cr}} \\
& \tau=\mathrm{KD}^{\mathrm{m}}
\end{aligned}
$$

$$
\text { where } \begin{aligned}
\mu & =\text { viscosity }(\mathrm{Pa} \mathrm{s}) \\
\tau_{\mathrm{y}} & =\text { Bingham yield stress }(\mathrm{Pa}) \\
\tau & =\text { shear stress }(\mathrm{Pa}) \\
\mathrm{D} & =\text { shear rate }(/ \mathrm{s}) \\
\mathrm{K} & =\text { consistency factor in power law } \\
\mathrm{m} & =\text { structural index in power law. }
\end{aligned}
$$

As in the earlier modeling (Terrones and Eyler 1993), it was necessary to specify Schmidt numbers in such a way as to avoid generating unrealistically high molecular and turbulent diffusivities. In TEMPEST, the total diffusivity of a species is calculated as the sum of molecular, laminar, and turbulent contributions:

$$
D_{\text {tot }}=D_{p}+\left(/\left(\rho S_{1}\right)\right)+\left({ }_{\text {eff }} /\left(\rho S_{r}\right)\right)
$$

where $D_{\text {tot }}=$ total species diffusivity

$$
\begin{aligned}
\mathrm{D}_{\mathrm{p}}= & \text { particle diffusion coefficient (the only non-zero term } \\
& \quad \text { under stagnant conditions) } \\
= & \text { dynamic viscosity of the fluid } \\
\rho & =\text { density of the fluid } \\
\text { eff } & =\text { turbulent effective viscosity } \\
\mathrm{Sc}_{\mathrm{L}} & =\text { laminar Schmidt number } \\
\mathrm{Sc}_{\mathrm{T}} & =\text { turbulent Schmidt number. }
\end{aligned}
$$




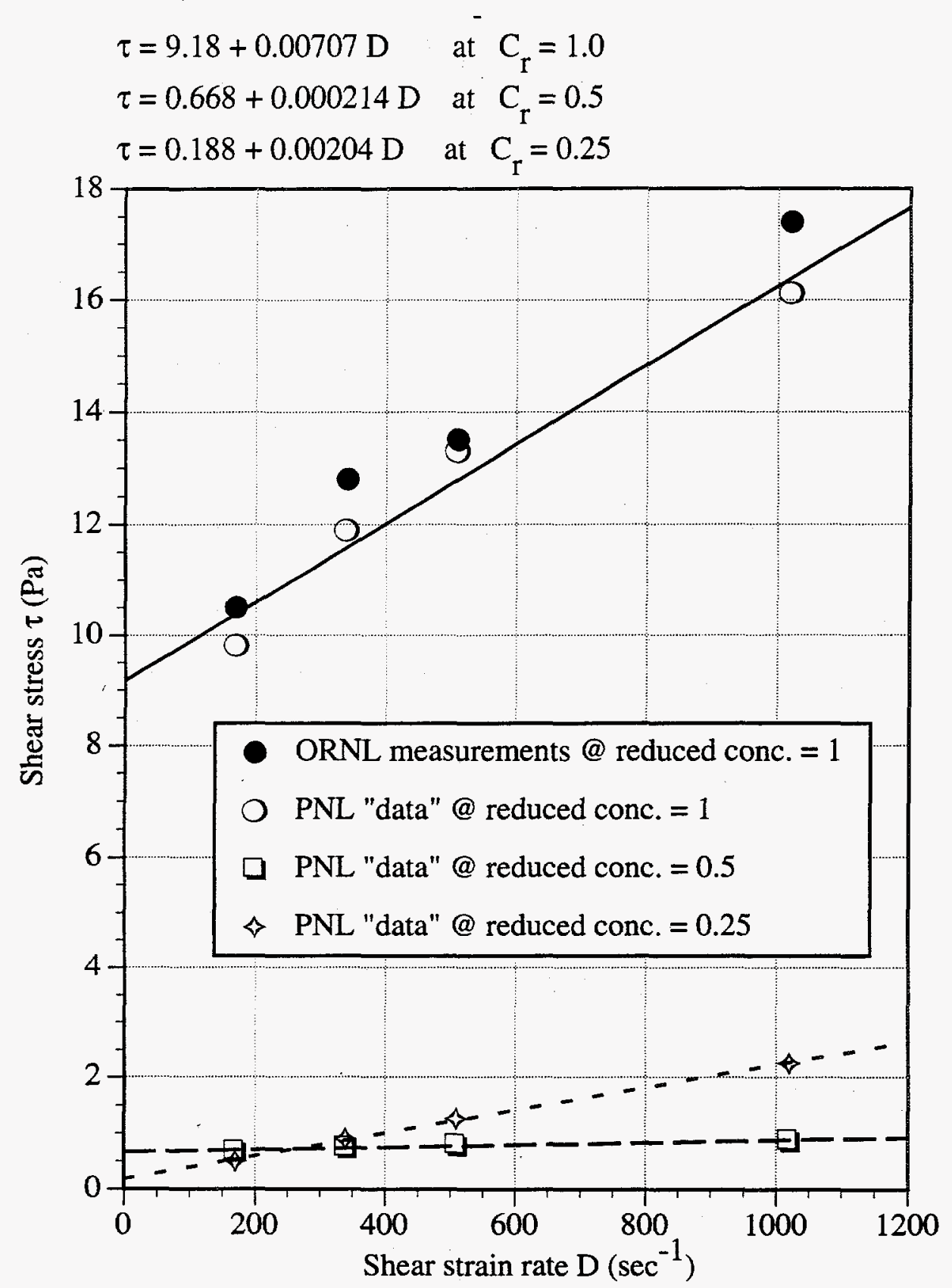

Figure 3.3. Fitting Bingham models to kaolin sludge rheological data derived from Terrones and Eyler (1993) 
The high sludge viscosity leads directly to a large laminar diffusivity (second term) and indirectly to a large turbulent diffusivity (third term). These unrealistically high terms were therefore effectively removed from the sludge model by setting the Schmidt numbers to $10^{9}$. On the other hand, the resulting low diffusivities were thought to be conservative because they would underestimate the mixing and overestimate the mixing time. The same approximation was employed as in Mahoney et al. (1994) and a value of $10^{-6}$ was initially used for $D_{p}$.

For a kaolin sludge particle, the particle diffusion coefficient in water would be expected to be about $10^{-14} \mathrm{~m}^{2} / \mathrm{s}$ (CRC 1976). The particle diffusion coefficient pertains to stagnant conditions and requires some modification to include the additional diffusivity that results from a local laminar velocity gradient (Eq. 3.8). The diffusivity that was used for sludge particles was therefore greater than the relatively negligible particle diffusion.

\subsubsection{Overburdened Sludge Properties}

Because the kaolin sludge in the $95 \mathrm{~m}^{3}$ (25,000-gal) tank was planned to have several weeks of settling time before the mobilization experiments started, settling might have led to water exclusion from the bottom of the sludge. Water exclusion results in an increase of solids fraction and viscosity with depth below the sludge surface. This effect has been observed (Selby 1981; Terrones and Eyler 1993) in kaolin sludges settling under their own weight. The effect has been shown to be increased in kaolin sludges that are overburdened by having a depth of supernatant above them. Runs were made with overburdened viscosity variation, and a Bingham yield model, to examine this effect on the computations.

Figures 13 through 15 of Selby (1981) show the effect of water exclusion and overburden on a kaolin slurry. The maximum viscosity increase appears to require about two months of settling and to remain constant after that time (Figure 13, op. cit.). Both the Bingham yield stress and the viscosity increase linearly with depth in a very strongly correlated manner, as shown in Figures 14 and 15 (op. cit.). Though these data were taken at five months settling time, they were probably about the same as at two months settling (viz Figure 13, op. cit.). These figures allow estimation of the yield stress and viscosity as functions of sludge depth. With an estimated sludge depth of about $18 \mathrm{in}$., the onemonth overburdened yield strength at the bottom of the sludge was calculated to be 3.6 times the freshly settled value, or $32.7 \mathrm{~Pa}$. The one-month overburdened viscosity was calculated to be 5.6 times the freshly settled value, or $0.0396 \mathrm{~Pa}$ s.

These fully overburdened rheological parameters were treated as being the ones that obtain at the true, fully overburdened maximum packing fraction $\mathrm{C}_{\mathrm{v}, \max }$, which was an unknown. The overburdened parameters were combined with the parameters already drawn from measurements (and correlated with Equations 3.2 and 3.3). Then the overburdened $C_{v, \max }$ value was estimated as being the one that allowed the best fit of $\mu$ and $\tau_{y}$ to the complete data set, including the values extrapolated for overburden. This new $C_{v, \max }$ was found to be 0.265 , indicating a relatively slight increase in packing under overburden. The new correlations for $\mu$ and $\tau_{y}$ are given in Equations 3.9 and 3.10.

Overburdened Bingham correlation:

$$
\begin{aligned}
\mu & =0.00204\left(1+18.45 \mathrm{C}_{\mathrm{r}}^{5.05}\right) \\
\tau_{\mathrm{y}} & =32.7 \mathrm{C}_{\mathrm{r}}^{3.2}
\end{aligned}
$$


The sludge solid volume fraction was modeled as increasing with depth from the original value of 0.178 at the sludge surface to the sludge-bottom value of 0.265 . The variation of solid fraction was set to make the viscosity and yield stress vary linearly with sludge depth.

\subsubsection{Fluid Properties Used in Sensitivity Tests}

The sludge density and the diffusion coefficient were both varied in several runs as tests of whether underestimated density or overestimated diffusion could explain the discrepancies between the preliminary predictions and preliminary test observations.

In the higher-density set of runs, the sludge and supernatant densities were increased to the same values used for Tank W-28 sludge (Mahoney et al. 1994). These values were $C_{v, \max }$ of 0.68 , solid density of $2.0 \mathrm{~g} / \mathrm{cc}$, and supernatant density of $1.285 \mathrm{~g} / \mathrm{cc}$. The rheological parameters were set at those for overburdened kaolin. Because beach formation had been predicted for the 1/6-scale tank with this set of densities, it was worth testing to see if this higher density would provide more realistic mobilization estimates.

It was also suspected that the model might be overpredicting diffusion because too high a diffusion coefficient $D_{p}$ was input. The diffusivity of $10^{-6} \mathrm{~m}^{2} / \mathrm{s}$ that was modeled for sludge particles in the base fluid was greater than the particle diffusion. To test the effect of diffusivity, a run was made with $D_{p}=10^{-14} \mathrm{~m}^{2} / \mathrm{s}$ and other properties unchanged from the overburdened kaolin case.

\subsection{Results of Preliminary Numerical Testing}

This section summarizes the results of the preliminary runs that were carried out to investigate changes in the fluid properties. Figure 3.3 provides a comparison of the predictions made by the power-law model of rheology, the Bingham model (without overburden), and the Bingham model (with overburden). All of these runs used the central suction/jet configuration, with the suction height set at $25.6 \mathrm{~cm}$ (10 in.) above the tank bottom, a flow rate of $200 \mathrm{gpm}$ (total from both jets), and the experimentally observed startup time of $30 \mathrm{~s}$ for the flow to ramp up from 0 to $200 \mathrm{gpm}$. The figure shows concentrations in a vertical plane along the length of the tank; the plane is a few inches away from the vertical center plane. The concentration contours in Figure 3.4 were set at volume fractions of 0.02 and 0.15 to represent, respectively, the final well-mixed concentration and the "top surface" of the remaining thick sludge. Contours 1 and 2 are the low and high concentrations for the base case model; 3 and 4 for the power-law model; and 5 and 6 for the overburdened Bingham model.

At an elapsed time of 10 min of mixing, all three rheological models show rapid mobilization of the sludge layer. Nearly all the sludge layer is predicted to be mobilized in a short time. Of the three models, the power-law predicts the fastest erosion, and the overburdened Bingham model predicts the slowest.

Accordingly, the remaining sensitivity tests were run with the overburdened Bingham rheological model. Its configuration was changed slightly to put the suction (still centrally located) at about two-thirds the tank height, to ensure the jet would be composed of clear fluid in the initial stages: This is probably a more realistic description of the liquid pumped in from the recirculation tank than is the thick sludge jet provided by having the suction at its actual level. In addition, the flow ramp-up time was increased from 30 to $300 \mathrm{~s}$. Figure 3.5 shows the effects at 5 min time of jet 


\section{Concentration and velocity}

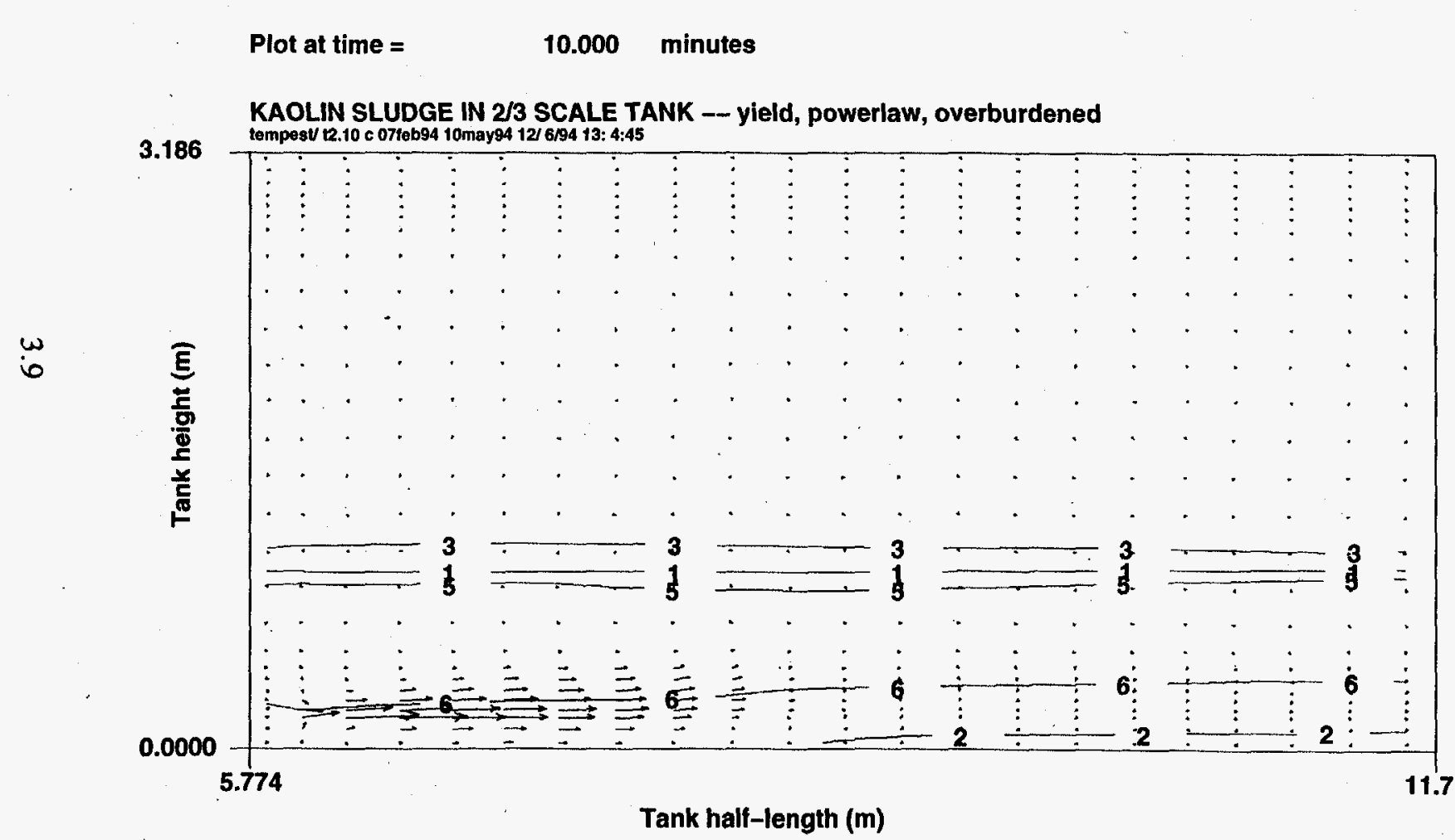

$r-z$ plane at $I=3$

$J=23$ to 44

$K=2$ to 28

plane $\min =2.797 E-15$

plane $\max =1.629 E-01$

array $\min =2.012 E-15$

array $\max =1.640 \mathrm{E}-01$

$-6-1.500 E-01$

- 5 2.000E-02

$-4-1.500 E-01$

- 3 2.000E-02

- 2 1.500E-01

- 1 2.000E-02

Vmax $=2.477$

Figure 3.4. Comparison of concentration contours from preliminary numerical testing with a Bingham model (curves 1,2$)$ a power-law model (curves 3,4), and an overburdened Bingham model (curves 5, 6) 


\section{Concentration and velocity}

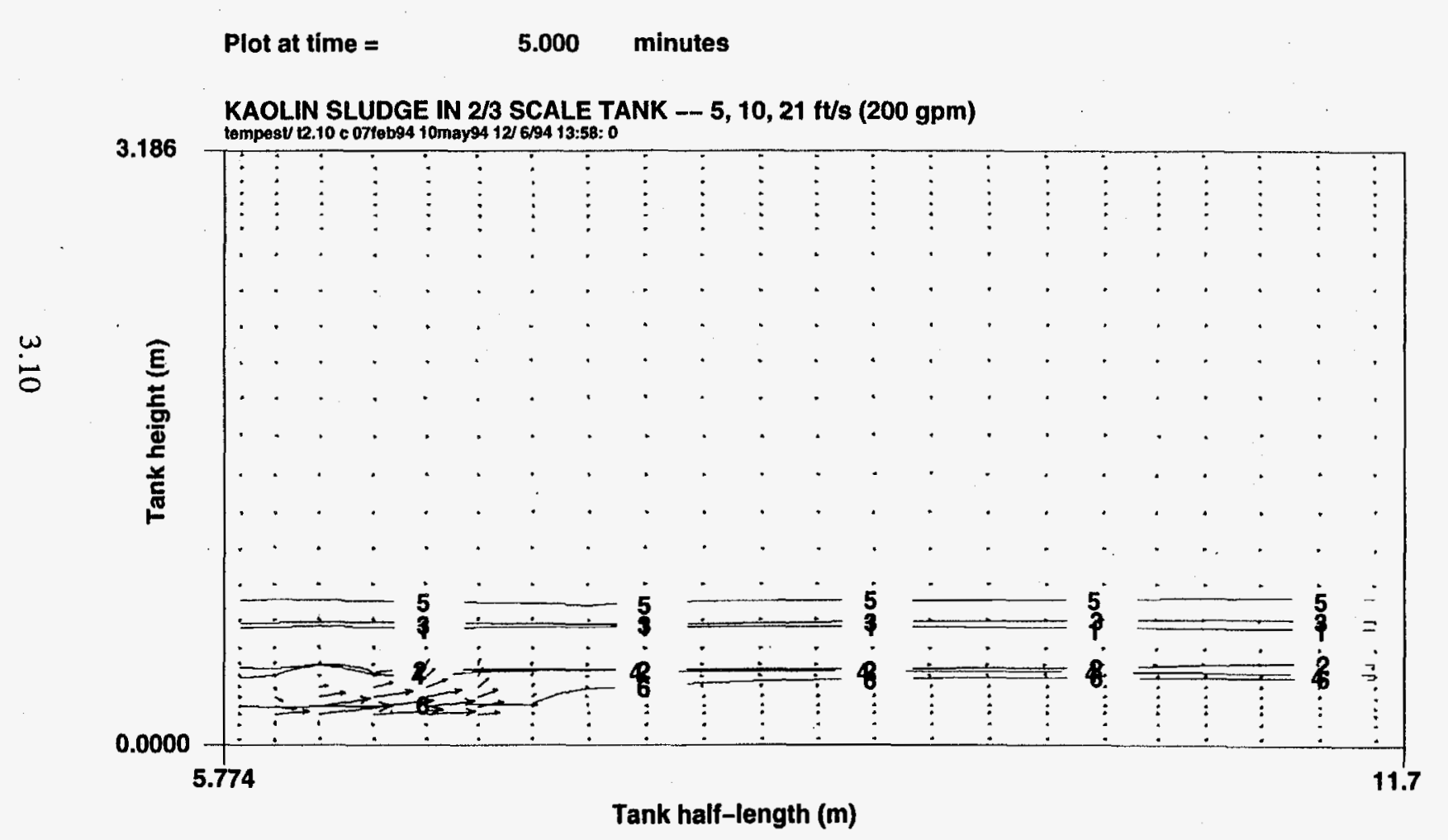

$r-z$ plane at $\mathrm{I}=3$

$J=23$ to 44

$K=2$ to 28

plane $\min =3.407 E-24$ plane $\max =2.627 \mathrm{E}-01$ array $\min =3.407 E-24$ array $\max =2.630 \mathrm{E}-01$

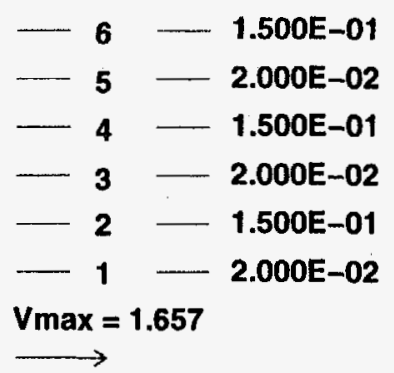

Figure 3.5. Comparison of concentration contours from preliminary numerical testing at center jet location and three jet velocities: $5 \mathrm{ft} / \mathrm{s}$ (curves 1, 2), $10 \mathrm{ft} / \mathrm{s}$ (curves 3, 4), and $20 \mathrm{ft} / \mathrm{s}$ (curves 5, 6) 
velocities of $1.52,3.05$, and $6.10 \mathrm{~m} / \mathrm{s}(5,10$, and $20 \mathrm{ft} / \mathrm{s}$ ) (this last corresponding to about $200 \mathrm{gpm}$ ). The concentration contours were chosen as in Figure 3.4. It can be clearly seen in Figure 3.5 that even at $1.52 \mathrm{~m} / \mathrm{s}(5 \mathrm{ft} / \mathrm{s})$ a substantial amount of sludge has been eroded from the dense bank into the less concentrated, more easily mobilized region above it. Even for the low velocity case, complete mobilization is predicted to occur in a short time.

A final set of sensitivity tests considered the effects of diffusivity and sludge density. The changes in these parameters were already described in Section 3.2.3. Figure 3.6 shows the effects at $5 \mathrm{~min}$ time, with a jet velocity of $3.05 \mathrm{~m} / \mathrm{s}(10 \mathrm{ft} / \mathrm{s})$ : contours 1 and 2 are for the base case; 3 and 4 are for the case using low diffusivity; and 5 and 6 are for the case of higher density sludge. Except for the high density case, the concentration contours in Figure 3.6 are set at the same values as in previous figures. For the high density case, higher values have been set to reflect the higher initial maximum packing fraction of the sludge. In all three cases the contours represent the same fractions of the initial concentration. Figure 3.6 shows that these three sensitivity runs are equivalent, and that density and diffusivity effects do not play a significant part in explaining the seemingly rapid and complete mobilization.

\subsection{Discussion of Preliminary Numerical Testing Results}

The preliminary numerical testing results indicated that the settled kaolin sludge layer was rapidly mobilized. The approach that was taken in these simulations was based on previous phases of this work as reported by Terrones and Eyler (1993) and Mahoney, Terrones, and Eyler (1994). This involved primarily using the assumption that the mobilization process could be approximated by using a nonhomogeneous non-Newtonian rheology model to define the complete range from fully settled solids to fully-mixed conditions. The previous work had primarily focused on using a power-law approximation. In the present work, the kaolin sludge exhibited sufficient strength such that a yieldbased model was used in the computer modeling.

The prediction of relatively rapid and complete mobilization of the sludge layer was not consistent with preliminary test result reported by ORNL test personnel ${ }^{(2)}$. At $200 \mathrm{gpm}$ total flow, preliminary test results indicated that only about $65 \%$ of the sludge layer was mobilized. This led the present work to re-evaluate the approach and assumptions being used in the numerical procedures to approximate the strength and mobilization resistance of the sludge layer.

In the re-evaluation, several sources of enhanced mobilization effects were identified in the model numerical procedures. The molecular diffusion could under certain conditions, cause an artificially enhanced degradation of the sludge layer. Thus, for final calculation, the molecular diffusion coefficient, $D_{p}$, was set to $10^{-14}$ to effectively eliminate its effect. The primary source of artificial mobilization enhancement, however, was identified as being caused by the yield strength model.

(a) Tom Hylton, Oak Ridge National Laboratory, personal communication, September 1994. 


\section{Concentration and velocity}

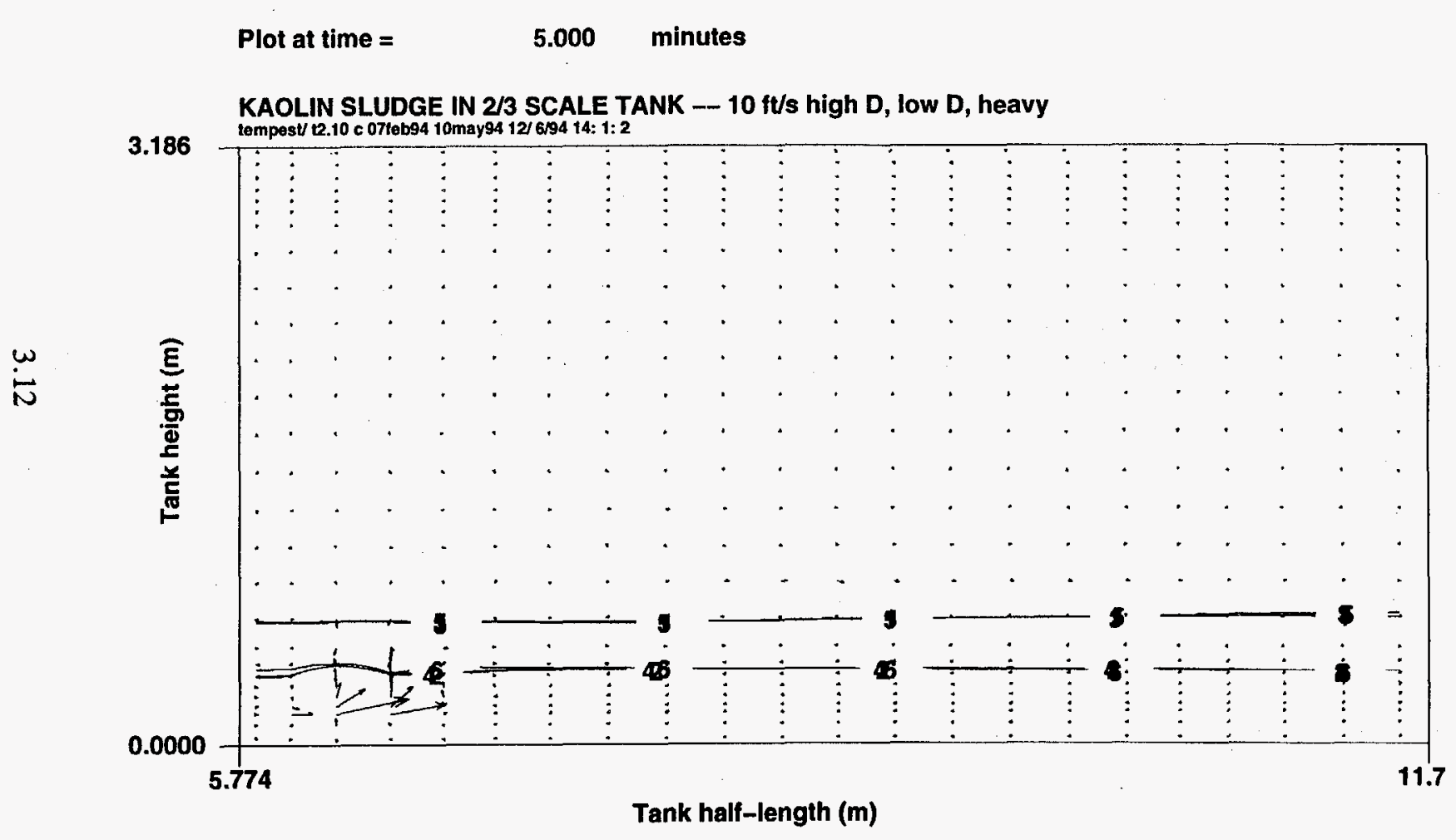

$r-z$ plane at $I=3$

$J=23$ to 44

$K=2$ to 28

plane $\min =4.087 E-26$

plane $\max =2.635 \mathrm{E}-01$

array $\min =4.087 E-26$

array $\max =2.639 E-01$

\begin{tabular}{rr}
-6 & $-3.800 \mathrm{E}-01$ \\
-5 & $-5.000 \mathrm{E}-02$ \\
-4 & $1.500 \mathrm{E}-01$ \\
-3 & $-2.000 \mathrm{E}-02$ \\
-2 & $1.500 \mathrm{E}-01$ \\
-1 & $-2.000 \mathrm{E}-02$ \\
$V_{\max }=0.324$ & \\
\hline
\end{tabular}

Figure 3.6. Comparison of concentration contours from preliminary numerical testing at base-case (curve 1, 2), low diffusivity (curves 3,4 ), and high density (curves 5,6 ) 
In TEMPEST, the yield strength of a material is modeled using a modified Bingham yield model (Trent and Eyler 1993, pg 5.111). The model for the yield stress, $\tau_{y}$, is:

$$
\tau_{\mathrm{y}}=\mathrm{a}^{\mathrm{b}}\left(\left(1-\mathrm{e}^{-\mathrm{c} \gamma}\right) /(\mathrm{c} \gamma+\epsilon)\right.
$$

where $\quad \mathrm{a}=$ the yield stress

$\mathrm{b}=\mathrm{a}$ moisture exponent

$c=a$ strain coefficient

$\epsilon=$ a small constant $\left(\sim 10^{-30}\right)$

$\gamma=$ the strain rate $(1 / \mathrm{sec})$

$=$ the reduced concentration, $\mathrm{C}_{\mathrm{v}} / \mathrm{C}_{\mathrm{v}, \max }$.

This model is used by calculating the strain rate in a computational cell based on local velocities. In the sludge exhibiting strength, these velocities are essentially computed to be zero and are the regular second invariant of strain in the fluid. This model is used by deciding that when the computed local yield as a function of strain and particle concentration exceeds a user specified yield for the sludge under consideration, the material is allowed to convect as a viscous material according to the rheology model in use. It was determined that this approach has a detrimental characteristic that results in two effects. One is that material at a sludge interface is artificially yielded prematurely. This occurs because of approximations included in calculating strain rate at the sludge/liquid interface. The effect of the premature yielding is to predict that mobilization occurs too rapidly ${ }^{(a)}$.

In an effort to circumvent this detrimental characteristic of the yield model as it pertains to rate of material mobilization in a sludge layer, several alternate techniques were tested. In doing so, it was recognized that the prediction of the rate of mobilization of a sludge layer must consider two facets-one being the numerical procedures and the other the physically controlling processes. The numerical procedures were tested first. This was done by determining a set of numerical conditions that could demonstrate that, in fact, an initialized sludge layer could be maintained numerically for an extended period of time without artificial degradation. This was done for two sludge layer configurations, a bank normal to the jet axis and an approximated beach. The results are presented in Figure 3.7. The calculations were conducted for a period of $1 \mathrm{~h}$. There was no noticeable degradation in either sludge layer configuration. These tests confirmed that if the appropriate criteria are invoked within the numerical procedures, a sludge layer could be maintained indefinitely in the extreme condition of never yielding.

Consideration for the physical processes governing the mobilization of kaolin are much more complicated, as evidenced by recent work reported by Powell ${ }^{(b)}$. In the present work, an approximating criterion was tested that decided the release of material in the sludge layer based on the

(a) It should be noted that calculations presented using W-28 sludge rheology by Mahoney, Terrones, and Eyler (1994) for the 100,000 gallon tanks used a power-law model of the W-28 sludge and the yield model being discussed here was not included in those calculations or results.

(b) M. R. Powell et al. September 1994. "Fiscal Year 1994 1/25-Scale Sludge Mobilization Testing." Pacific Northwest Laboratory, Richland, Washington (Draft report). 


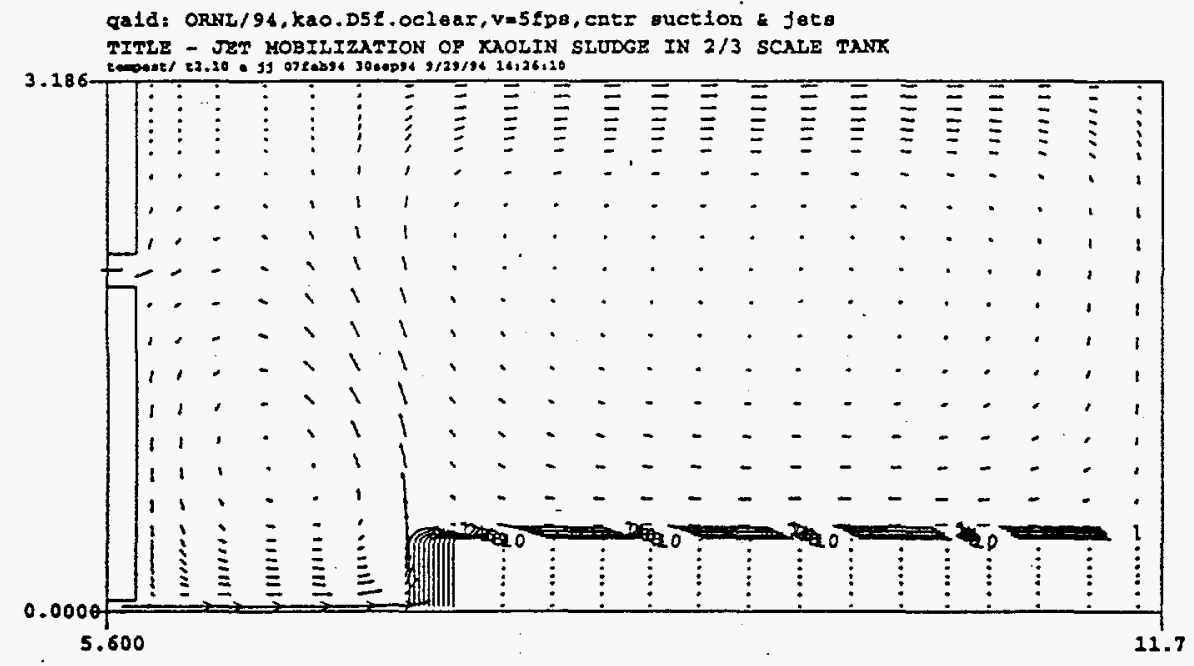

plane mla = 5.132E-11

plane max - 2.650E-01

array mia = 5.1328-11

array $\max =2.650 \mathrm{E}-01$
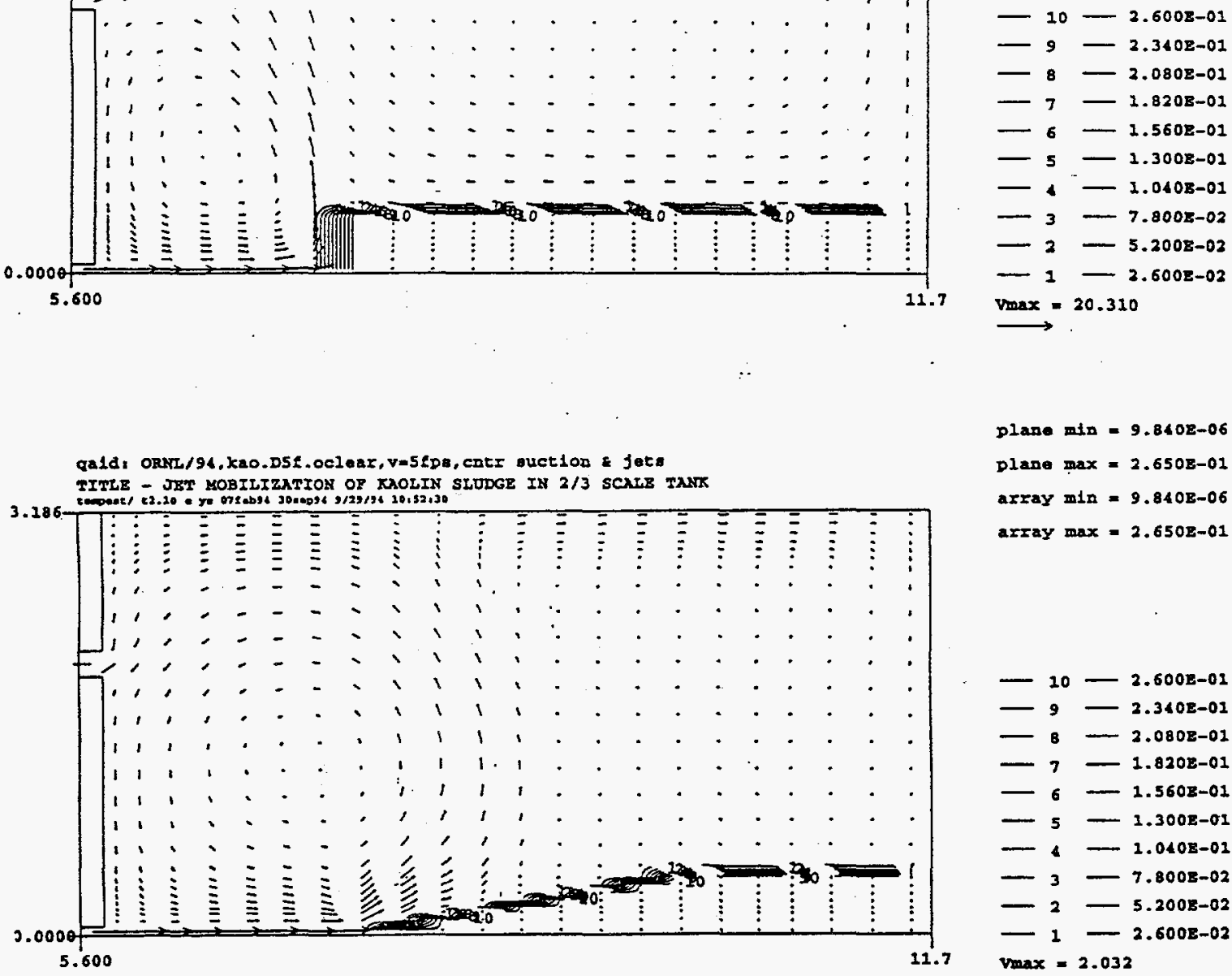

plane min $=9.8408-06$

plane $\max =2.650 \mathrm{z}-01$ array $\min =9.840 \mathrm{E}-06$ array $\max =2.650 \mathrm{E}-01$

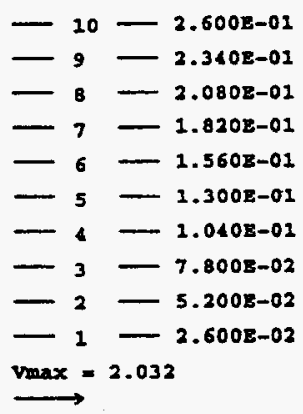

Figure 3.7. Simulated stationary sludge banks 
computed yield strength from Eq: (3.11) relative to the material yield and the local particle concentration. The criterion, in words, is as follows: If the local concentration of particles is greater than a certain fraction of the maximum packing fraction and of the predicted yield is greater than some fraction of the user-supplied material yield strength, then set numerical conditions to maintain the sludge in the computational cell; otherwise, release the strength and compute the fluid dynamics of the material according to prescribed rheology.

This procedure gave the appearance of being effective in several short-time numerical tests. Thus, it was applied to the $95 \mathrm{~m}^{3}$ (25,000-gal) simulation model and calculations were conducted. The results of these calculations are presented in Section 4 of this report. 


\subsection{Sludge Layer Mobilization Results}

Results are presented in this section for the two-jet configuration at two locations in the $95 \mathrm{~m}^{3}$ $(25,000$-gal) horizontal cylindrical tank. The first location is for the jets at the center (lengthwise) of the tank. The suction is also at the center and at approximately the same height above the tank floor as the jets. The second location is for the jets at $1 / 4$ of the tank length and the suction at the opposite end at $1 / 8$ of the tank length. The height of the suction line intake above the floor in this latter case was approximately $52 \mathrm{~cm}$ ( $20 \mathrm{in}$.). Several flow rates for each of the two locations are conducted. For the center jet location, flow rates of 50,100, and $200 \mathrm{gpm}$ were conducted to a time of $2 \mathrm{~h}$. One additional case was simulated at about $200 \mathrm{gpm}$ using a modified yield criterion for the sludge layer. For the quarter-length location, flow rates of about 100 and $200 \mathrm{gpm}$ were simulated, and one additional simulation was done at about $200 \mathrm{gpm}$ for the modified yield criterion for the sludge layer.

In the computer model, the jet diameter of $3.5 \mathrm{~cm}$ (1.38 in.) was modeled. Boundary conditions were specified as a velocity at the jet nozzle. Table 4.1 presents the specified jet velocity condition and corresponding equivalences. Note that throughout this section, the flow rates are referred to as 50,100 , and $200 \mathrm{gpm}$ whereas the actual modeled flow rates are 46.6, 93.2, and $186.3 \mathrm{gpm}$. Flow rates are the total for both jets.

Table 4.1. Specified Jet Velocity and Equivalent Values

\begin{tabular}{|c|c|c|c|}
\hline $\begin{array}{l}\text { Specified } \\
\text { Jet Veloc. } \\
\text { (f/sec) }\end{array}$ & $\begin{array}{l}\text { Equivalent } \\
\text { Jet Veloc. } \\
(\mathrm{m} / \mathrm{sec})\end{array}$ & $\begin{array}{l}\text { Modeled } \\
\text { Flow Rate } \\
\text { (gpm) }\end{array}$ & $\begin{array}{l}\text { Referenced } \\
\text { Flow Rate } \\
\text { (gpm) }\end{array}$ \\
\hline 5 & 1.52 & 46.6 & 50 \\
\hline 10 & 3.05 & 93.2 & 100 \\
\hline 20 & 6.10 & 186.3 & 200 \\
\hline
\end{tabular}

For calculations presented in this section, the basic model developed and discussed in Section 3 was used. However, following the discussion in Section 3.4, modifications were made to the criterion used to maintain and release the material strength. Further, the effects of overburden and diffusion were eliminated by assuming that the initial layer was uniform in concentration and that there was effectively no molecular, laminar, nor turbulent diffusion occurring in the system (except, of course, numerical diffusion which to a certain unquantifiable degree, is present in any computational fluid dynamics system).

Results of the mobilization and mixing are examined in several forms. Flow field and sludge layer particle volume fraction contours are presented to examine the interaction of the fluid dynamics and the sludge layer in Section 4.1. The character of the mobilization process is examined by a mass balance of the amount of material retained in the sludge layer as a function of time. This is done by plotting the fraction of the initial sludge layer volume remaining at a given time in Section 4.2. After material is removed from the strength-exhibiting sludge layer, mixing in the supernatant is examined by plotting the time-dependent position of the interface of the mixed solid particles. This is done in 
Section 4.3. Section 4.4 presents a discussion of the computer resource requirements for these calculations. Finally, in Section 4.5, a discussion of mobilization resistance and computer modeling criteria is presented and recommendations are made for improvements to the procedure of modeling mobilization predictions.

The results presented for the center location of the jets indicate that at $200 \mathrm{gpm}$, the sludge layer is completely mobilized in just over $1 \mathrm{~h}$. For $100 \mathrm{gpm}$ flow, about $5 \%$ of the sludge layer remains after $2 \mathrm{~h}$. For $50 \mathrm{gpm}$ flow, nearly $40 \%$ of the initial sludge layer remains after $2 \mathrm{~h}$. For the jets at the quarter-length location, at $200 \mathrm{gpm}$, about $10 \%$ of the initial sludge layer remains after $1 \mathrm{~h}$. For $100 \mathrm{gpm}$, about $40 \%$ of the sludge layer remains after $1 \mathrm{~h}$. The modified strength criterion only minimally affected these results.

\subsection{Flow Field and Sludge Layer Characteristics}

Figure 4.1 presents the flow field for the three flowrate cases simulated with the jets located at the center. The rectangular areas in this and subsequent figures represent numerical approximation of penetrations assumed present in the tank. Vectors represent the flow field and contours of solids volume fraction represent the sludge layer. In Figure 4.1, the flow field and contours on the left are at a time of $1 \mathrm{~h}$ and those on the right are at a time of $2 \mathrm{~h}$ of simulation. A central symmetry plane was used in these calculations. For graphical presentation, one end of the tank has been mirrored to give a side-by-side perspective of the results at two different times.

Figure 4.2 presents the time-dependent progression of the mobilization of the sludge layer for the three flow cases for the center jet location. The contour lines of solids volume fraction are plotted at 10-min intervals to a time of $2 \mathrm{~h}$. Of particular note in these figures is the difference in the character of the $200 \mathrm{gpm}$ case relative to the other two cases. At the higher flow rate, the sludge layer appears to be degraded as if it is being pushed back. At the lowest flow rate, the appearance of the sludge layer degradation appears to be more dominated by degradation along the top surface. The contours indicate more of a beach shape to the sludge layer as it is degraded. Figure 4.3 presents a comparison of the sludge layer profile at $1 \mathrm{~h}$ and $2 \mathrm{~h}$ of simulation for the three different flow rates. Again there is more evidence of a beach-shape layer present for the lower flow rates.

Figure 4.4 presents the flow field for the three flowrate cases simulated with the jets located at the quarter position. Vectors represent the flow field and contours of solids volume fraction represent the sludge layer. The contours shown indicate the upward progression of the mixing layer with time. This case is different from the center jet location results in that the jet flow must traverse the length of the tank to reach the suction intake at the far end of the tank. The degradation of the sludge layer as indicated by the contour lines shows material is being removed by shearing action of the fluid flowing along the length of the tank just above the sludge/liquid interface.

Figure 4.5 presents the time-dependent progression of the mobilization of the initial sludge layer for two flow cases of 100 and $200 \mathrm{gpm}$. The contours are plotted at 10-min intervals during the transient. The results indicate that by $1 \mathrm{~h}$, sludge layer in the short end of the tank has been mobilized whereas the material in the long end of the tank is degrading by a top surface material 
unds $00 Z$ pue '00I 'OS Jo sajeI MoLf

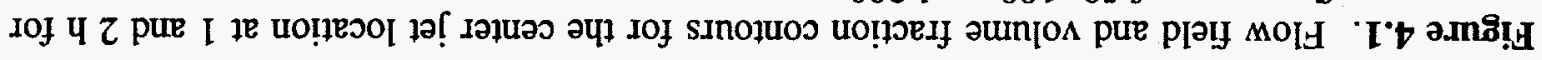

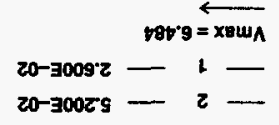

$20-95262=$ Xew Keur

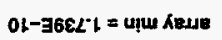

$20-3 \angle \angle L L L=x$ Eew euejd

$60-3006 ' s=$ u!u ourjd

$\angle 202 z=y$

$\forall 01 \varepsilon z=r$

$z=\mid$ we eusid z-1

gro' $\varepsilon=$ xBwA

$20-300927+$

$20-300 z s-2-$

$20-30082$ -

$10-3050.1-b$

$10-30081-s-$

$10-3099^{\prime 1}-9-$

10-3028' $1-2$

$10-30802 \mathrm{Z}-8-$

10-30tez - 6

$10-30092-01$

\begin{tabular}{|c|c|c|c|}
\hline & tes & & xewn \\
\hline $20-\exists 009^{\circ} 2$ & - & । & $\longrightarrow$ \\
\hline $20-300 z 5$ & - & 2 & 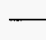 \\
\hline $20-30082$ & - & $\varepsilon$ & $\longrightarrow$ \\
\hline $10-30+0.1$ & - & $\downarrow$ & 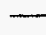 \\
\hline $10-\exists 0081$ & - & 9 & \\
\hline $10-30951$ & - & 9 & 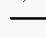 \\
\hline $10-3028 \%$ & - & $L$ & 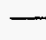 \\
\hline $10-3080 \div 2$ & - & 8 & 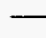 \\
\hline 10-30teiz & - & 6 & $\longrightarrow$ \\
\hline $10-3009^{\prime} 2$ & - & or & $\longrightarrow$ \\
\hline
\end{tabular}

$10-30599^{\circ} Z=$ XEW KEUE $60-\exists L \angle 8^{\circ} \mathrm{L}=$ บ!

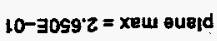

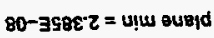

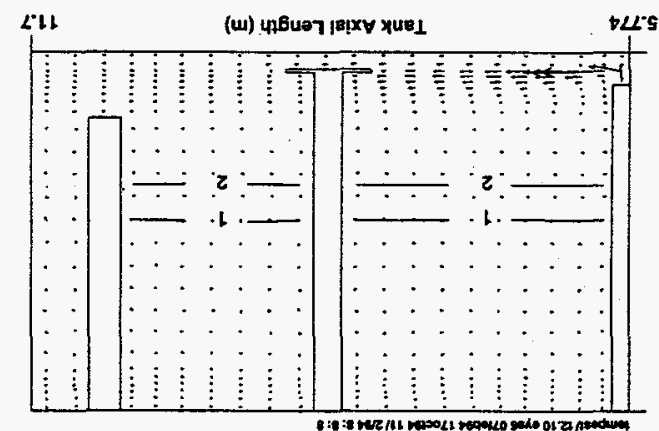

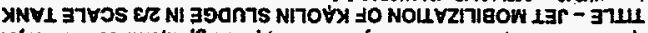

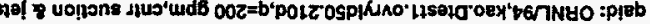

sinou 0002

$=$ aแn we jold

sunoH Z 'WdS 00Z

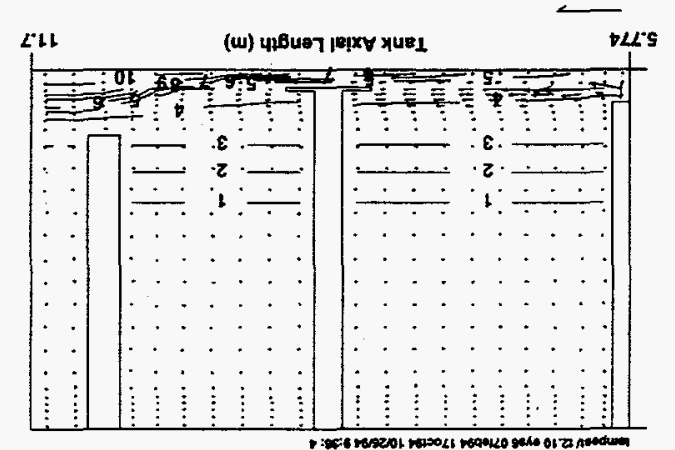

YNY 1 3า

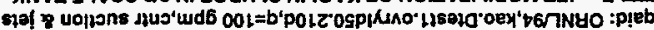

sinou

$000^{2} 2$

= awn be jold

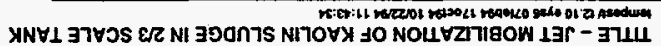

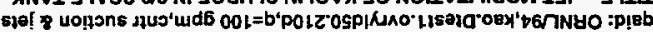

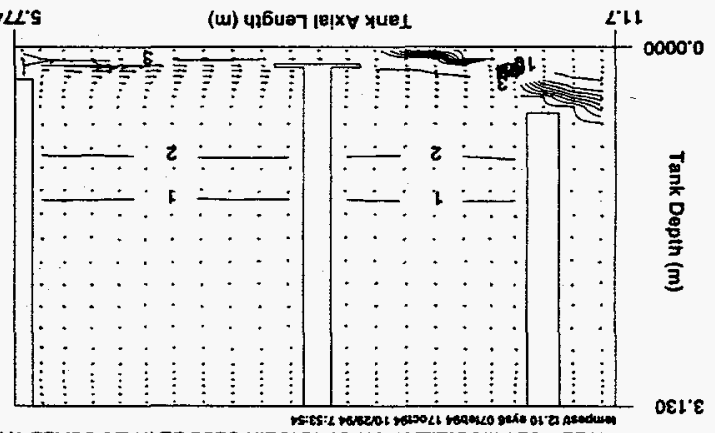

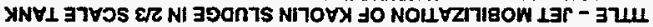

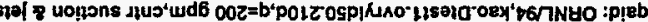

seinu!̣u 00009 = aun te told

InoH \& 'WdD ooz

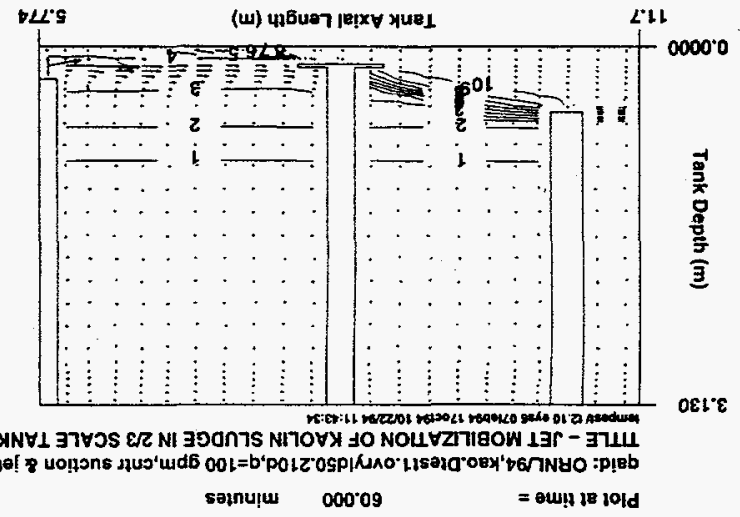

sınoH Z 'WdO 001

JnoH I 'WdD 00 ᄂ

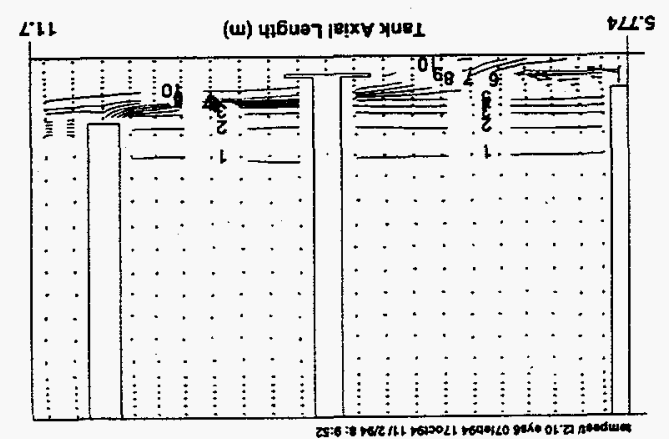

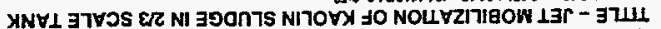

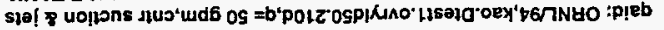

$$
\text { sinou, } 000 \text { ' } \quad \text { = su!! ze told }
$$

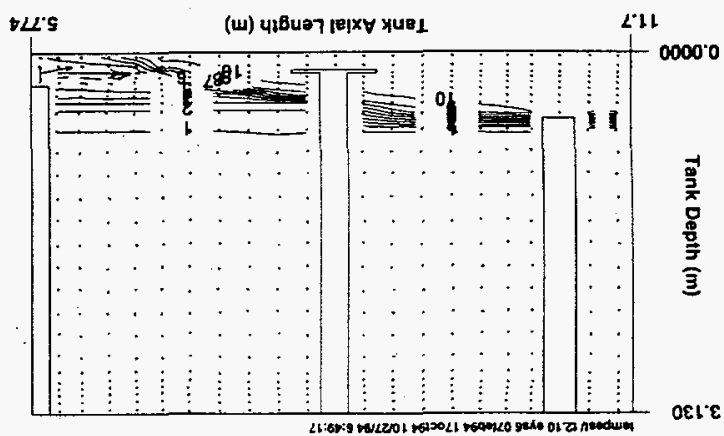

XNY 1 37ชOS \&/Z NI 300กาS NIาO

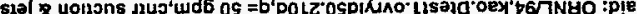

səmu!̣u $\quad 000.09$

= aw! I je jold
snoH \& 'WdS OS 


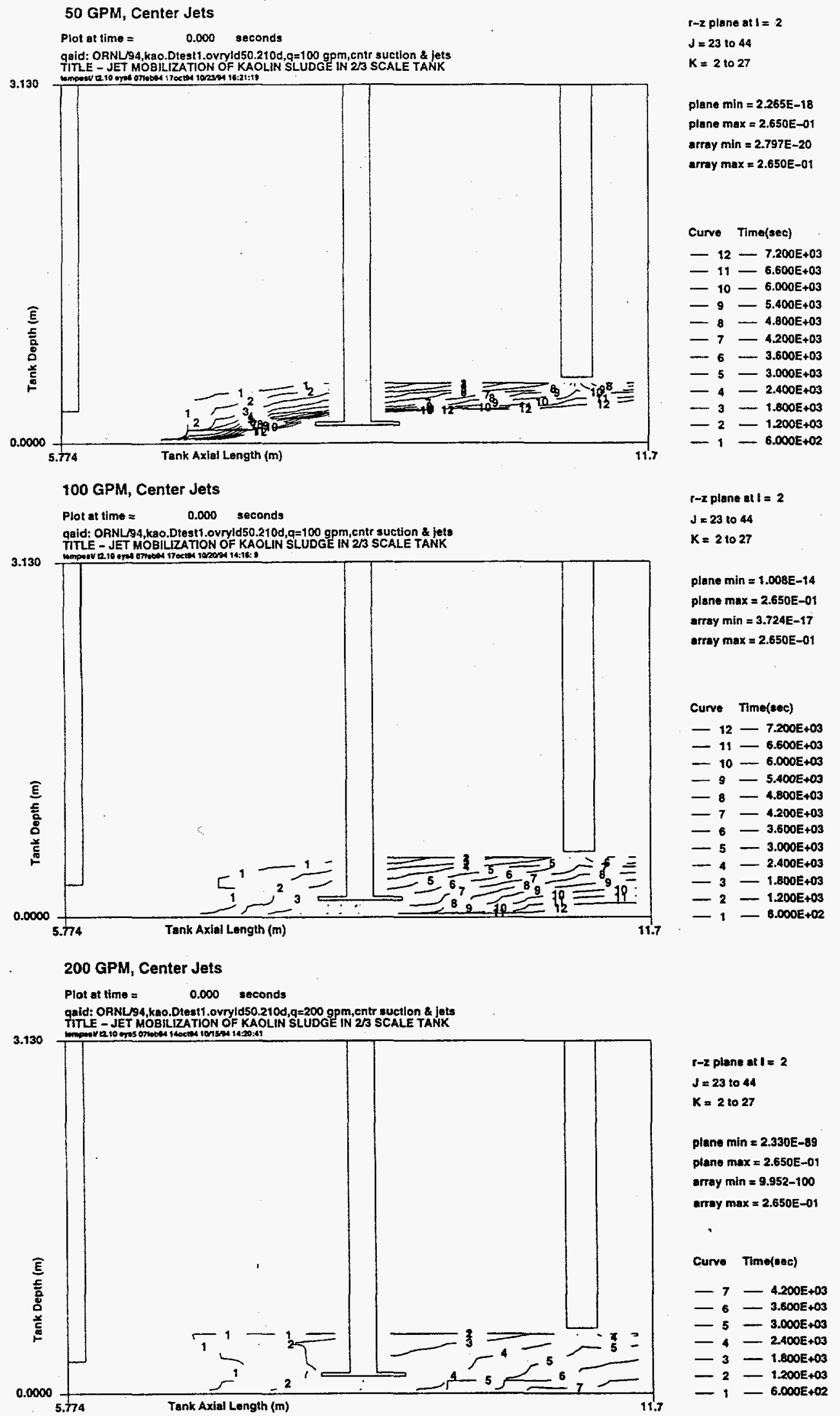

Figure 4.2. Volume fraction contours at 10-min intervals for 50, 100, and $200 \mathrm{gpm}$ showing mobilization of sludge layer for the center jet location 


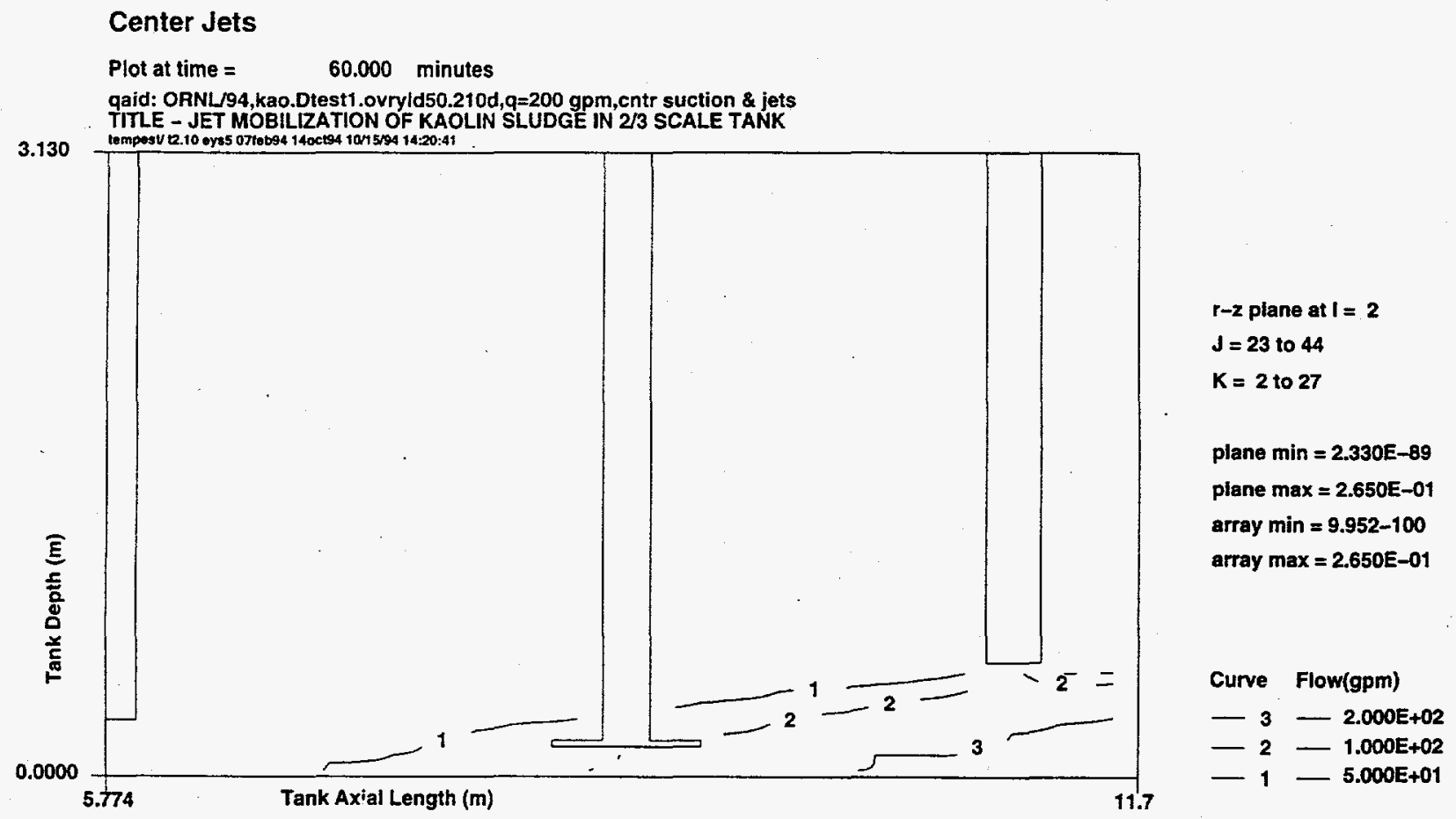

Center Jets

Plot at time $=\quad 2.000$ hours

qaid: ORNL 94 ,kao.Dtest1.ovryld50.210d, q=200 gpm,cntr suction \& jets TITLE - JET MOBILIZATION OF KAOLIN SLUDGE IN $2 / 3$ SCALE TANK

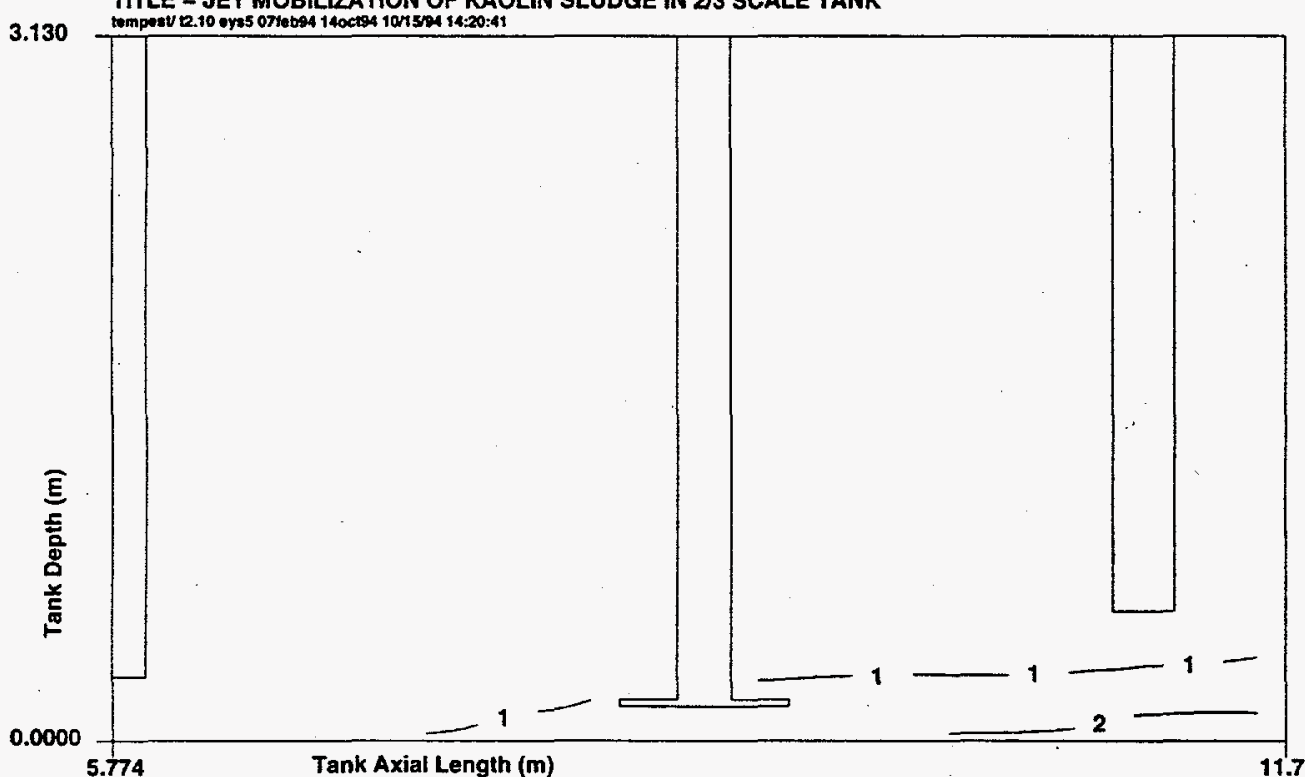

$\mathrm{r}-\mathrm{z}$ plane at $\mathrm{I}=\mathbf{2}$

$J=23$ to 44

$K=2$ to 27

plane $\min =2.330 E-89$

plane $\max =2.650 \mathrm{E}-01$

array $\min =9.952-100$

array $\max =2.650 \mathrm{E}-01$

Curve Flow(gpm).

$-2-1.000 E+02$

$-1-5.000 E+01$

Figure 4.3. Comparison of the sludge layer interface contour at 1 and $2 \mathrm{~h}$ for flow rates of 50,100 , and $200 \mathrm{gpm}$ for the center jet location 


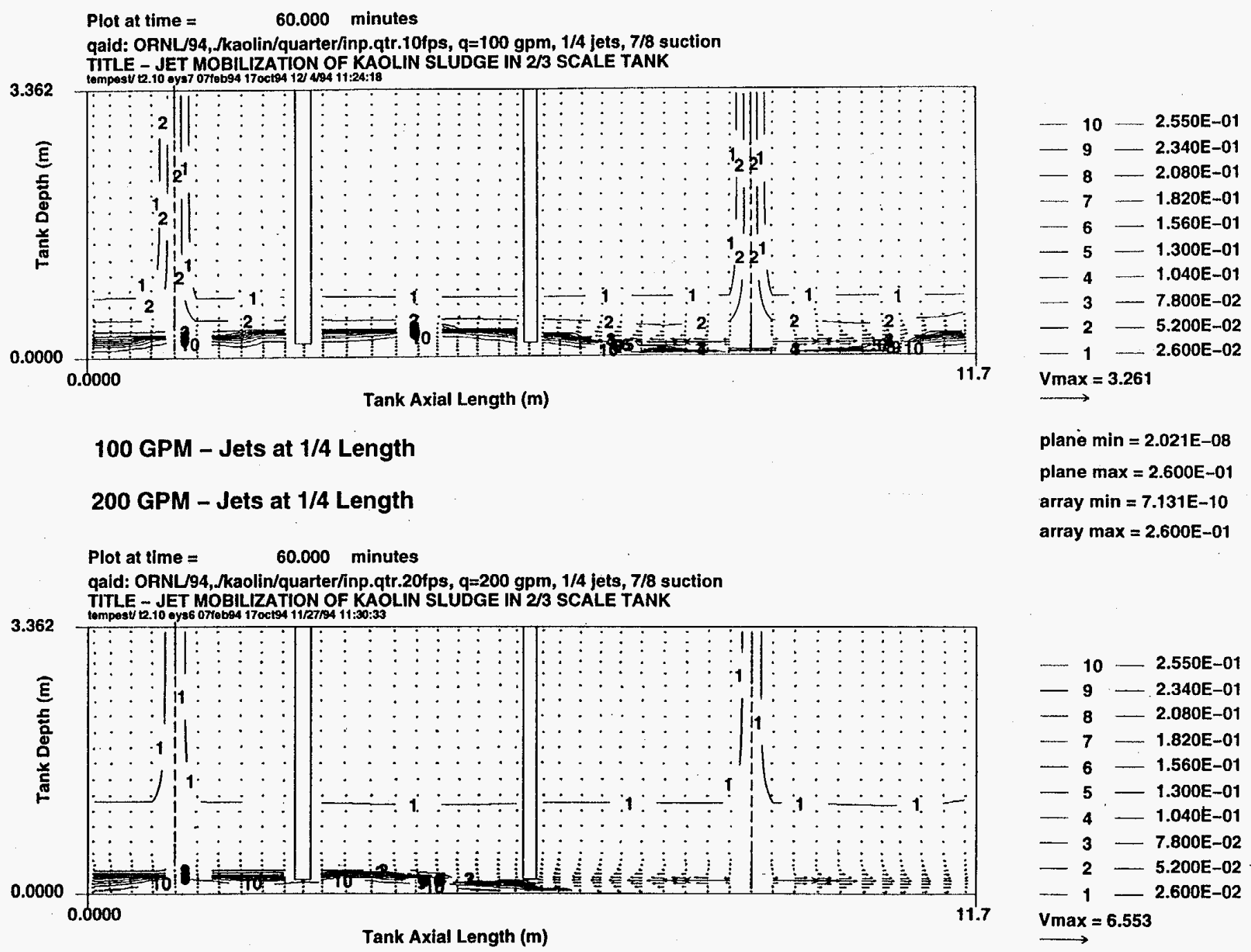

Figure 4.4. Flow field and volume fraction contours for the quarter jet location at $1 \mathrm{~h}$ for flow rates of 100 and $200 \mathrm{gpm}$ 
100 GPM - Jets at 3/4 Length

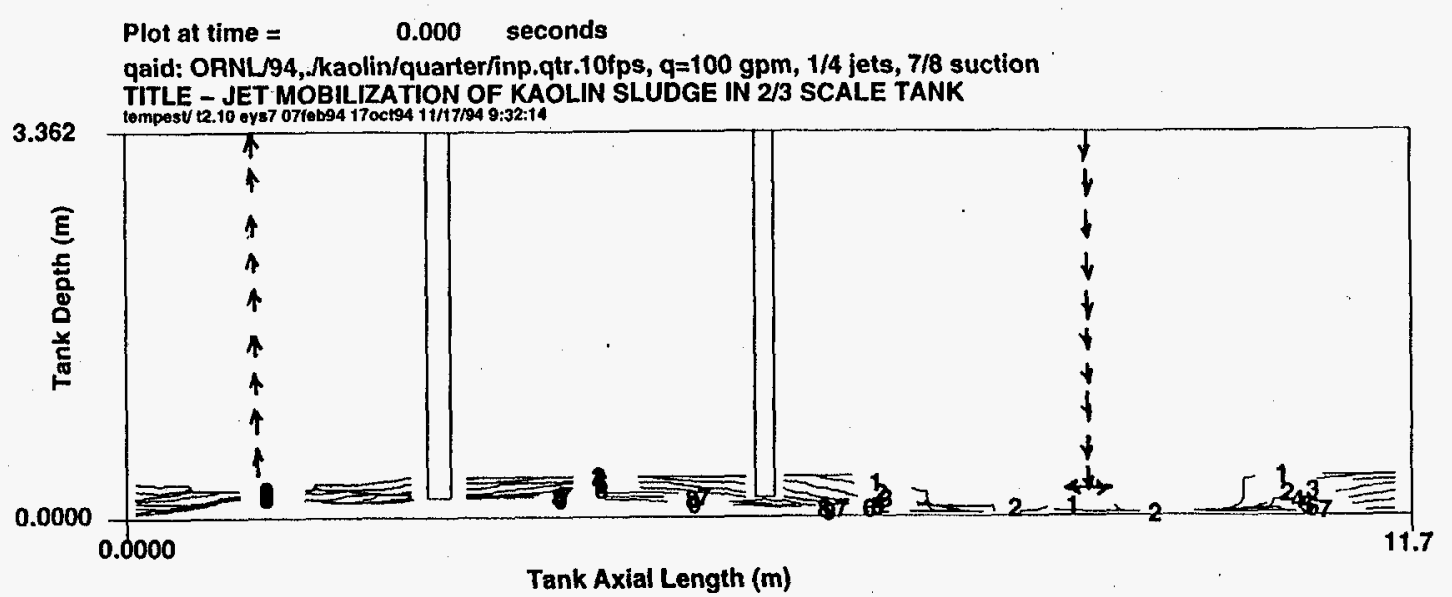

Curve Time(sec)

$-9-5.400 E+03$

- $8-4.800 \mathrm{E}+03$

$-7-4.200 E+03$

$-6-3.600 E+03$

$-5-3.000 E+03$

$-4-2.400 E+03$

$-3-1.800 \mathrm{E}+03$

$-2-1.200 E+03$

$-1-6.000 E+02$

200 GPM - Jets at 3/4 Length

plane $\min =1.136 \mathrm{E}-09$

plane $\max =2.600 E-01$

array $\min =1.355 E-12$

qaid: ORNL/94,/kaolin/quarter/inp.qtr.20fps, $q=200 \mathrm{gpm}, 1 / 4$ jets, $7 / 8$ suction

TITLE - JET MOBILIZATION OF KAOLIN SLUDGE IN 2/3 SCALE TANK

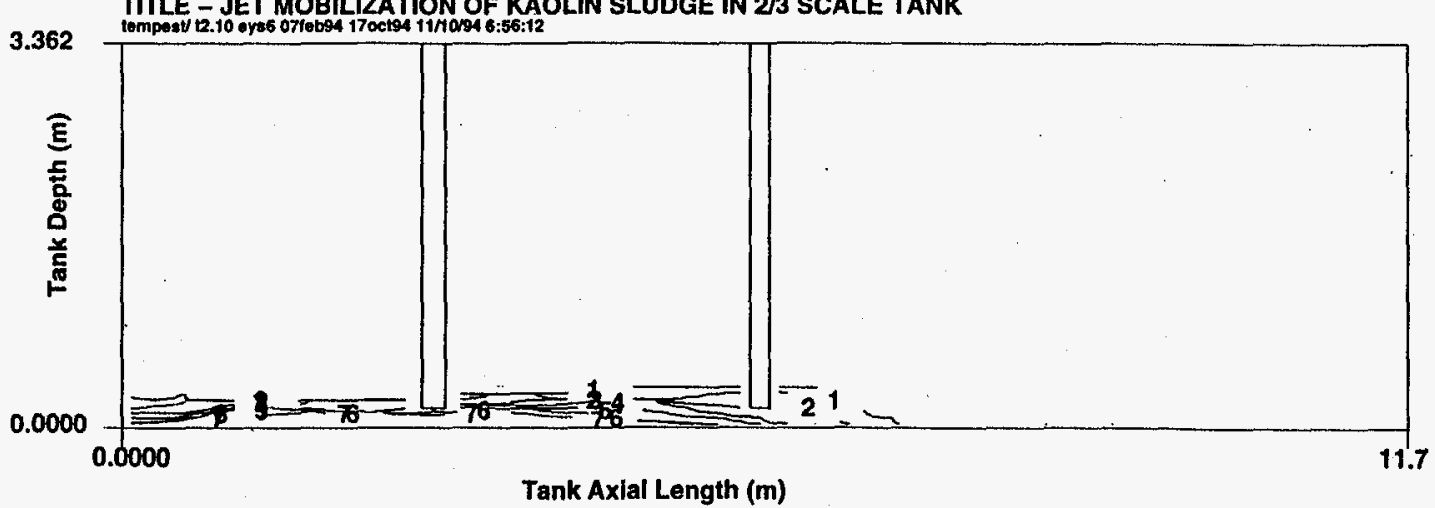

array $\max =2.600 E-01$

Curve Time(sec)

$$
\begin{array}{r}
7-4.200 \mathrm{E}+03 \\
-6-3.600 \mathrm{E}+03 \\
-5-3.000 \mathrm{E}+03 \\
-5-2.400 \mathrm{E}+03 \\
-3-1.800 \mathrm{E}+03 \\
-3-1.200 \mathrm{E}+03 \\
-21-6.000 \mathrm{E}+02
\end{array}
$$

Tank Axial Length (m)

Figure 4.5. Volume fraction contours at 10-min intervals for 100 and $200 \mathrm{gpm}$ showing mobilization of sludge layer for the quarter jet location 
removal process. Figure 4.6 presents a comparison of the sludge layer profile at $1 \mathrm{~h}$ of simulation for the two different flow rates. This is further evidence that the prediction is indicating top surface material removal.

The flow vector field and sludge layer particle volume fraction contours are useful in understanding the interaction of fluid dynamic effects and the mobilization and mixing processes and in understanding the nature of predicted time-dependant material retention and mixing time predictions. The latter results are presented in the next sections.

\subsection{Sludge Layer Material Retention Results}

In the computer simulations, a layer of kaolin is specified as an initial condition. This is done by specifying a volume fraction of solid particles over a range of computational cells. Evaluation of the mobilization of this initial layer in response to imposing the recirculating liquid jet can be done several ways. Figures 4.7 and 4.8 present the results as a time-dependent curve of the fraction of the tank volume that contains a solids fraction greater than a given percentage of the maximum packed concentration, $\mathrm{C}_{\mathrm{v}, \max }$. Figure 4.7 presents results for the center location jets and Figure 4.8 presents results for the jets located at $(3 / 4) \mathrm{L}$ with the recirculation at the opposite end at $(1 / 8) \mathrm{L}$. In these two figures, the solid symbols represent the fraction of the tank volume that is classified as being the sludge by containing a solids volume fraction greater than $98 \%$ of the maximum packing fraction. The open symbols represent the fraction of the tank volume containing more than $10 \%$ of the maximum packing fraction. Four cases are presented for the center jet location and three cases are presented for the quarter jet location. Note that the curves are classified by jet velocity according to equivalences given in Table 4.1. The two curves identified as "20fps(6)" and "20fps(7)" in Figures 4.7 and 4.8 respectively are repeat calculations using slightly modified criteria representing the material yield. These latter two cases were repeat calculations run to investigate the sensitivity of the criteria used for sludge strength within the numerical procedures.

Defining the sludge layer as being bounded by material with a volume fraction greater than $98 \%$ of the maximum packing factor is somewhat arbitrary. However, using this as a bounding criterion indicates that in a little over an hour, the $6.10 \mathrm{~m} / \mathrm{s}(20 \mathrm{ft} / \mathrm{s})$ jets have completely mobilized the sludge layer in the predictions for the center jet location. The $1.52 \mathrm{~m} / \mathrm{s}(5 \mathrm{ft} / \mathrm{s})$ and the $3.05 \mathrm{~m} / \mathrm{s}(10 \mathrm{ft} / \mathrm{s})$ jet flow rates have not completely mobilized the layer by a time of $2 \mathrm{~h}$. By comparison, the quarter jet location seems to indicate that less of the total sludge layer had been mobilized by a time of $1 \mathrm{~h}$. This can be observed better in Figures 4.9 and 4.10 where the material in the sludge layer has been normalized by the initial amount. For the center location jets, the sludge layer is gone by $1.2 \mathrm{~h}$ at $6.10 \mathrm{~m} / \mathrm{s}(20 \mathrm{ft} / \mathrm{s})$. About $5 \%$ remains at $2 \mathrm{~h}$ for $3.05 \mathrm{~m} / \mathrm{s}(10 \mathrm{ft} / \mathrm{s})$, and about $40 \%$ remains at $2 \mathrm{~h}$ for $1.52 \mathrm{~m} / \mathrm{s}(5 \mathrm{ft} / \mathrm{s})$ jet flow.

It is interesting to note the comparison in the $6.10 \mathrm{~m} / \mathrm{s}(20 \mathrm{ft} / \mathrm{s})$ cases for the center jet and quarter jet locations. Early in the calculation, the quarter jet location tends to mobilize more material sooner than does the center location. However, at about $1 \mathrm{~h}$, the rate of material mobilization for the quarter jet location tends to decrease. By $1.2 \mathrm{~h}$, the center jet location indicates complete mobilization whereas nearly $10 \%$ of the sludge layer remains for the quarter jet location. The $3.05 \mathrm{~m} / \mathrm{s}$ $(10 \mathrm{ft} / \mathrm{s})$ case also shows a larger rate of mobilization for the quarter jet location early in time. The quarter jet case simulation was not computed far enough in time to determine if it, too, decreased in its rate of mobilization. 
Jets at $3 / 4$ Length

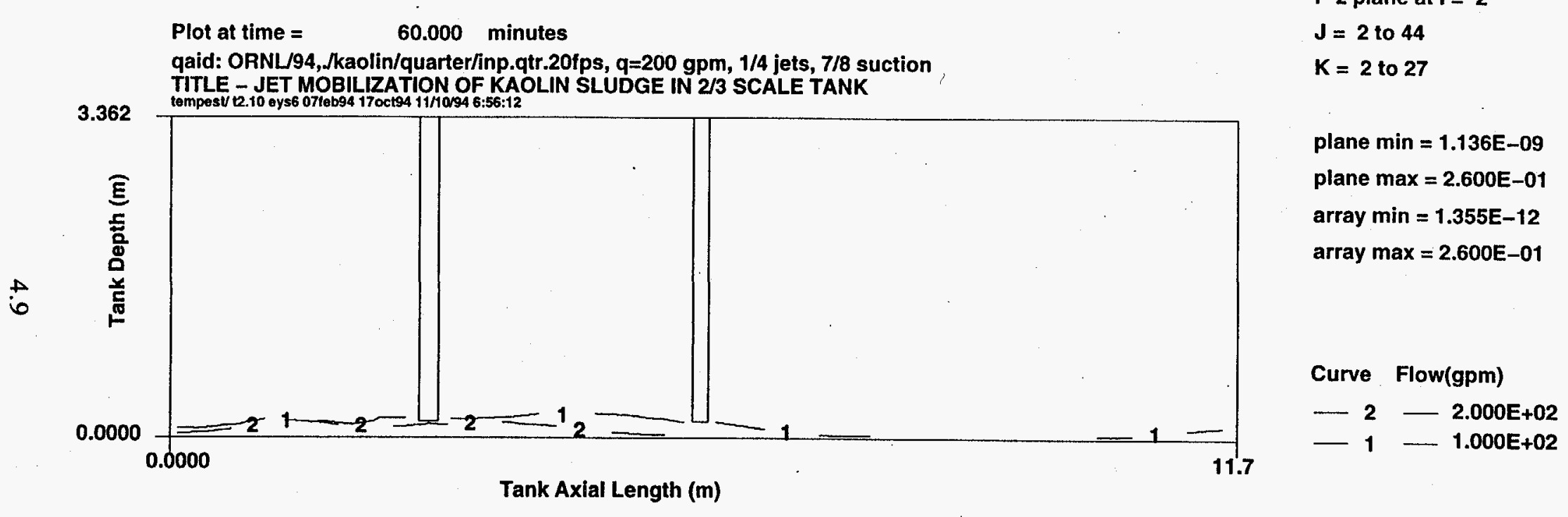

Figure 4.6. Comparison of the sludge layer interface contour at $1 \mathrm{~h}$ for flow rates of 100 and $200 \mathrm{gpm}$ for the quarter jet location 


$$
0 I^{\circ} \mathrm{t}
$$

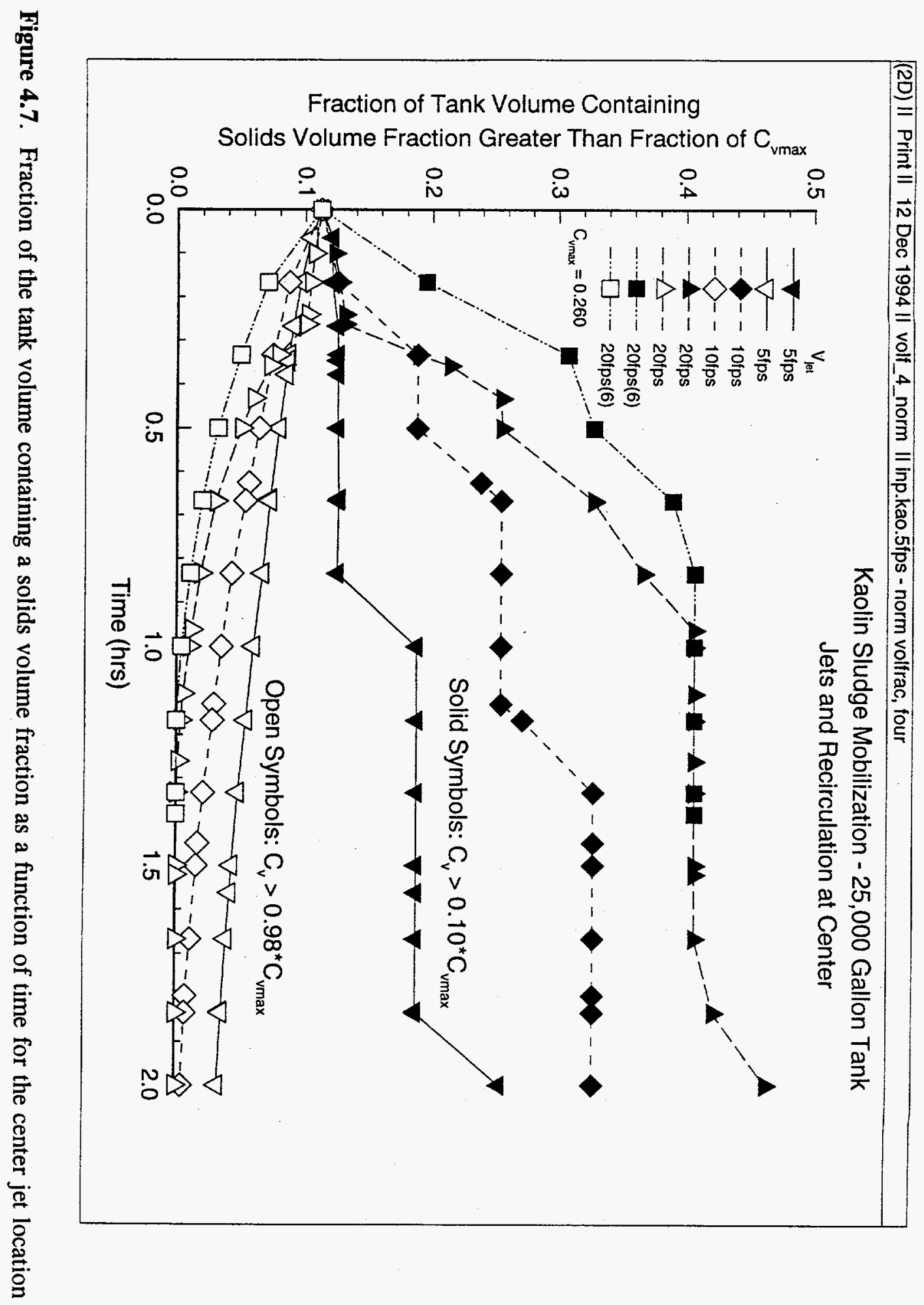




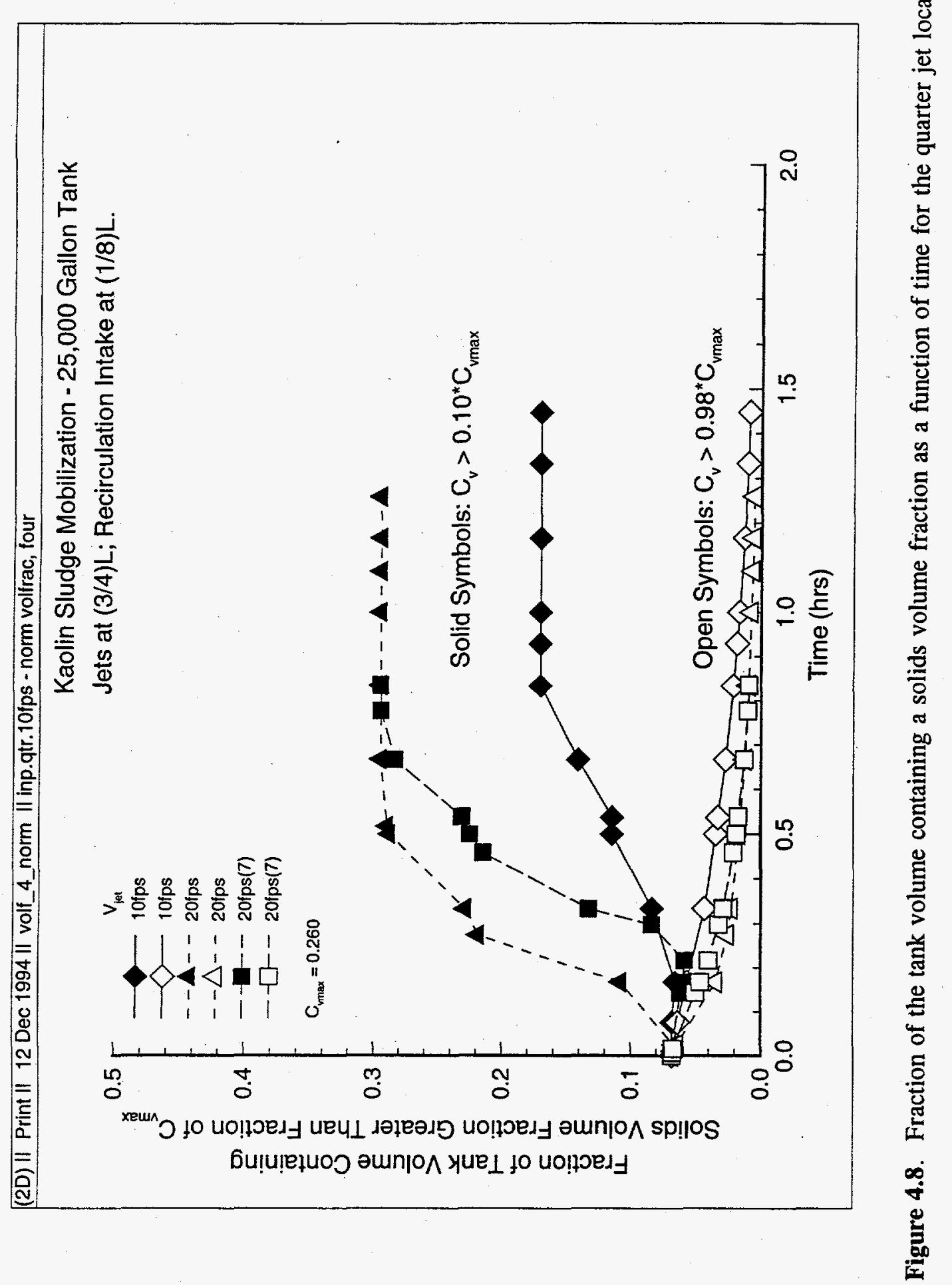




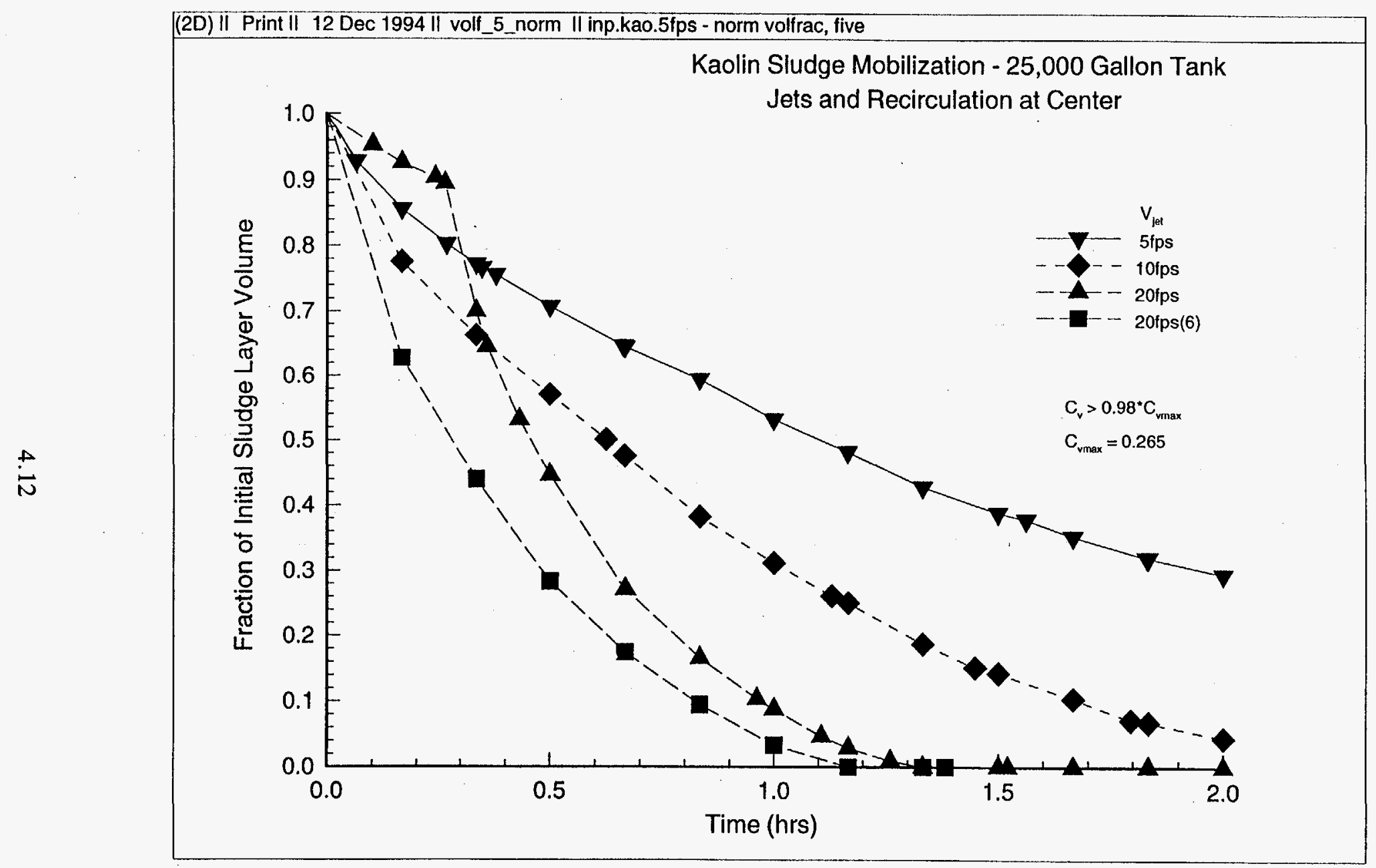

Figure 4.9. Normalized fraction of the initial sludge layer volume as a function of time for the center jet location 
$\varepsilon I^{\circ} \downarrow$

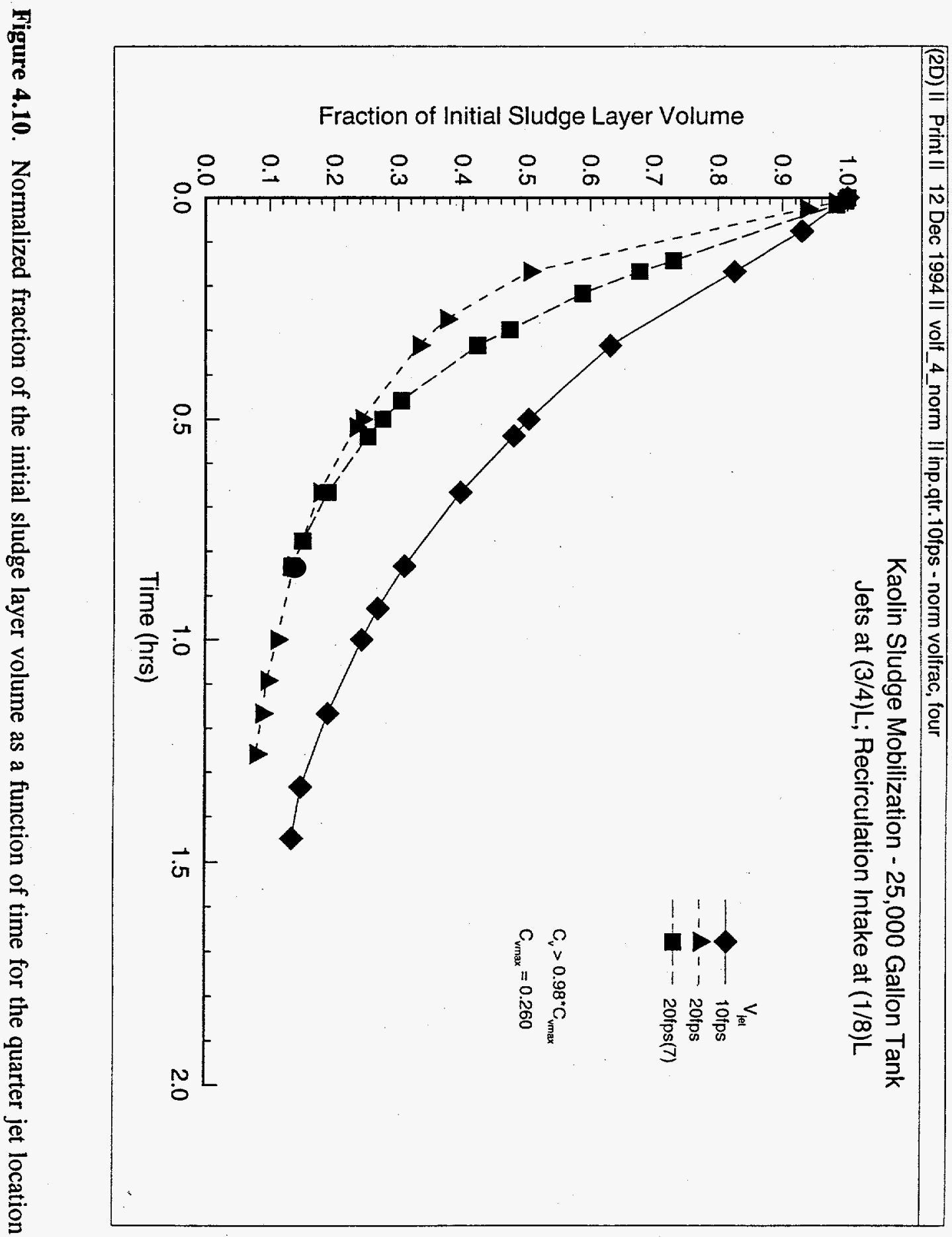




\subsection{Recirculation Line Concentration and Estimates of Mixing Time Results}

The volume fraction of solids in the recirculation line as a function of time is presented in Figures 4.11 and 4.12 for the center jet location and the quarter jet location, respectively. For the center jet location, the recirculation line suction is located directly adjacent to the jet at a height of two jet diameters above the jet axis. For the quarter jet location, the jets are at a distance of $3 / 4$ of the tank length from one end of the tank and the recirculation suction is located at a distance of $1 / 8$ of the tank length. The suction is about $51 \mathrm{~cm}$ (20 in.) above the tank floor in the latter case.

For the center jet location simulation, the problem was initialized with an initial sludge depth such that if all the kaolin were fully mixed in the tank volume, the fully mixed volume fraction would be 0.0298 as noted in Figure 4.11. For the quarter jet location simulation, the computational system was re-noded and when the initial solids layer was specified, lesser total material ${ }^{(a)}$ was imposed such that the final fully mixed volume fraction would be 0.0177 as noted in Figure 4.12.

The concentration in the recirculation line for the center jet location is plotted in Figure 4.11 for the four cases simulated (three flow rates and one repeat calculation with a modified criterion for material yield identified as "20fps(6)." Because of a difficulty in the numerical procedure used in modeling a material with yield strength, it was necessary to initialize the immediate region around the jet and suction location with no solids. Thus the concentration curves indicate zero concentration to start. It is apparent in both Figures 4.11 and 4.12 that for the time these simulations were computed, the concentration in the recirculation line is high relative to the final, fully mixed values. Because of this, it is not possible to determine mixing times directly from these results using a criterion approach such as developed and discussed by Terrones and Eyler (1993).

An alternate approach was used in the present work that is similar to that developed and discussed by Mahoney et al. (1994). In this approach, use is made of the fact that the interface of the low concentration mixed material is very flat (see Figure 4.1 for example) as it diffuses upward. With this observation, the time dependent position of the concentration contour corresponding to the final, fully-mixed value can be tracked and curve fitted. An estimate of the mixing time can then be made. As a basis for this method, the distribution of solids concentration in a vertical line is plotted as a function of time. This distribution for the center jet location is presented in Figures 4.13 to 4.15 for flow rates of 200,100 , and $50 \mathrm{gpm}$, respectively. The distributions are at a distance of $2 \mathrm{~m}$ from the jet nozzle and are presented at 10-min intervals up to $2 \mathrm{~h}$. The fully mixed concentration (0.0298) is indicated by the dotted line. The height of the fully mixed concentration position as a function of time is presented in Figure 4.16. Before discussing this latter result, it is useful to note some features in the results in Figures 4.13 to 4.15 because they exhibit three very distinctively different effects.

(a) This occurred because of an input initialization problem which was not realized until after several lengthy calculations had been completed. The result was that the modeled initial sludge layer depth was several centimeters less than in the center-located jet simulations. 


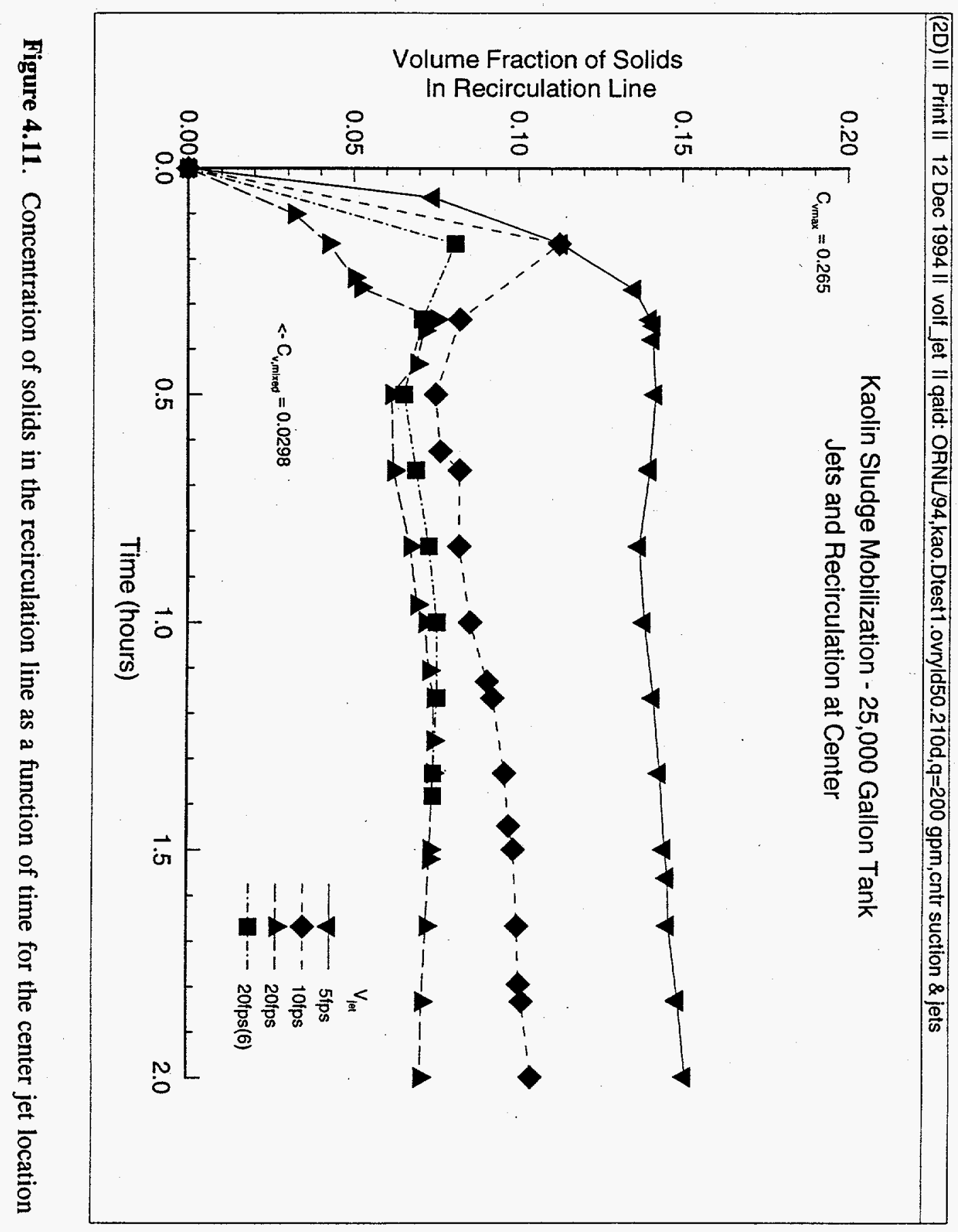


$9 I^{\circ} \mathrm{t}$

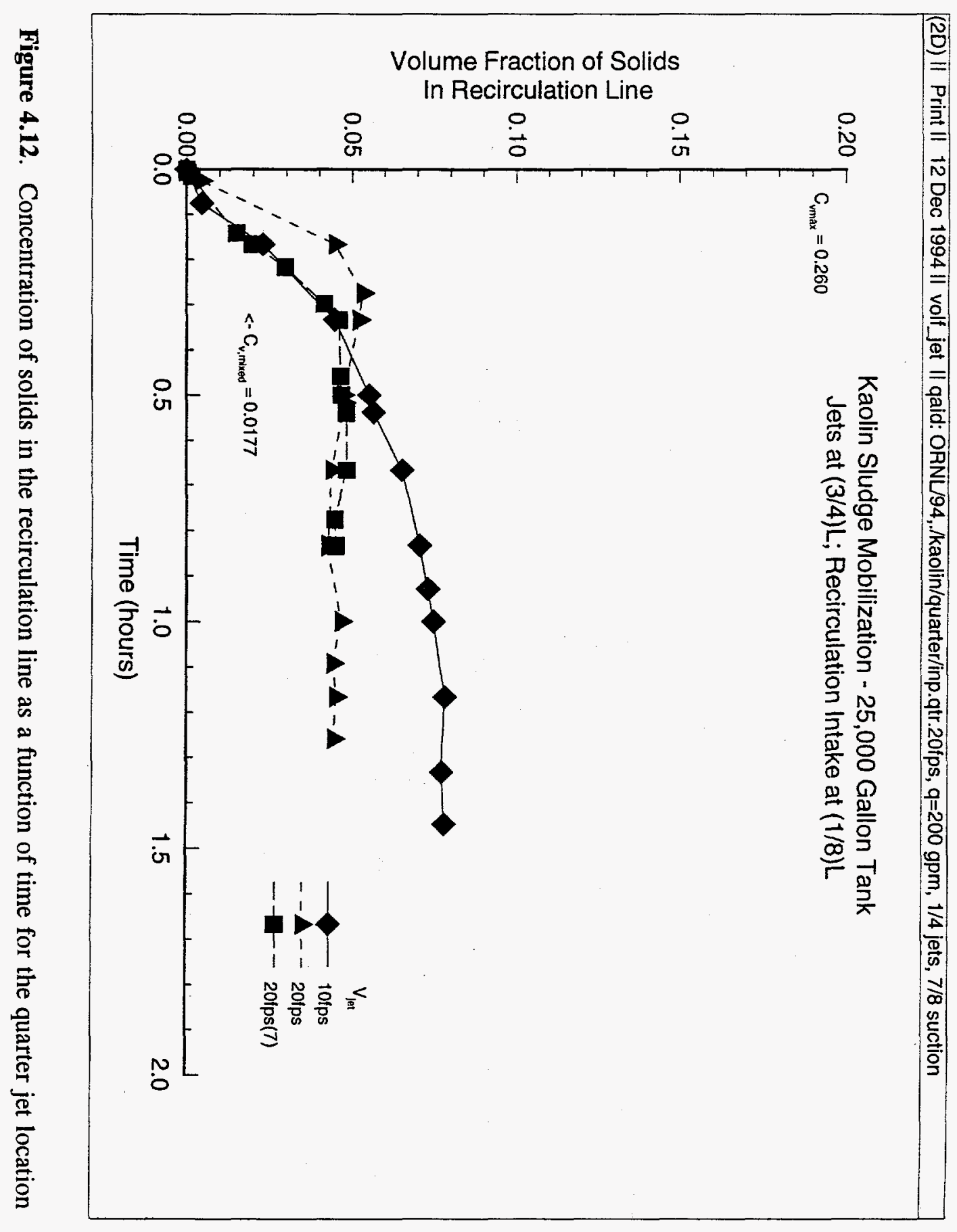




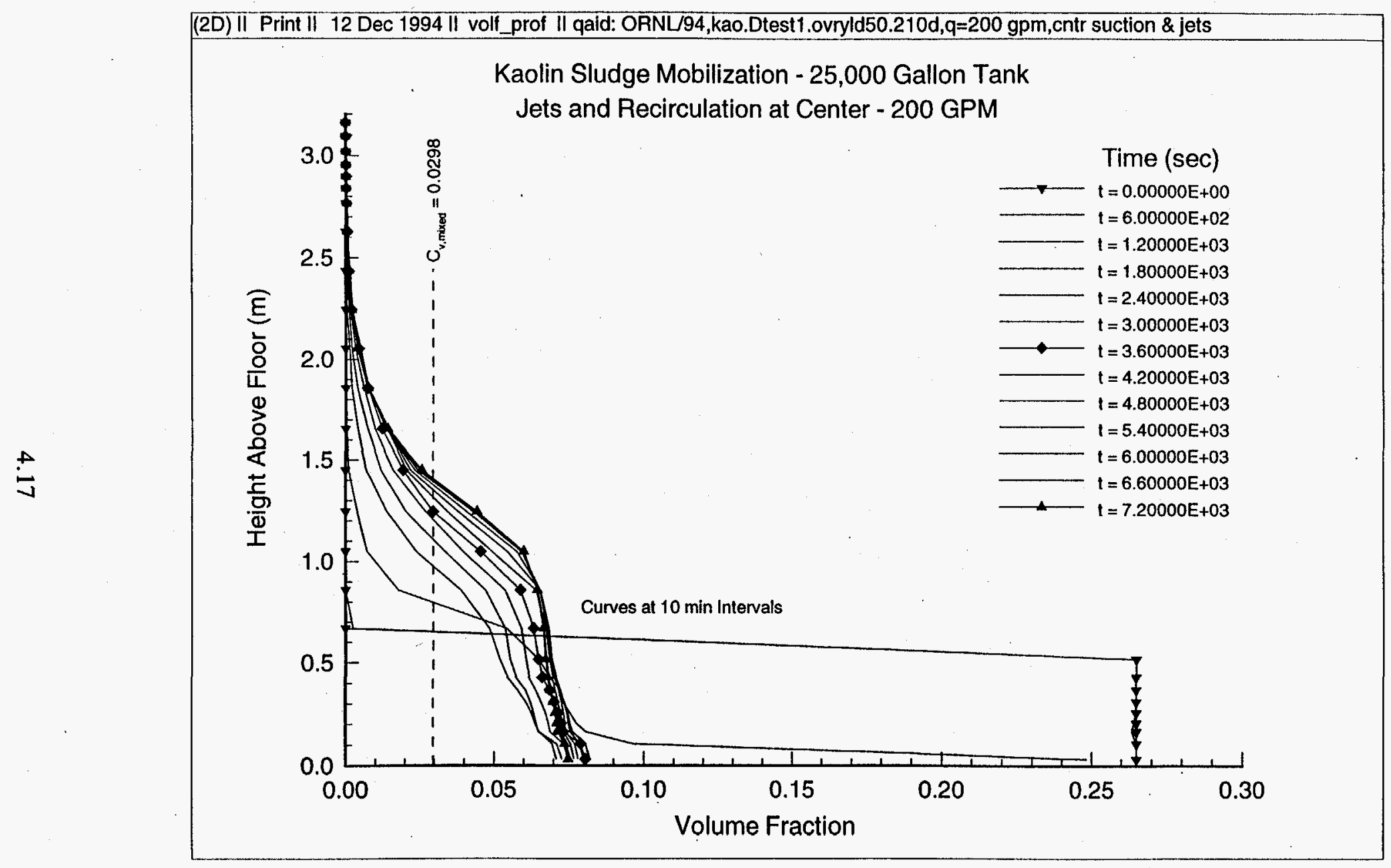

Figure 4.13. Solids fraction volume concentration distribution at 10 -min intervals for the center jet location and flow rate of 200 gpm 


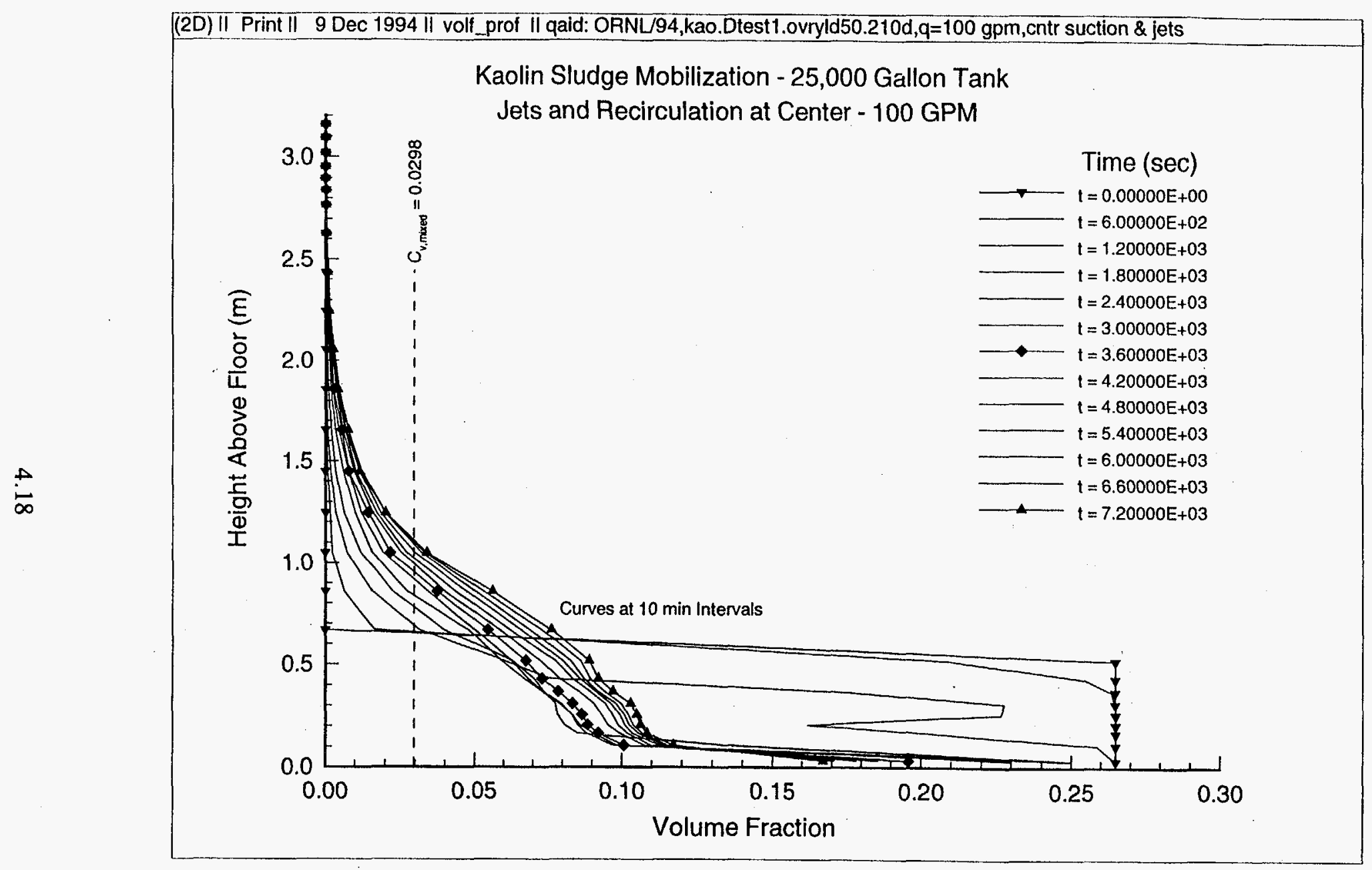

Figure 4.14. Solids fraction volume concentration distribution at 10 -min intervals for the center jet location and flow rate of $100 \mathrm{gpm}$ 


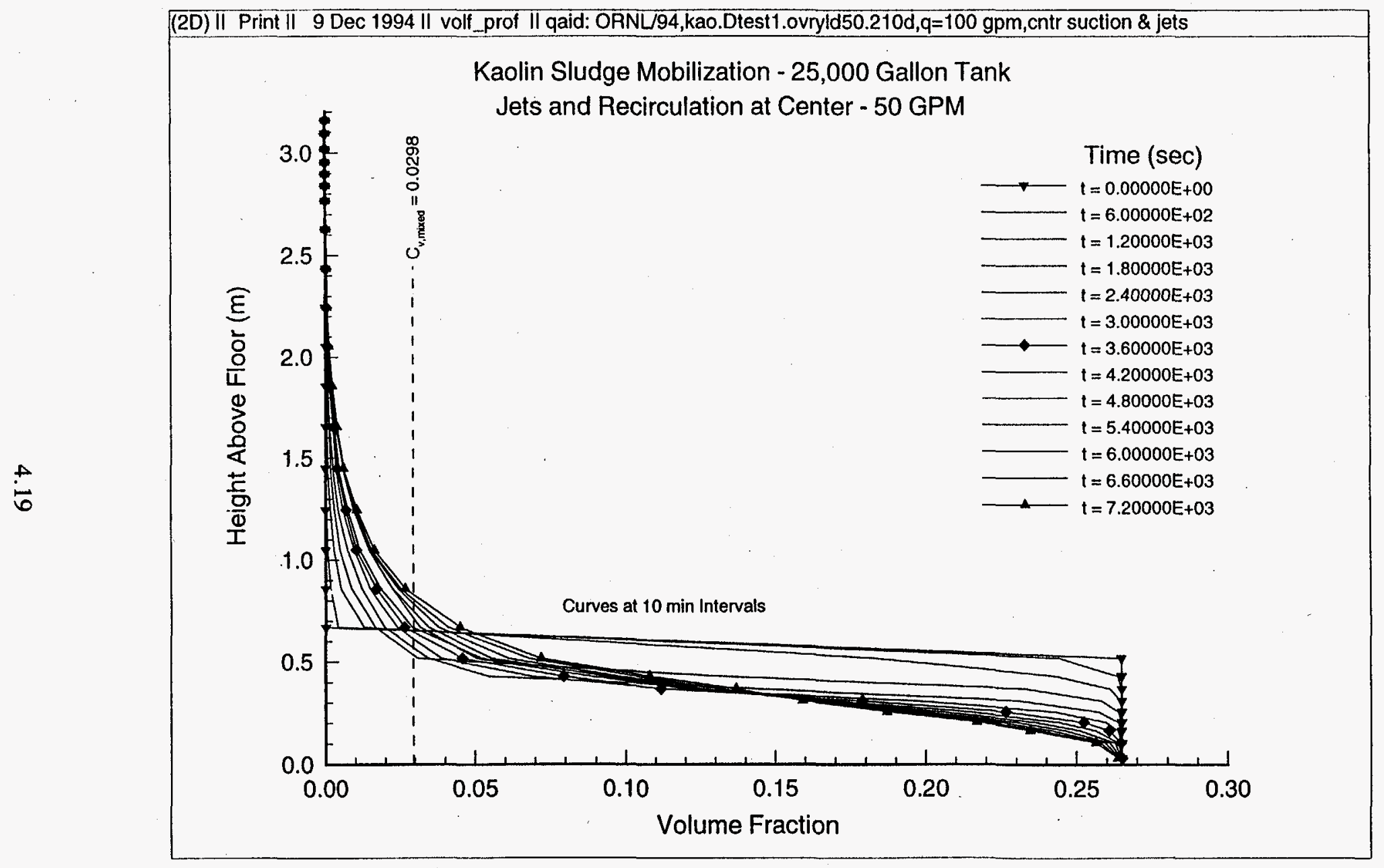

Figure 4.15. Solids fraction volume concentration distribution at 10 -min intervals for the center jet location and flow rate of 50 gpm 


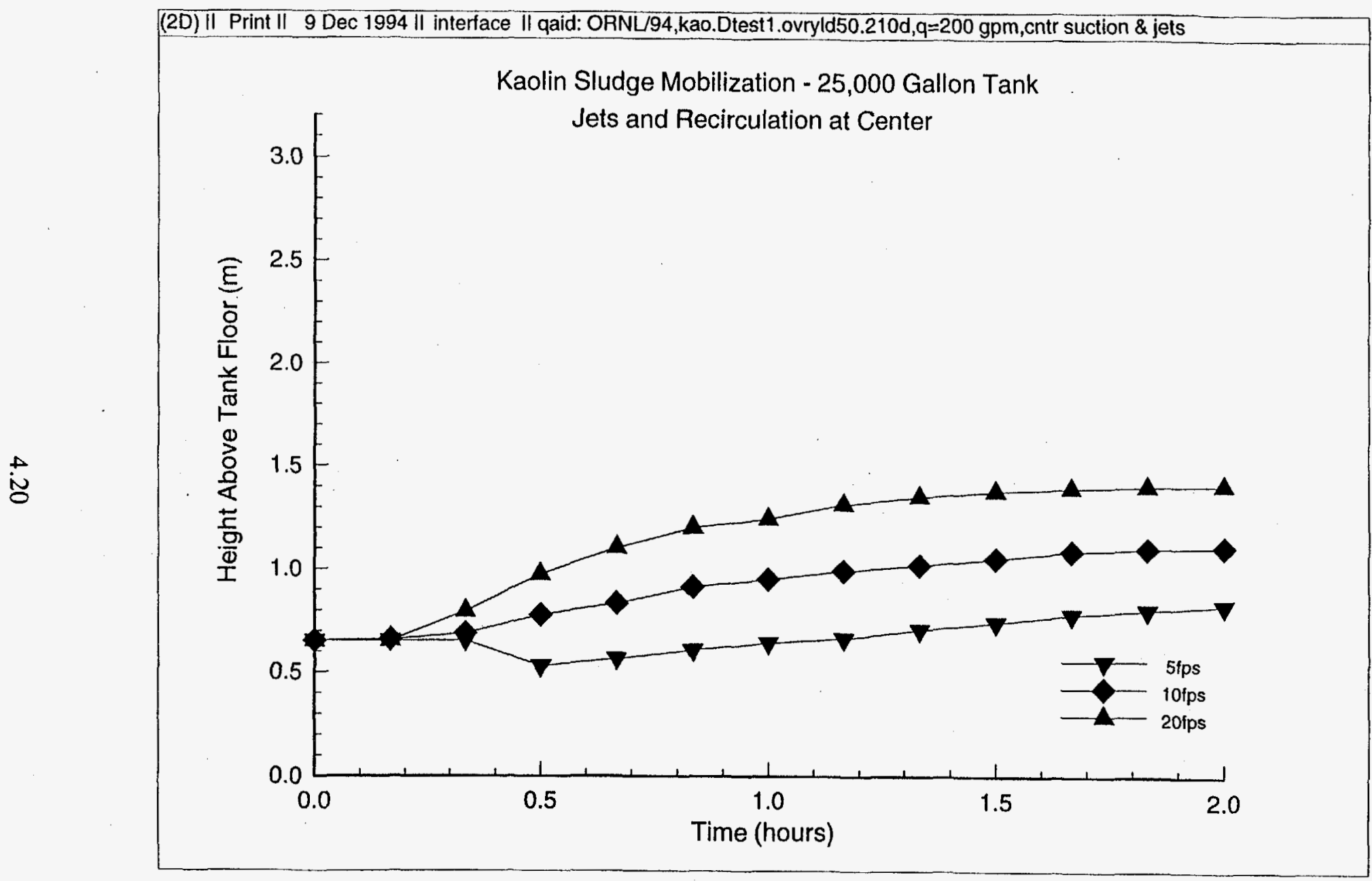

Figure 4.16. Position of the fully mixed concentration contour as a function of time for the center jet location at 50,100 , and $200 \mathrm{gpm}$ 
At $200 \mathrm{gpm}$, the jet appears to mobilize the sludge by pushing it back. At the jet height, there is relatively little change in the concentration distribution with time. By $1 \mathrm{~h}$, the initial sludge layer had been largely mobilized (Figure 4.9 for example) and the concentration in the recirculation line is relatively constant with time (see Figure 4.11). As a result, the concentration distribution is very slowly changing with time. Further, it appears that the distribution is nearly unchanging with time at $2 \mathrm{~h}$. The upward progression of the fully-mixed concentration interface is very slow indicating that the total time to attain complete mixing in the tank is very long.

By comparison, the distribution results for 100 gpm exhibits a quite different characteristic early in time. At 20 min (Figure 4.14) there is an apparent penetration of the jet into the sludge layer followed by a slow, more uniformly increasing distribution between 1 and $2 \mathrm{~h}$. The $50 \mathrm{gpm}$ results in Figure 4.15 exhibit a third characteristic. For this case, the mobilization appears to be occurring in a mode that is typified by a shearing action along the top surface of the sludge layer. While the higher jet velocity seems to exhibit more of a process of mobilizing at a sludge bank, the lower jet velocity seems to exhibit more of a top surface shearing/erosion mechanism and development of a beach shape as compared to a sludge bank shape. Both of these characteristics have been observed experimentally in scaled kaolin tests ${ }^{(a)}$. Although a critical comparison of the mixing results predicted here with the experiments under way at ORNL remains to be done, preliminary data indicate that mixing times for the $200 \mathrm{gpm}$ case are approximately $10-11 \mathrm{~h}$ and somewhat in excess of $12 \mathrm{~h}$ for the $100 \mathrm{gpm}$ case $^{(\mathrm{b})}$.

Figure 4.16 presents the height above the tank floor of the fully mixed concentration as a function of time for the 50,100, and $200 \mathrm{gpm}$ flow cases. This position was obtained by interpolating to find the intersection of the fully mixed concentration line (dotted line in Figures 4.13 to 4.15 ) with the concentration distribution results. After the first half hour, there appears to be a rather smooth albeit slow progression upwards. The shape of the time-dependence indicates that they might be readily curve fit with an exponential function. Such a function could then be used to estimate the mixing time as defined by the time for the fully mixed concentration interface to reach the height of the tank.

Several curve fits were prepared for data presented in Figure 4.16. The data and curve fits are presented in Figures 4.17 to 4.19 . In the first fit, a form of

$$
h=a+b e^{c t}
$$

where $a, b, c$ are constants, $t$ is time in hours, and $h$ is interface height in meters. Values of the constants are included in Figure 4.17. While the curve fit is good, the long-time asymptote indicates that the interface will never reach the top of the tank for any of the three flow rates. Included in the figure is a (dotted) line which represents the amount of time a single, free-falling particle of the type used to model the kaolin takes to settle from the top of the tank to the bottom.

(a) M. R. Powell et al., September 1994. "Fiscal Year 1994 1/25-Scale Sludge Mobilization Testing." Pacific Northwest Laboratory, Richland, Washington (Draft report).

(b) Tom Hylton, Oak Ridge National Laboratory, personal communication, October 1994. 


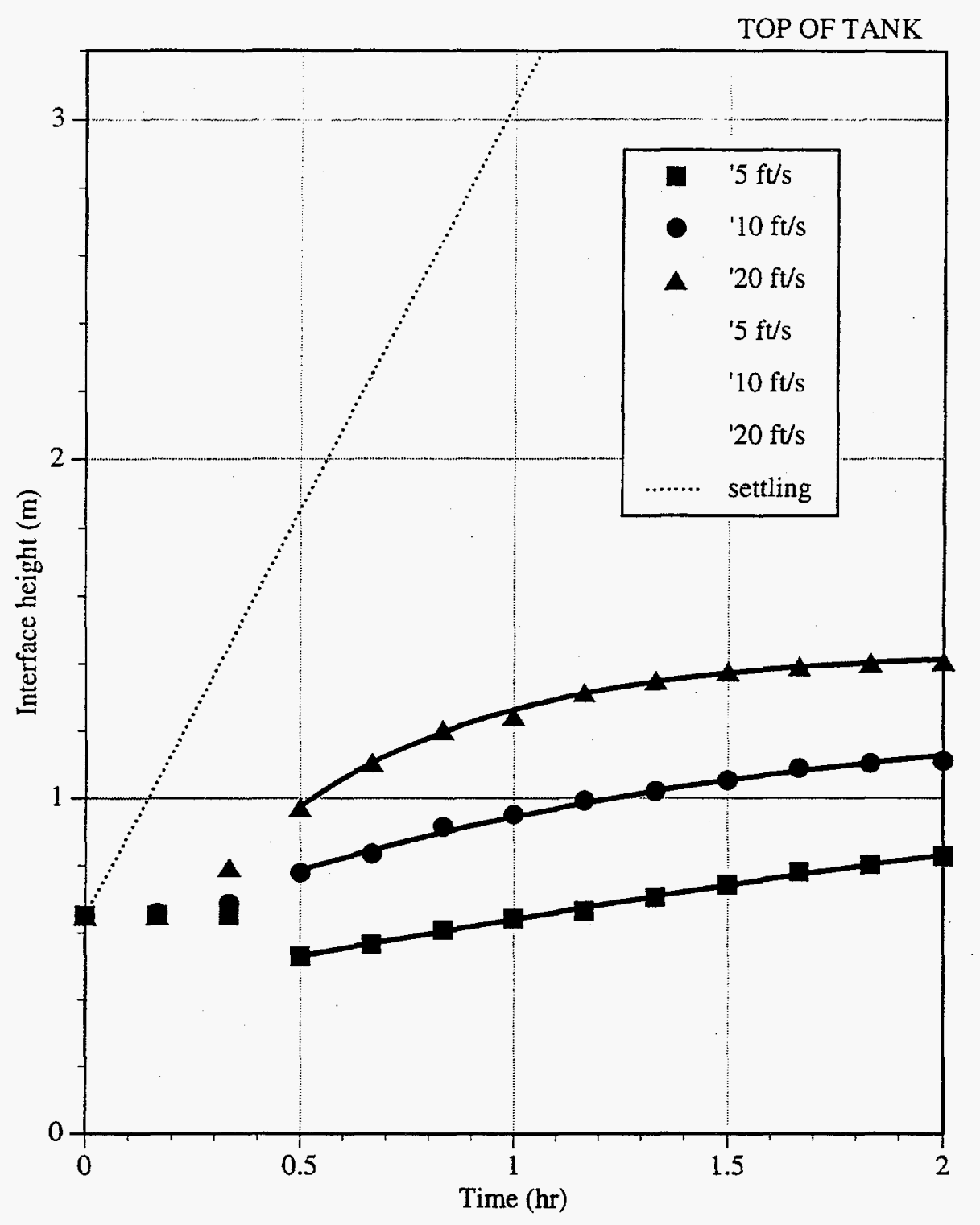

$$
\begin{array}{lll}
5 \mathrm{ft} / \mathrm{s}: & h=1.69-1.28 \mathrm{e}^{-0.201 t} & \mathrm{R}^{2}=0.99 \\
10 \mathrm{ft} / \mathrm{s}: & \mathrm{h}=1.28-0.73 \mathrm{e}^{-0.766 t} & \mathrm{R}^{2}=0.99 \\
20 \mathrm{ft} / \mathrm{s}: & \mathrm{h}=1.44-1.22 \mathrm{e}^{-1.96 \mathrm{t}} & \mathrm{R}^{2}=0.99
\end{array}
$$

Figure 4.17. Curve fit 1 of data in Figure 4.16 


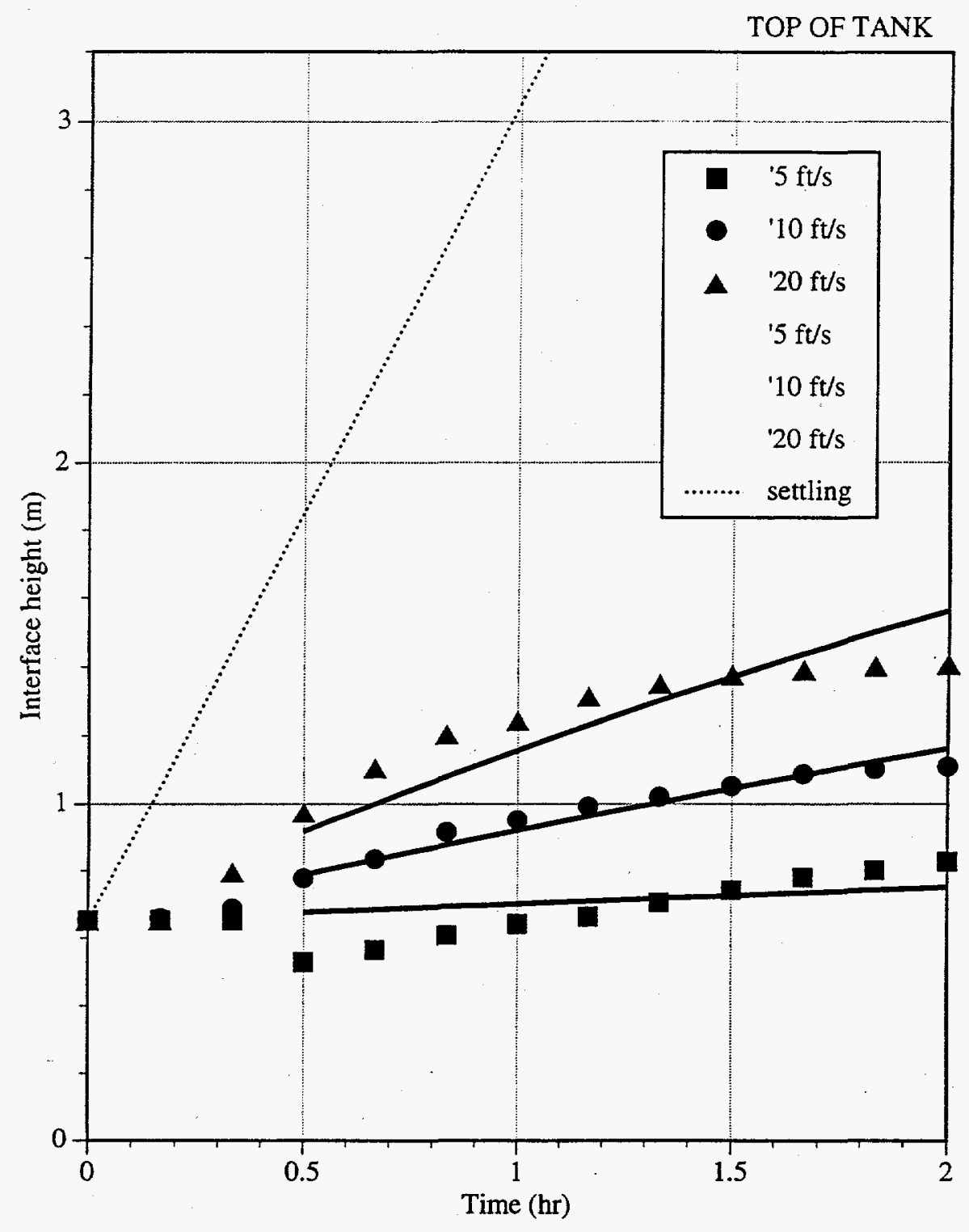

$$
\begin{array}{lll}
5 \mathrm{ft} / \mathrm{s}: & \mathrm{h}=0.65+2.55\left(1-\mathrm{e}^{-0.0203 t}\right) & \mathrm{R}^{2}=0.92 \\
10 \mathrm{ft} / \mathrm{s}: & \mathrm{h}=0.65+2.55\left(1-\mathrm{e}^{-0.112 \mathrm{t}}\right) & \mathrm{R}^{2}=0.95 \\
20 \mathrm{ft} / \mathrm{s}: & \mathrm{h}=0.65+2.55\left(1-\mathrm{e}^{-0.221 \mathrm{t}}\right) & \mathrm{R}^{2}=0.87
\end{array}
$$

Figure 4.18. Curve fit 2 of data in Figure 4.16 


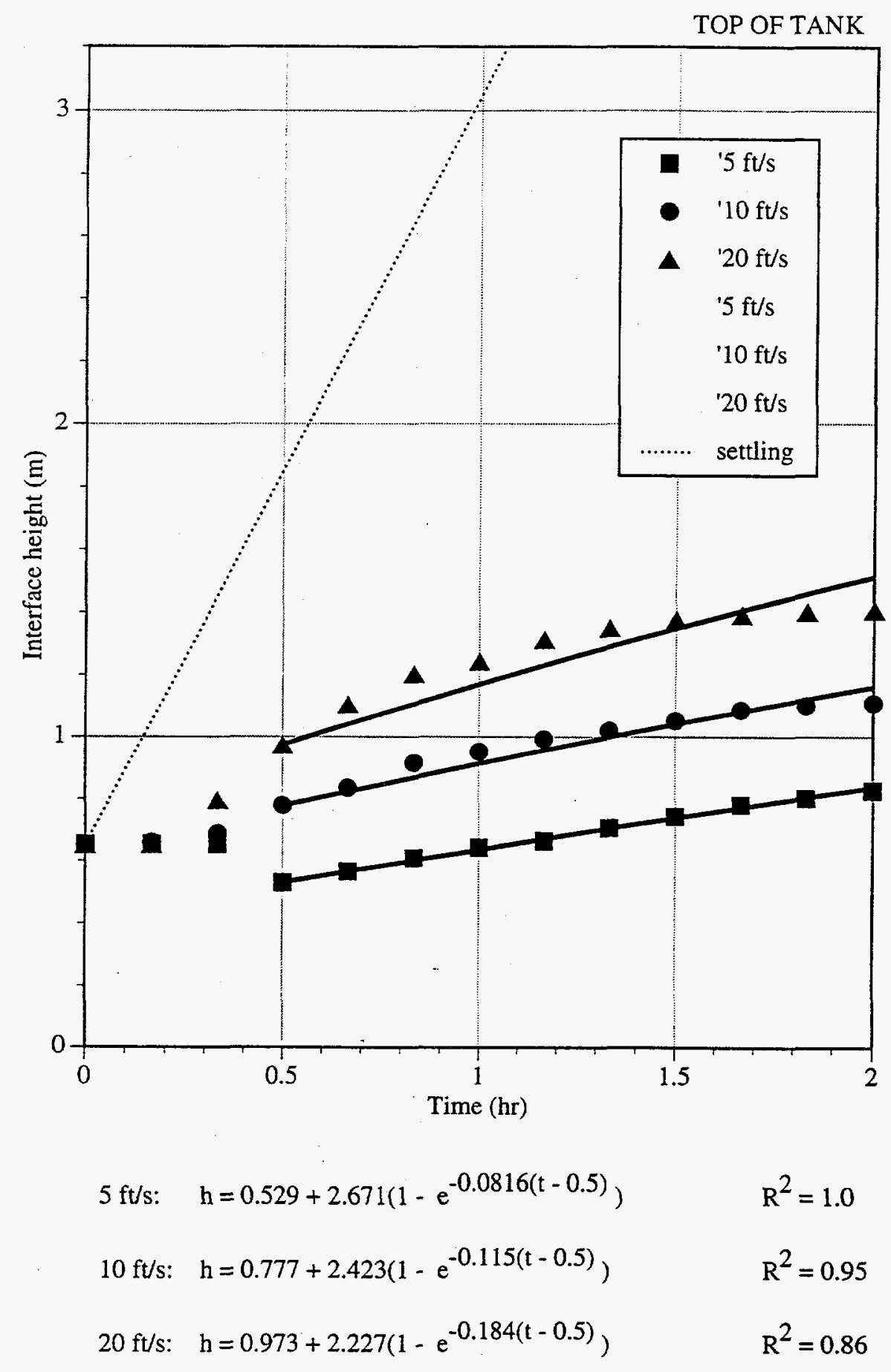

Figure 4.19. Curve fit 3 of data in Figure 4.16 
In the second fit, a form of

$$
\mathrm{h}=0.65+2.55\left(1-\mathrm{e}^{\mathrm{ct}}\right)
$$

was used. In this form, at zero time, the height is at the top of the initial sludge layer $(0.65 \mathrm{~m})$ and at infinite time, the height is at the top of the tank $(3.2 \mathrm{~m})$. Results of this curve fit are plotted with interface data in Figure 4.18. Note that for these fits, all the data from $t=0$ to $t=2 h$ was used. Inverting the curve fit form, the time for the interface to reach a fraction of the tank height can be determined as

$$
\mathrm{t}=(1 / \mathrm{c}) * \ln (1-(\mathrm{h}-0.65) / 2.55)
$$

where $\mathrm{c}$ is the curve fit constant. Estimated mixing times from Eq. (4.3) are listed in Table 4.2 for a tank depth of $\mathrm{H}=3.2 \mathrm{~m}$.

Table 4.2. Estimated Mixing Times Using Eq. (4.3).

\begin{tabular}{ccccc}
$\begin{array}{c}\text { Reference } \\
\begin{array}{c}\text { Flow Rate } \\
(\mathrm{gpm})\end{array}\end{array}$ & $\begin{array}{c}\text { Constant } \\
(\mathrm{c})\end{array}$ & & $\begin{array}{c}\text { Frac. of } \mathrm{H} \\
(\mathrm{H}=3.2 \mathrm{~m})\end{array}$ & $\begin{array}{c}\text { Mixing Time } \\
(\mathrm{hr})\end{array}$ \\
\cline { 1 - 2 } 50 & -0.0203 & & 0.95 & 139.0 \\
& & & 0.90 & 102.4 \\
100 & -0.112 & & 0.95 & 24.7 \\
& & 0.90 & 18.5 \\
200 & -0.221 & 0.95 & 12.5 \\
& & & 0.90 & 9.4
\end{tabular}

The third form of a curve fit is similar to Eq. (4.2), but uses an offset time. The equation is of the form

$$
h=a+b\left(1-e^{(b(1-0.5)}\right)
$$

where $a, b$, and $c$ are curve constants. These were fit such that $a+b=3.2 \mathrm{~m}$ at $t=0.5 \mathrm{~h}$. The mixing time can then be calculated as

$$
\mathrm{t}=0.5+(1 / \mathrm{c}) * \ln (1-(\mathrm{h}-\mathrm{a}) / \mathrm{b})
$$

Table 4.3 lists the mixing times estimated from this expression. 
Table 4.3. Estimated Mixing Times Using Eq. (4.5)

\begin{tabular}{|c|c|c|c|c|c|}
\hline $\begin{array}{c}\text { Reference } \\
\text { Flow Rate } \\
\text { (gpm) } \\
\end{array}$ & $\begin{array}{l}\text { Consta } \\
\text { (a) }\end{array}$ & $\begin{array}{l}\text { nts } \\
\text { (b) }\end{array}$ & (c) & $\begin{array}{l}\text { Frac. of } \mathrm{H} \\
(\mathrm{H}=3.2 \mathrm{~m})\end{array}$ & $\begin{array}{l}\text { Mixing Time } \\
(\mathrm{hr})\end{array}$ \\
\hline 50 & 0.529 & 2.671 & -0.0816 & $\begin{array}{l}0.95 \\
0.90\end{array}$ & $\begin{array}{l}35.5 \\
26.5\end{array}$ \\
\hline 100 & 0.777 & 2.423 & -0.115 & $\begin{array}{l}0.95 \\
0.90\end{array}$ & $\begin{array}{l}24.1 \\
18.1\end{array}$ \\
\hline 200 & 0.937 & 2.227 & -0.184 & $\begin{array}{l}0.95 \\
0.90\end{array}$ & $\begin{array}{l}16.2 \\
11.7\end{array}$ \\
\hline
\end{tabular}

It is not known how well these predicted mixing times agree or disagree with measured data. The only preliminary information available was that the $200 \mathrm{gpm}$, center located jet configuration required about $12 \mathrm{~h}$ of running before the clouded interface was observed to reach the top of the liquid in the tank and that for $100 \mathrm{gpm}$, quarter jet location the interface had not reached the surface when the experiment was terminated at $12 \mathrm{~h}^{(\mathrm{a})}$.

Similar curve fitting analyses of mixing times were conducted for the quarter jet location configuration. Results of the concentration profiles at 10-min intervals are presented in Figures 4.20 to 4.22 . For this configuration, the sludge layer was initialized to a depth of $37.8 \mathrm{~cm}$ (15 in.). The fully mixed volume fraction is 0.0177 as indicated by the dotted line in the figures. The quarter jet location mobilization seems to be proceeding more in a top surface shear process than in a sludge bank impingement process. This would be consistent with the physical configuration of the inlet jets and outlet suction. Flow from the jets has to traverse the length of the tank along the surface of the sludge bank in order to reach to outlet suction. By comparison, the center jet and suction location configuration is more of a recirculation-type flow. The jet flow does not necessarily have to traverse tangentially along the surface of the sludge.

Figure 4.23 presents the time-dependent position of the interface of the fully mixed concentration contour. These data were obtained by interpolating the intersection of the concentration profiles (Figures 4.20 to 4.22 ) with the fully mixed concentration (dotted) line. It is apparent that these data at 10 -min intervals are not far enough in time to provide sufficient estimates of mixing time. The data were curve fit with the same three forms presented above for the center jet configuration. The results are presented in Figures 4.24 to 4.26 . It is clear that the curve fits are not nearly as good. For that reason, estimates of the time for the interface to reach the top of the tank have not been determined.

\subsection{Discussion of Computer Requirements}

The computations presented in above sections are computationally intensive. The physics of the processes are by their very nature, transient. The CPU time used on each of the runs computed for

(a) Tom Hylton, Oak Ridge National Laboratory, personal communication, November 1994. 


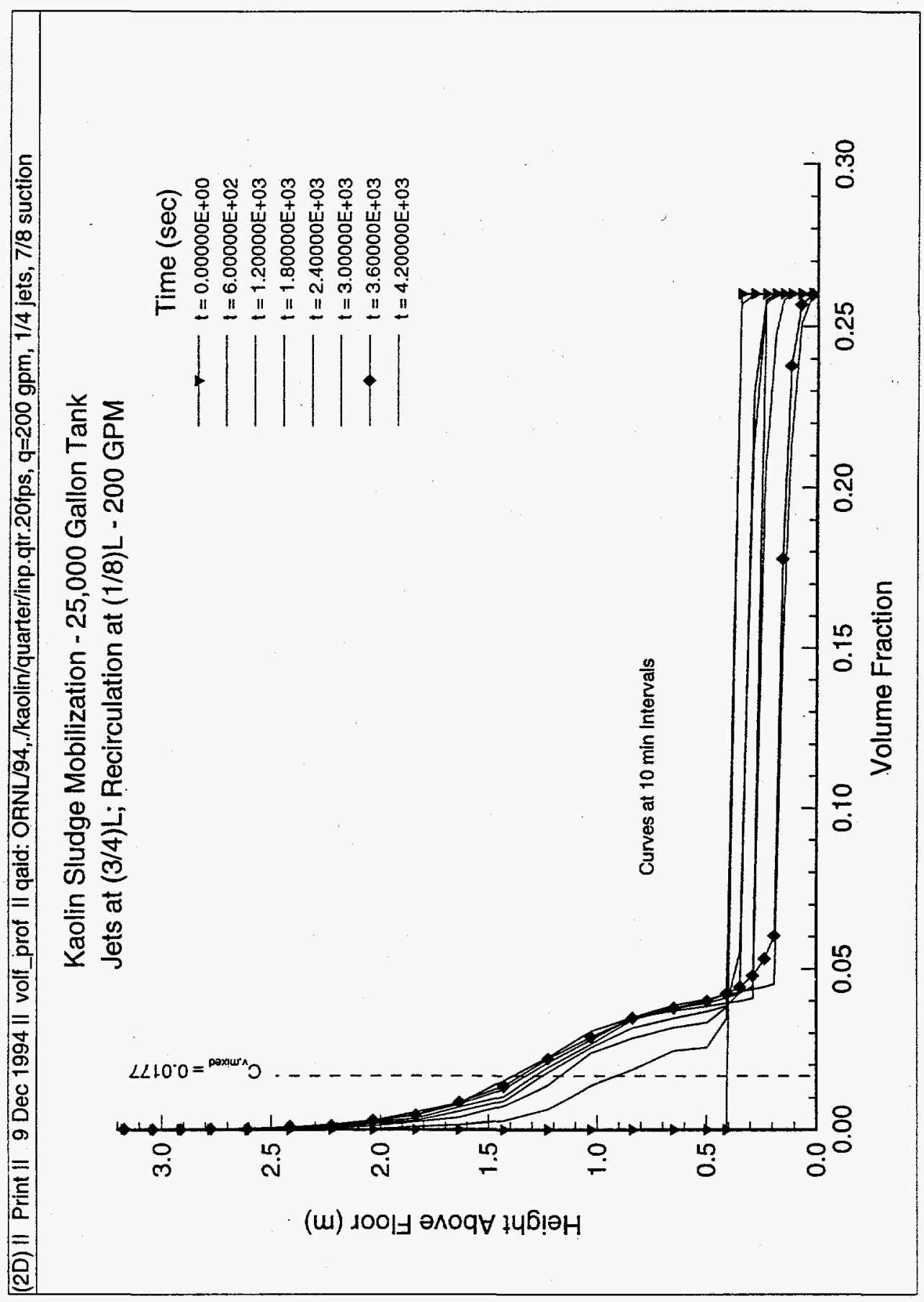

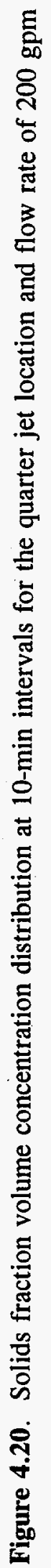




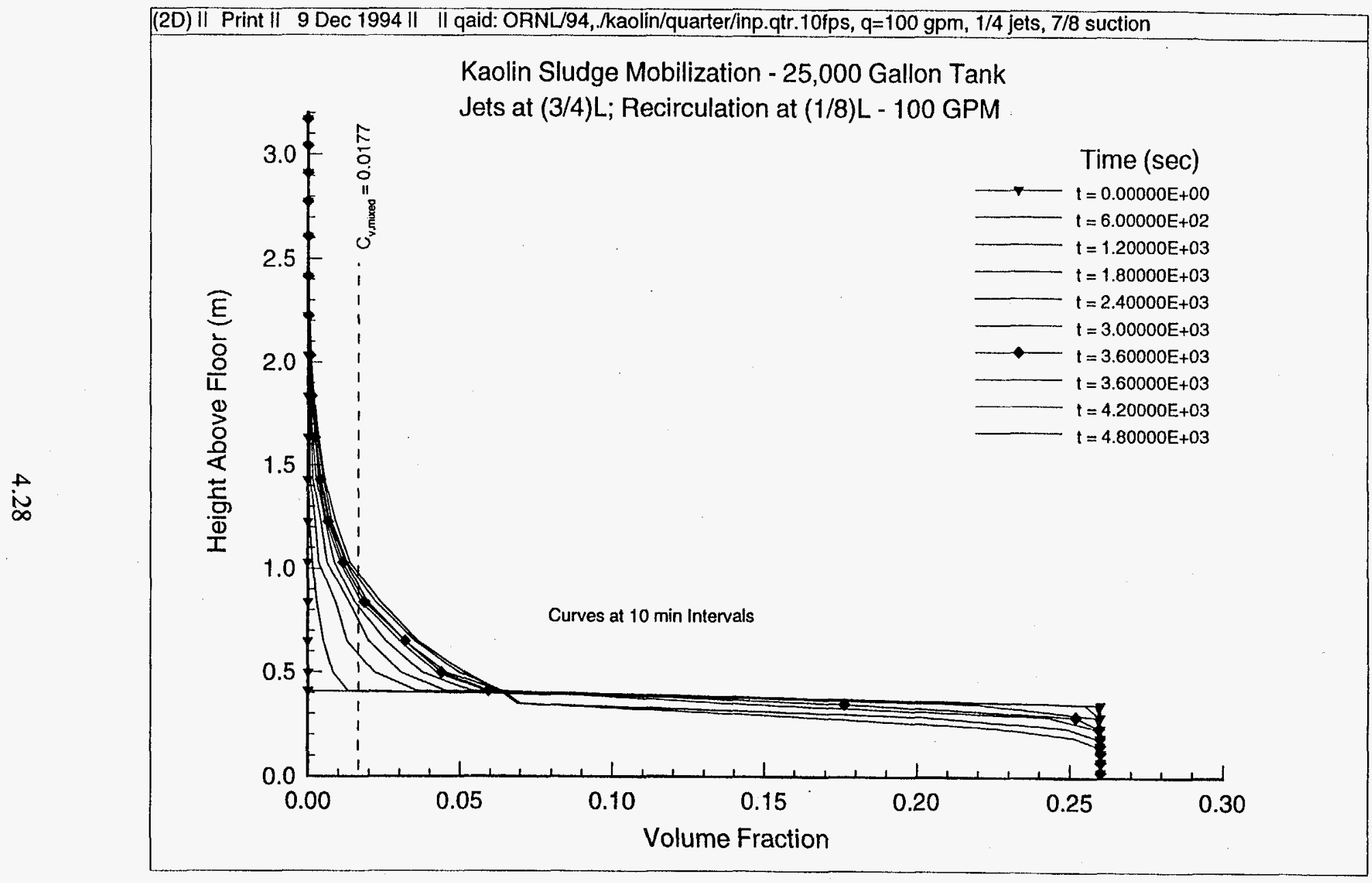

Figure 4.21. Solids fraction volume concentration distribution at 10-min intervals for the quarter jet location and flow rate of $200 \mathrm{gpm}$ for a modified strength criterion 


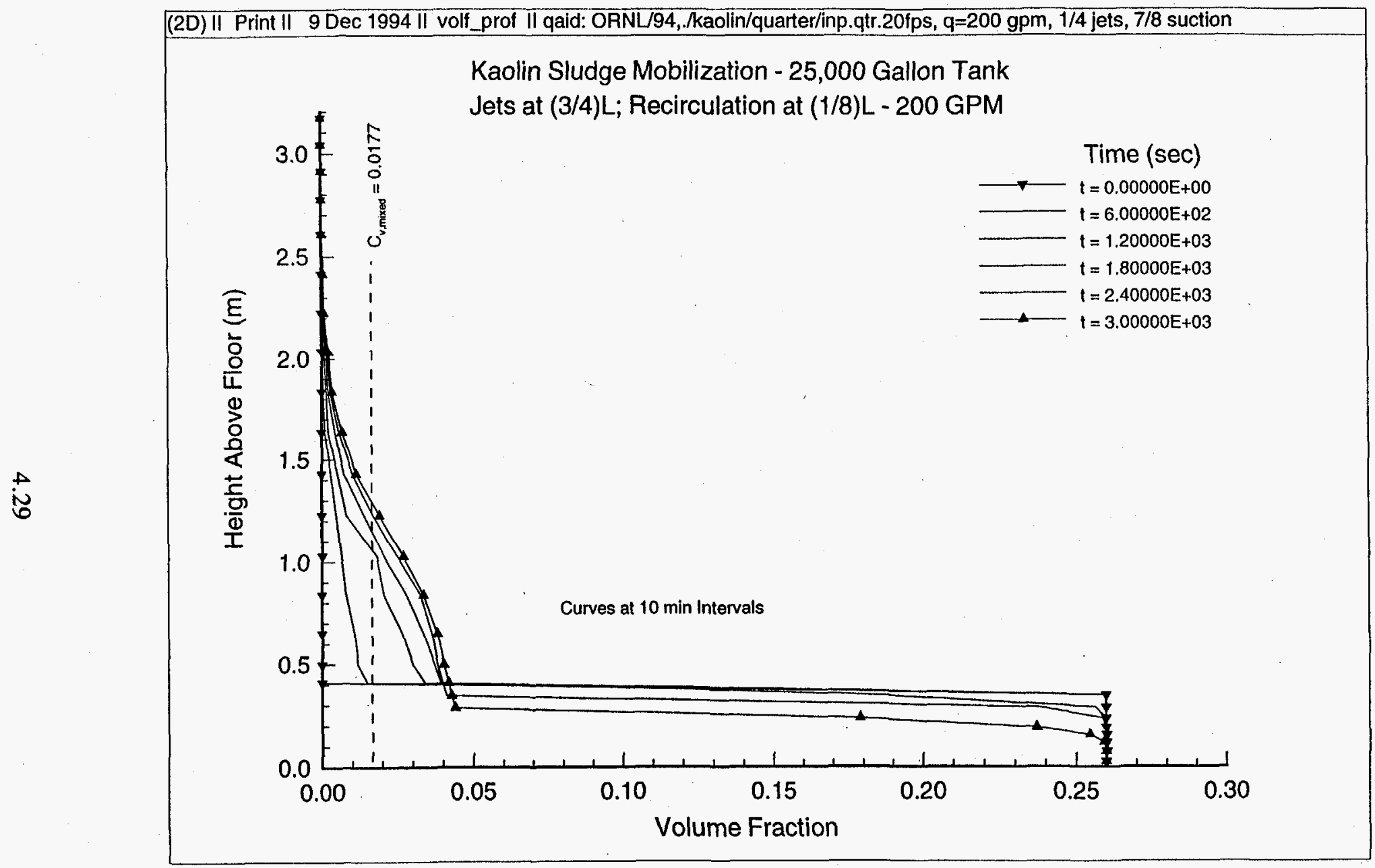

Figure 4.22. Solids fraction volume concentration distribution at 10 -min intervals for the quarter jet location and flow rate of 100 gpm 


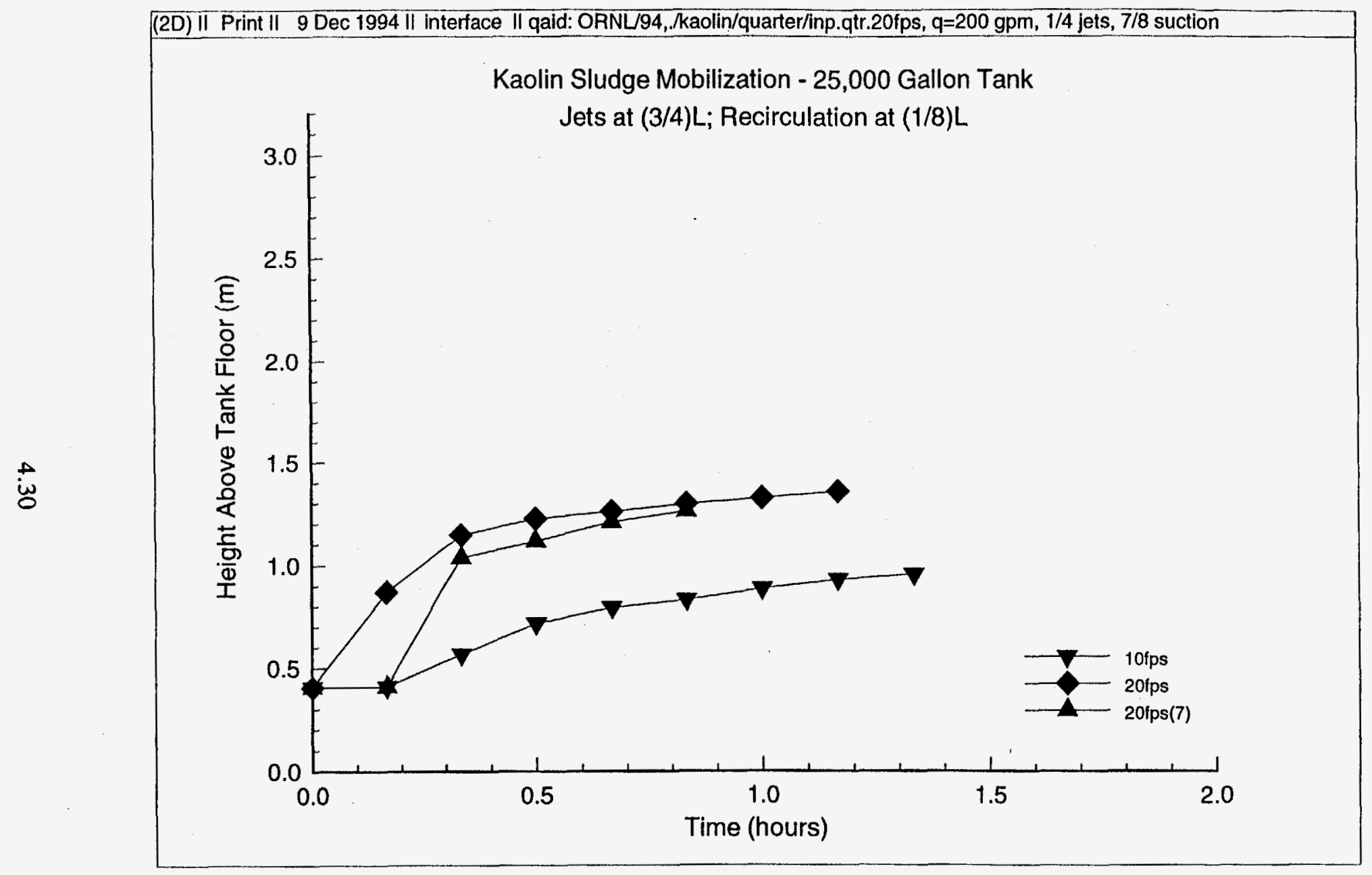

Figure 4.23. Position of the fully mixed concentration contour as a function of time for the quarter jet location at 100 and 200 gpm 


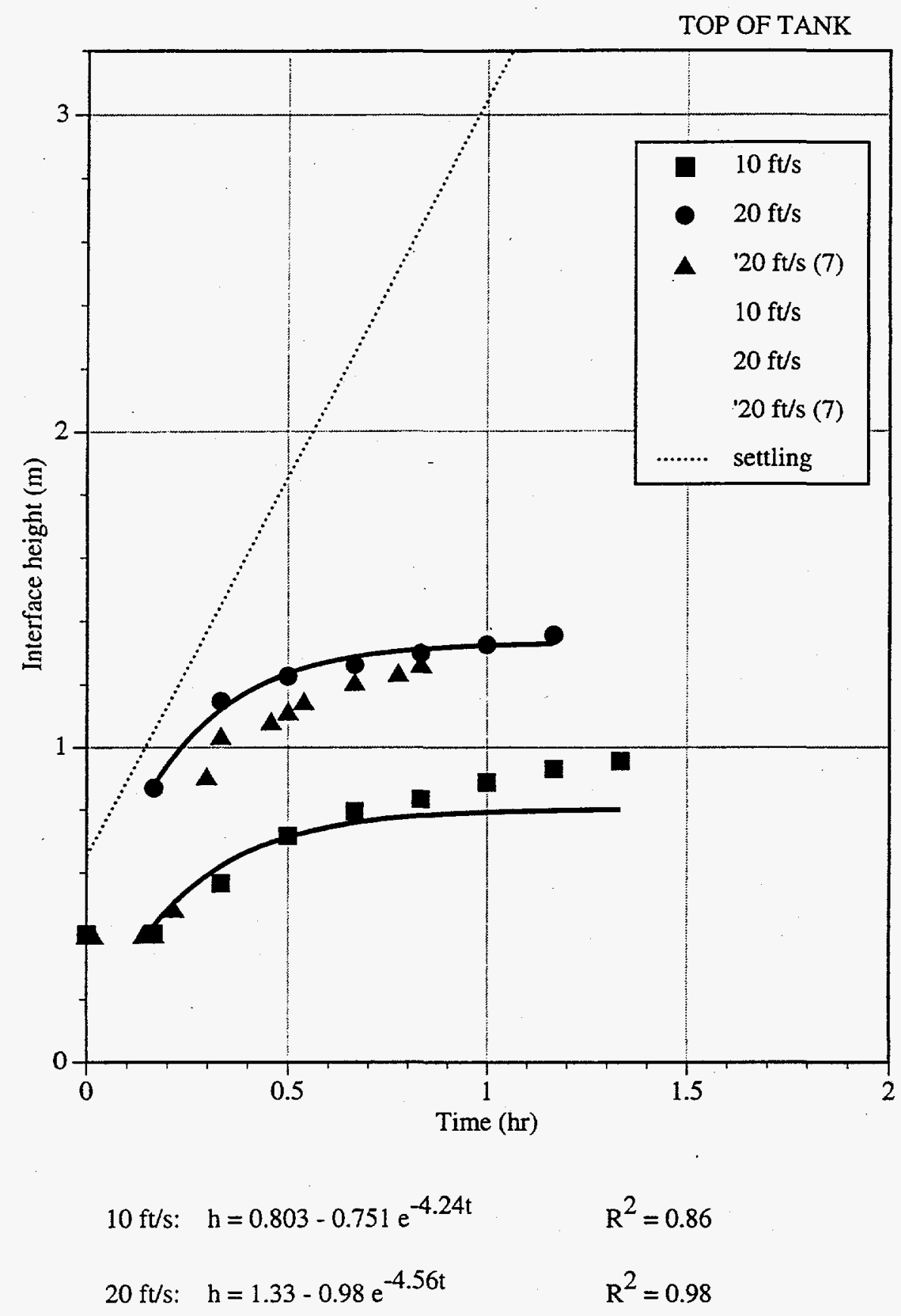

Figure 24. Curve fit 1 of data in Figure 23 


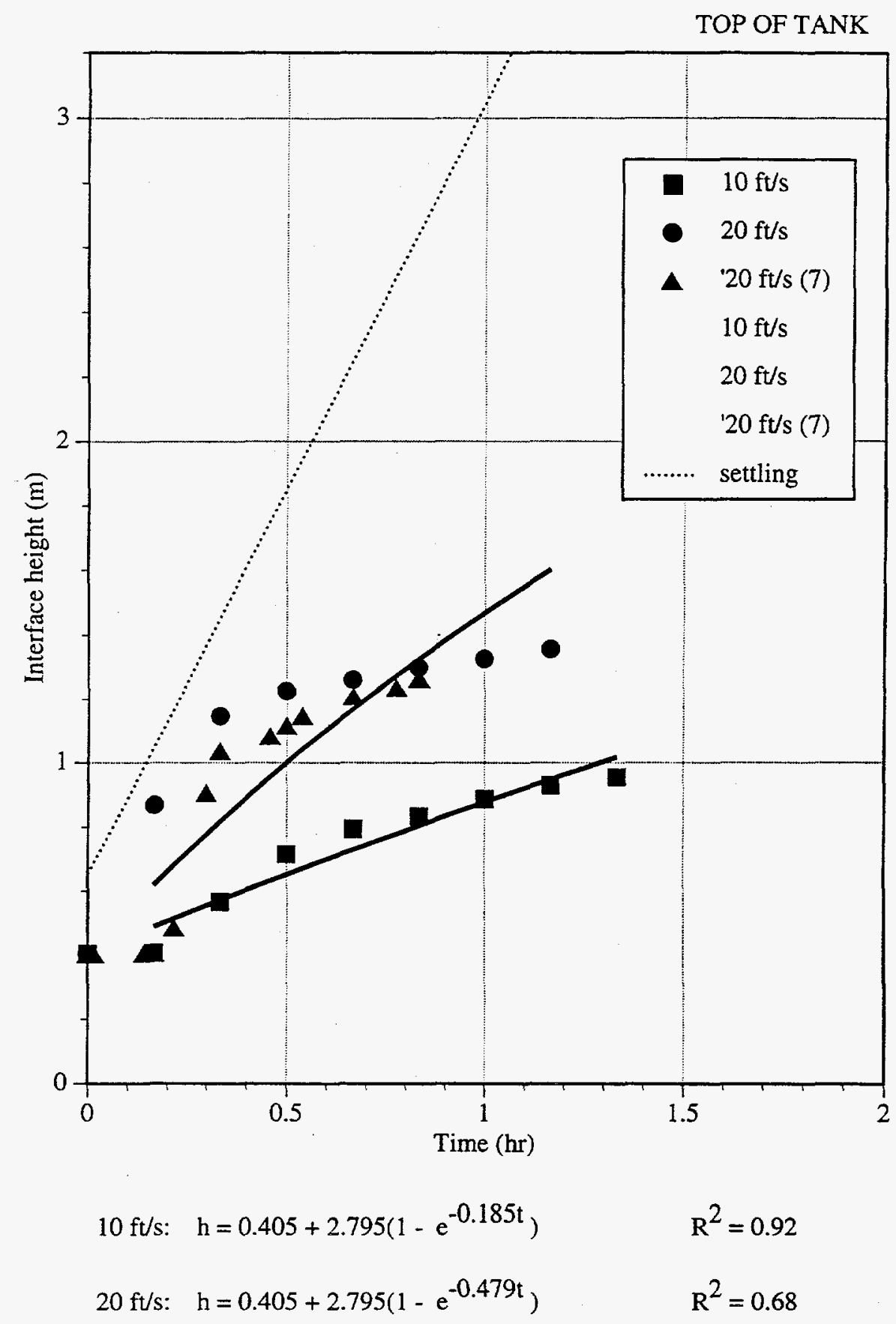

Figure 25. Curve fit 2 of data in Figure 4.23 


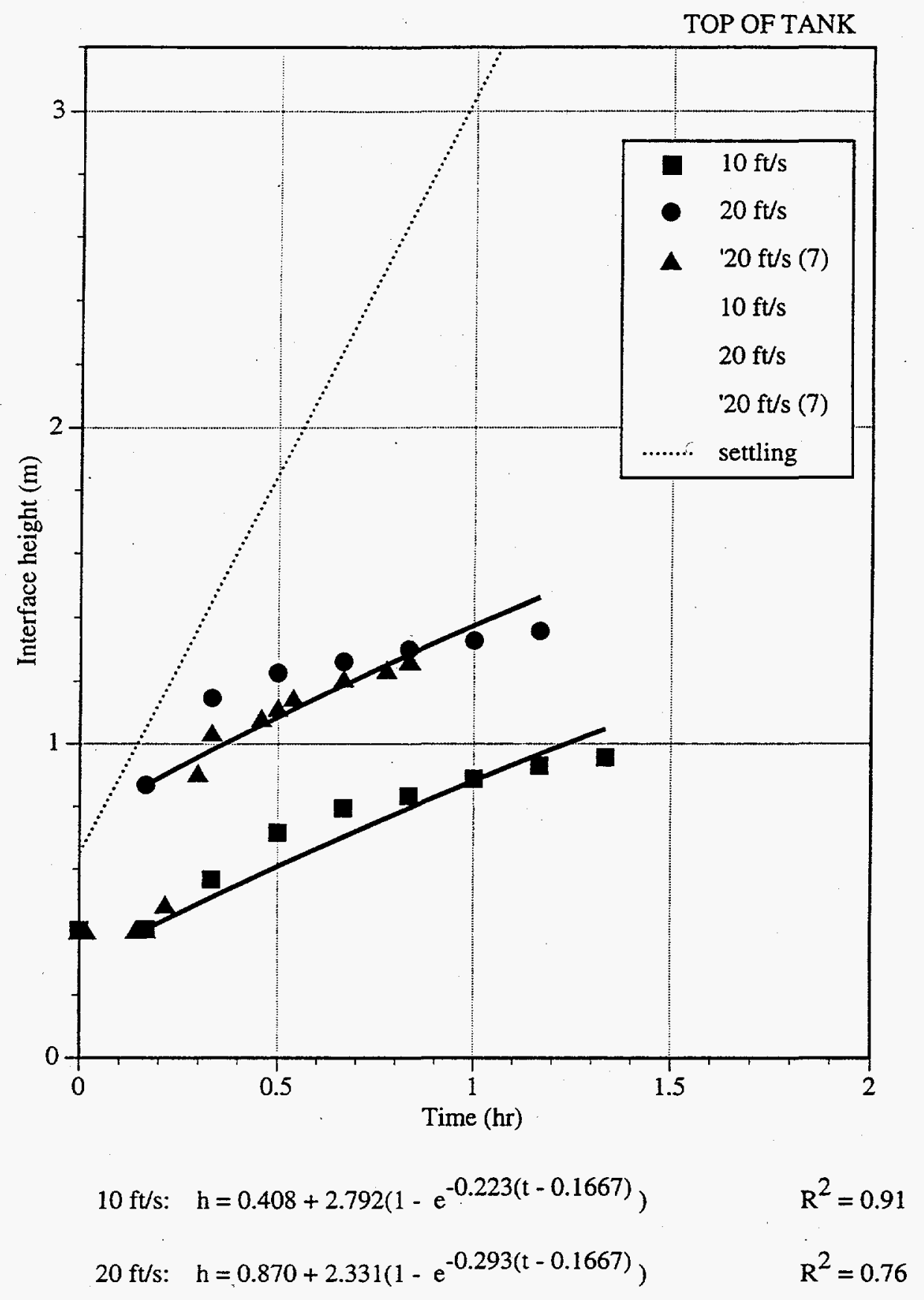

Figure 26. Curve fit 3 of data in Figure 4.23 
the center jet location configuration ranged from 150 to 330 CPU-hours in IBM RS-6000 580/590 class work stations. Normally, to accurately track a transient process in computational fluid dynamics, it is necessary to restrict the time-step to a Courant limitation. To resolve the jet flow from a small diameter jet in a large tank, small computational cells must be used. The combination of small computational cells and large velocities causes the Courant limitation to be restrictive. There are over 400,000 computational steps taken in some of the simulations presented above. To further these types of analyses, it may be useful to explore alternate numerical schemes to gain more computational efficiency.

\subsection{Discussion of Mobilization Resistance and Computer Model Criteria}

Even after modifying the criterion and approach to modeling a sludge layer which exhibits material strength, there are still discrepancies between the predictions and preliminary test data. Further work is required to improve the TEMPEST computer model for predicting sludge mobilization. The computer simulations of the kaolin mobilization and mixing experiments have not been totally successful as indicated by the comparison of the predictions and preliminary test data. With the approach being used in the present numerical model of the sludge, the total layer of kaolin is predicted to be mobilized in approximately $1 \mathrm{~h}$ at flow rate of $200 \mathrm{gpm}$ with the jets in the central configuration. In the experimental test, after $11 \mathrm{~h}$ of operation, the mobilized material becomes mixed, but only about $65 \%$ of the kaolin was mobilized. This lack of agreement in the total amount of material mobilized can only be attributed to the modeling approach to the sludge strength. Improved predictions and better agreement with the ORNL test results can only be accomplished if further model development is done to better approximate the mobilization resistance of the kaolin sludge.

The fundamental basis for the numerical modeling approach is the assumption that rheology in the form of stress versus strain-rate data could be used to describe the mixture. This approach has the advantage of spanning the complete range from fully settled sludge layer to well-mixed supernatant within a complete model of the tank and the jet mixing. Early work in this project (Terrones and Eyler, 1993) showed that the approach was computationally feasible and comparison of mixing time results were favorable with experimental data. Unfortunately, simulating the mobilization of settled kaolin sludge does not seem to work as well using the present approach. Attempts to improve the approach by applying a yield stress model to the kaolin sludge have only been partially successful.

In applying the yield stress model, both numerical and physical considerations are important. In the numerical implementation, it has been shown that a stationary sludge bank or layer being impinged with a jet can be maintained computationally. While this is encouraging, and in fact a necessity, it does not solve the problem. At present, the weakness lies in describing numerically the physical process(es) that control mobilization. This is complicated by the fact that the controlling physical processes and properties may be strongly dependent upon particle size. In one extreme, granular material may not have a yield strength associated with it and may be described by an erosion process. In the other extreme of very small particles, interparticle effects play a significant role in defining a cohesiveness of the material. Kaolin tends to fall into this latter category and evidence exists that shows additional strength development occurs with the slow settling of the small particles and water exclusion occurs. 
In summary, numerical simulation of the mobilization process is much more complex than that which can be approximated by an effective viscosity rheology approach, even one with a yield strength model in its present state. To improve on this approach requires that a method be developed that approximates an interface between a region exhibiting strength and an adjacent region governed by continuum fluid dynamics. These two regions need to be connected by an interface mass transport model. This is the essence of the proposed next step in complexity to simulation of mobilization of the kaolin. To accomplish this improved model approach, the following steps are suggested:

- Review recent 1/25-scale kaolin mobilization experiments conducted at PNL to determine the important parameters that have been identified.

- Implement logic in TEMPEST to track an approximate interface between a strength-containing sludge region and adjacent fluid region.

- Implement an interface mass transport model.

- Numerically test the model improvement to demonstrate that it can be used to predict partial mobilization of a sludge layer.

Subsequent to numerically testing and demonstrating this approach, simulations of the $95 \mathrm{~m}^{3}$ $(25,000$-gal) tank kaolin sludge mobilization tests have to be re-computed to determine the applicability of the improved model to real data. Proposed application of this approach to MVST and other tank sludge at ORNL is dependent upon successful application to the scaled experiments. 


\subsection{References}

CRC. 1975. Handbook of Chemistry and Physics, 56th Edition, p. F-270. CRC Press, Cleveland, Ohio.

Mahoney, L.A., G. Terrones, and L.L. Eyler. 1994. Modeling and Analysis of ORNL Horizontal Storage Tank Sludge Mobilization and Mixing, pg 6.3. PNL-9961, Pacific Northwest Laboratory, Richland, Washington.

Perry, R.H., and C.H. Chilton. 1973. Chemical Engineers' Handbook, 5th Edition, p. 5-64. McGraw-Hill Book Company, New York.

Selby, C.L. 1981. Rheological Properties of Kaolin and Chemically Simulated Waste. DP-1589, Savannah River Laboratory, Aiken, South Carolina.

Terrones, G., and L.L. Eyler. 1993. Computer Modeling of ORNL Storage Tank Sludge Mobilization and Mixing, Section 5.2.1. PNL-8855, Pacific Northwest Laboratory, Richland, Washington.

Trent, D. S., and L.L. Eyler. 1993. TEMPEST: A Computer Program for Thiree-Dimensional Time Dependent Computational Fluid Dynamics. PNL-8857, Pacific Northwest Laboratory, Richland, Washington. 